University of Massachusetts Amherst

ScholarWorks@UMass Amherst

Masters Theses

Dissertations and Theses

July 2015

\title{
Does Change in Physical Activity Predict Mental Health Outcomes in Pre-Adolescent African American Girls?
}

Sarah A. Burkart

University of Massachusetts Amherst

Follow this and additional works at: https://scholarworks.umass.edu/masters_theses_2

Part of the Maternal and Child Health Commons, and the Mental and Social Health Commons

\section{Recommended Citation}

Burkart, Sarah A., "Does Change in Physical Activity Predict Mental Health Outcomes in Pre-Adolescent African American Girls?" (2015). Masters Theses. 184.

https://doi.org/10.7275/7031807 https://scholarworks.umass.edu/masters_theses_2/184

This Open Access Thesis is brought to you for free and open access by the Dissertations and Theses at ScholarWorks@UMass Amherst. It has been accepted for inclusion in Masters Theses by an authorized administrator of ScholarWorks@UMass Amherst. For more information, please contact scholarworks@library.umass.edu. 
Does change in physical activity predict mental health outcomes in pre-adolescent African American girls?

A Thesis Presented

by

SARAH A. BURKART

Submitted to the Graduate School of the

University of Massachusetts Amherst in partial fulfillment

of the requirements for the degree of

MASTER OF SCIENCE

May 2015

Department of Kinesiology 


\title{
Does change in physical activity predict mental health outcomes in pre- adolescent African American girls?
}

\author{
A Thesis Presented \\ by \\ SARAH A. BURKART
}

Approved as to style and content by:

Sofiya Alhassan, Chair

John Sirard, Member

Patty Freedson, Member

Patty Freedson, Department Chair

Department of Kinesiology 


\begin{abstract}
DOES CHANGE IN PHYSICAL ACTIVITY PREDICT MENTAL HEALTH OUTCOMES IN PRE-ADOLESCENT AFRICAN AMERICAN GIRLS?
\end{abstract}

MAY 2015

\title{
SARAH A. BURKART, B.S., SACRED HEART UNIVERSITY M.S., UNIVERSITY OF MASSACHUSETTS AMHERST
}

Directed by: Dr. Sofiya Alhassan

Pediatric obesity is a significant clinical and public health issue for African American girls in which low physical activity (PA) is a contributor. The mother-daughter relationship (MDR) has rarely been examined in the context of improving health behaviors such as PA and mental health outcomes (MHO) within this population.

PURPOSE: To examine if change in PA following a 12-week culturally-tailored motherdaughter PA intervention predicts change in MHO variables (self-esteem, depressive symptoms, body image dissatisfaction) and MDR in pre-adolescent African American girls. METHODS: Mothers $(\mathrm{n}=27$; age $=36.0 \pm 17.0$ years; body mass index $\left.(\mathrm{BMI})=34.0 \pm 7.4 \mathrm{~kg} / \mathrm{m}^{2}\right)$ and daughters $\left(\mathrm{n}=27 ;\right.$ age $=9.0 \pm 1.4$ years; $\mathrm{BMI}=20.3 \pm 5.7 \mathrm{~kg} / \mathrm{m}^{2}$, BMI percentile $=73 \%$ ) randomized to the mother-daughter dance group were examined in this analysis. Physical activity levels were assessed with Actigraph GT3X+ accelerometers for seven days and validated questionnaires. Mental health outcome variables and MDR were assessed using validated questionnaires. Spearman correlations were used to examine associations between variables. MANOVA was used to assess differences in PA levels across three time points. Paired $t$-tests and ANOVA were used for MHO variables and MDR across two and three time points, respectively. Simple regression was used to assess if PA self-efficacy and MDR mediated changes in PA. 
Hierarchical linear modeling (HLM) assessed if changes in PA variables predicted changes in MHO variables. RESULTS: Several significant correlations were observed at baseline and post-intervention such as the negative relationships between daughters' light PA (\% time) and depressive symptoms as well as a daughters' BMI percentile and body image dissatisfaction. Significant reduction was observed in daughters' self-reported PA $(p=0.04)$ pre- to post-intervention. No other significant changes were observed. Change in PA did not predict change in MHO variables, but there was a negative effect of average BMI percentile on self-esteem $(p=0.017)$ and body image dissatisfaction $(p=0.002)$. CONCLUSION: In this sample of pre-adolescent African American girls, change in objectively measured PA did not predict change in MHO. The lack of significant findings could be attributed to low attendance of the intervention. Future studies should examine these relationships in a larger sample and explore the use of technology to combat low attendance.

Supported by: NIH:NIDDK (K01 DK087812) 


\section{TABLE OF CONTENTS}

Page

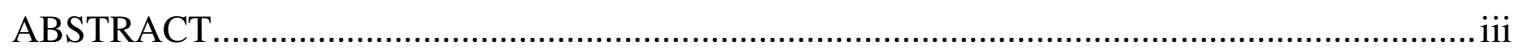

\section{CHAPTER}

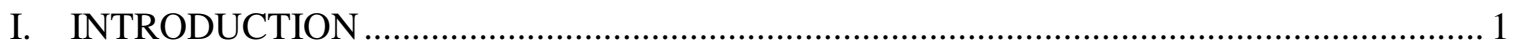

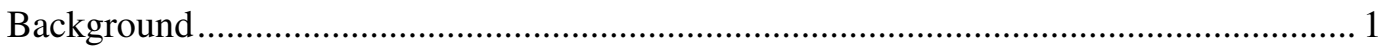

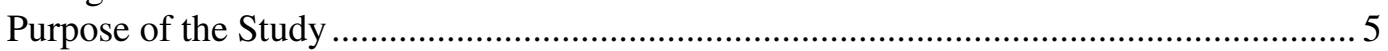

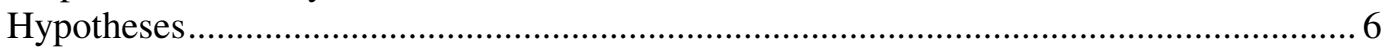

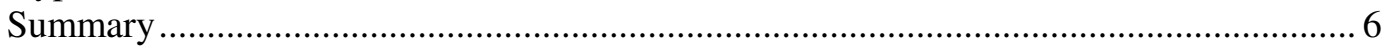

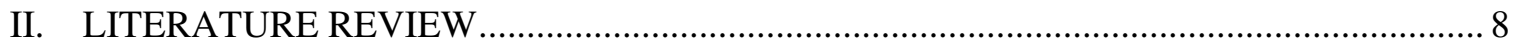

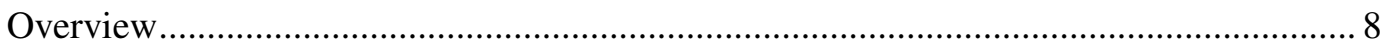

Prevalence of Pediatric Obesity and Health Consequences............................................. 9

Physical Activity Levels in Children and Adolescents ..................................................... 10

Sedentary Behavior Levels in Children ........................................................................ 11

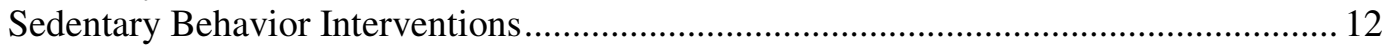

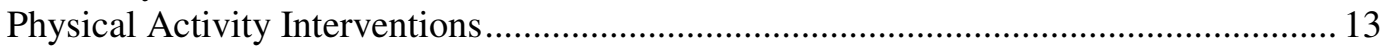

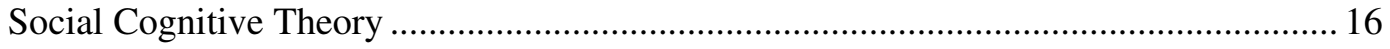

Determinants of Physical Activity ............................................................................ 17

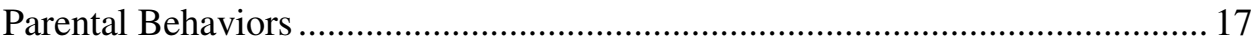

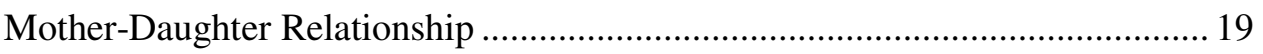

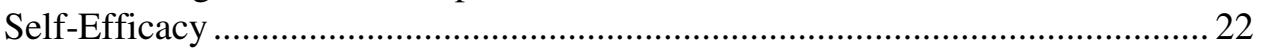

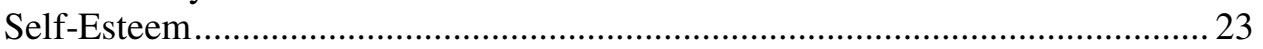

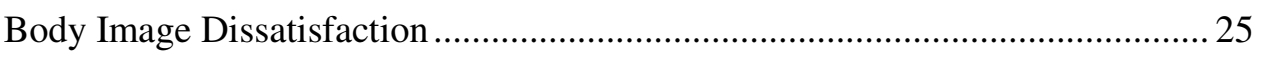

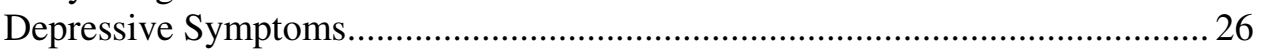

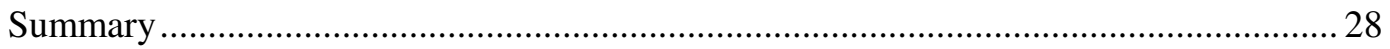

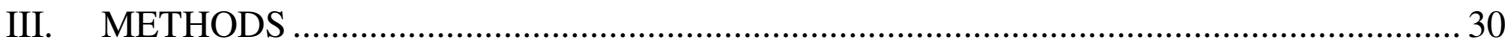

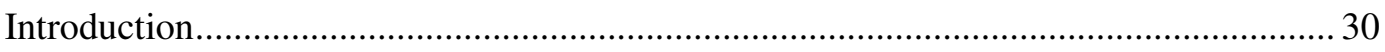

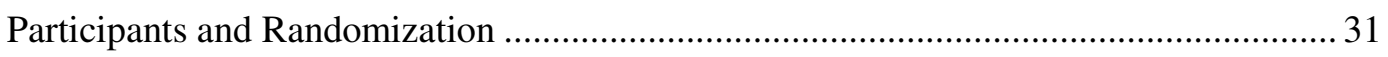

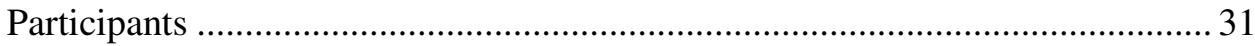

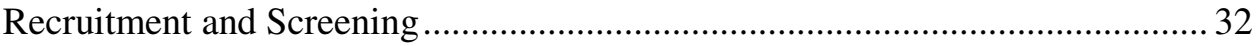

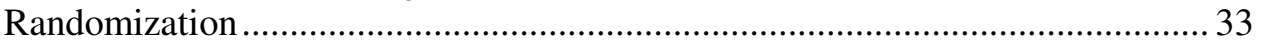

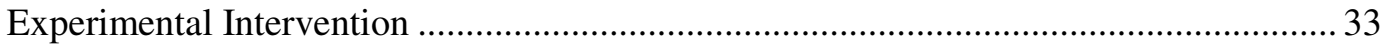

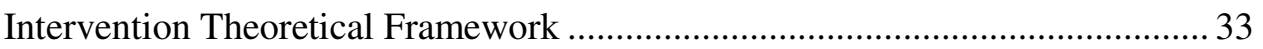

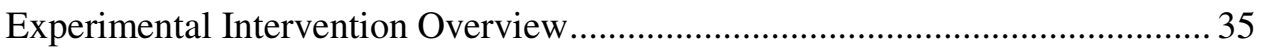

Treatment (Dance) Intervention........................................................................ 36

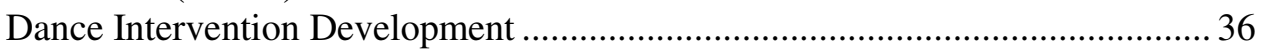

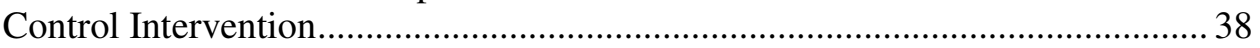




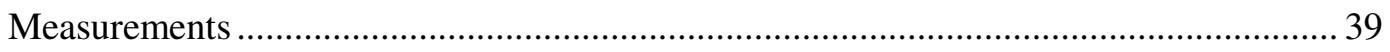

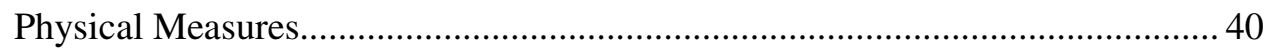

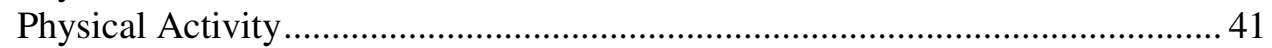

Mental Health Outcome Variables.................................................................. 43

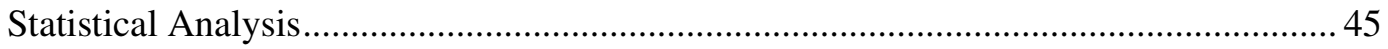

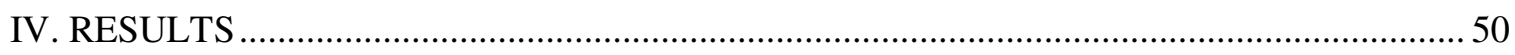

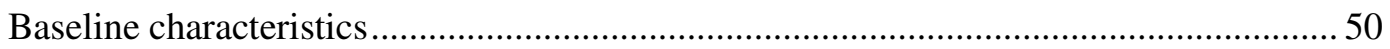

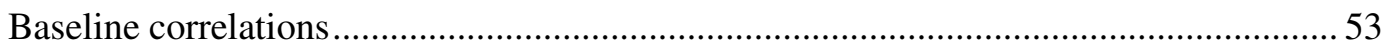

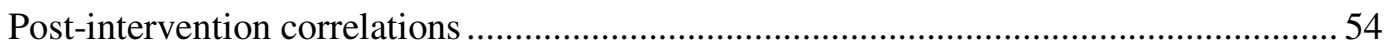

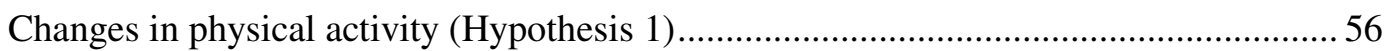

Change in mother-daughter relationship (Hypothesis 2) ............................................... 57

Effects of mediators on increases in physical activity (Hypothesis 3)..............................58

Change in mental health outcome (Hypothesis 4) …................................................... 58

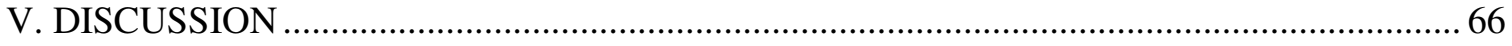

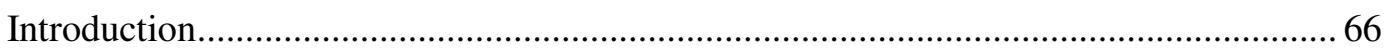

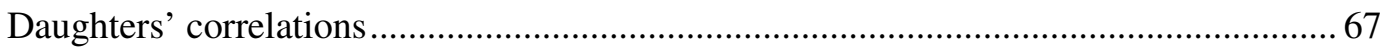

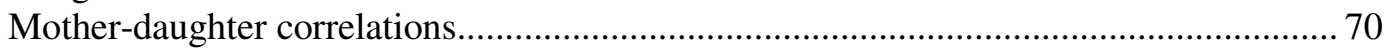

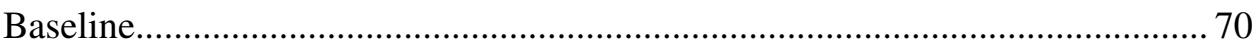

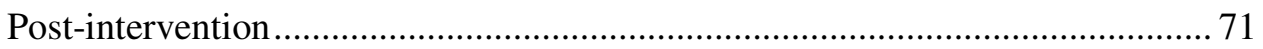

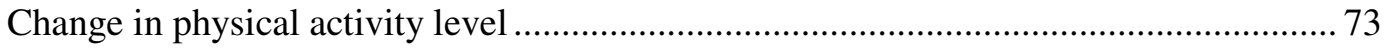

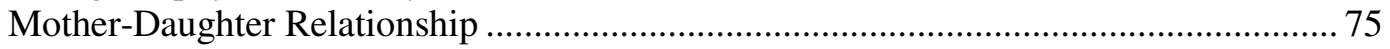

Effect of mediators on increases in physical activity levels ........................................76

Change in physical activity variables predict change in mental health outcomes ............. 77

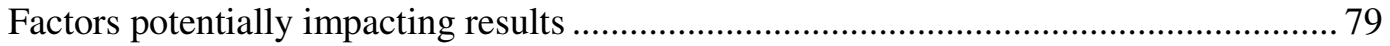

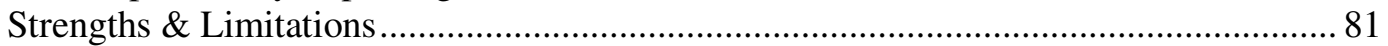

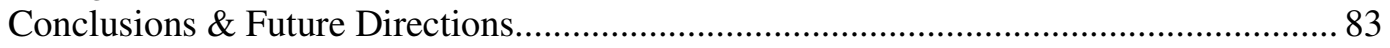

\section{APPENDICES}

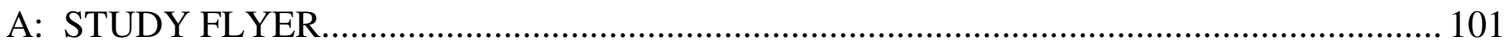

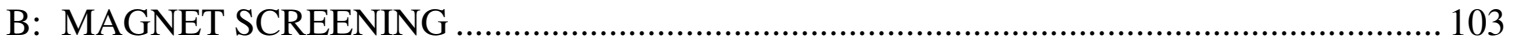

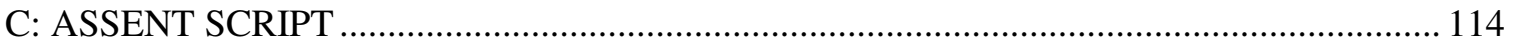

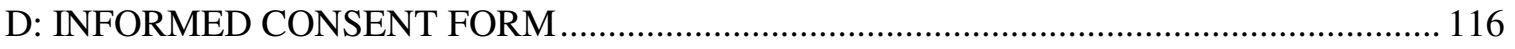

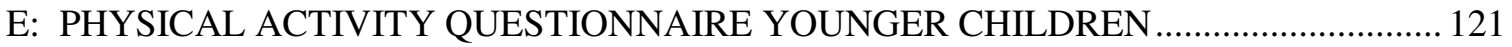

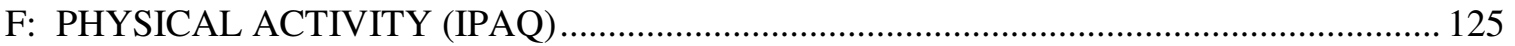

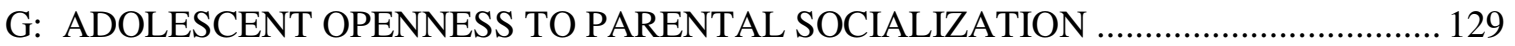

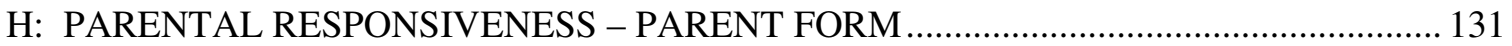

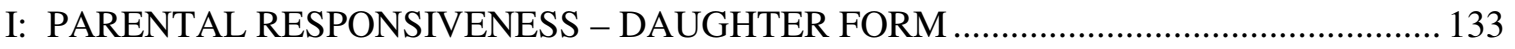

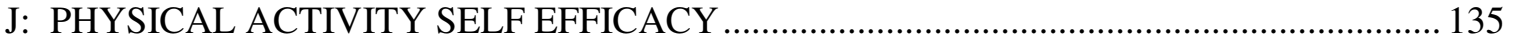

K: CHILD SELF-PERCEPTION OF ADEQUACY AND PREDILECTION FOR PA

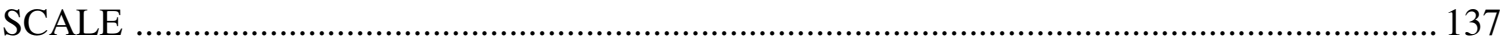

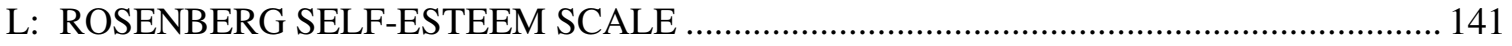

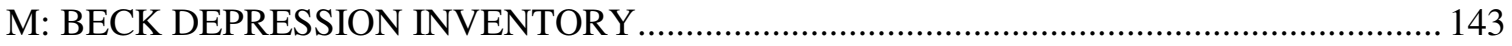

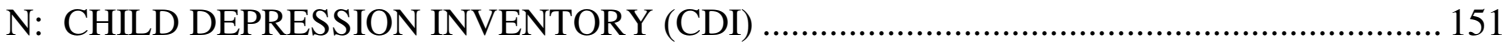

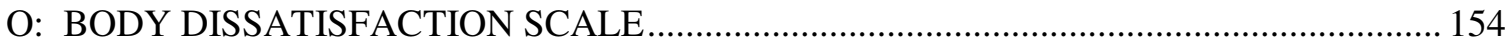




\section{LIST OF TABLES}

Table

Page

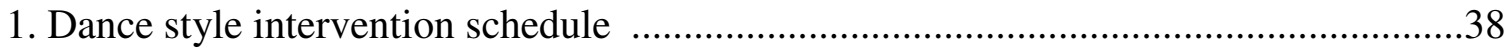

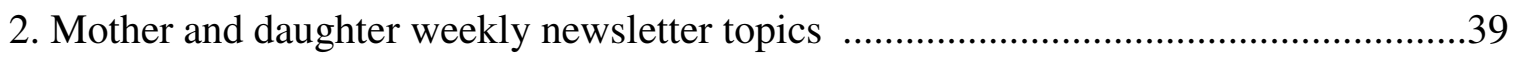

3. Assessment time points of variables of interest .....................................................40

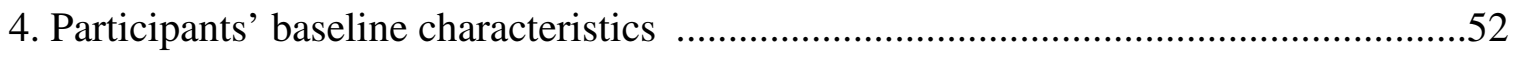

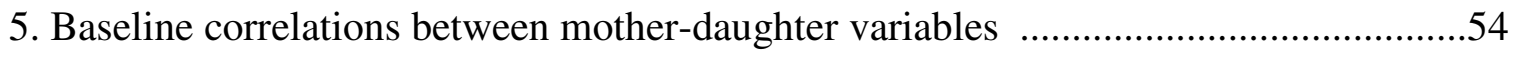

6. Post-intervention correlations between mother-daughter variables ...........................55

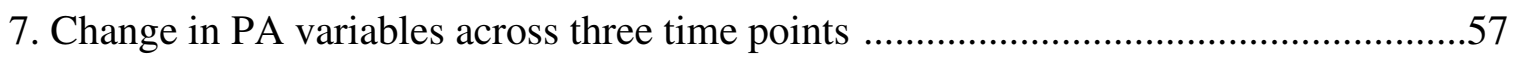

8. Change in mental health outcome variables across two time points ..........................59

9. HLM results for PA predictor variables on self-esteem ......................................61

10. HLM results for PA predictor variables on body image dissatisfaction ...................62

11. HLM results for PA predictor variables on depressive symptoms …......................63 


\section{LIST OF FIGURES}

Figure

Page

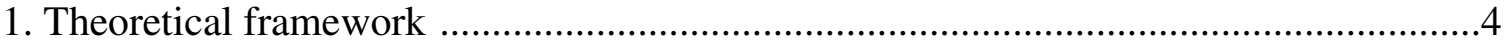

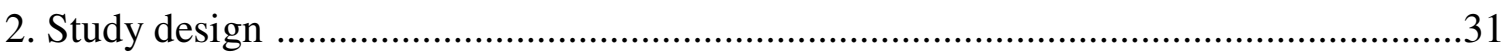

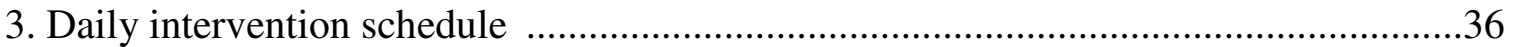

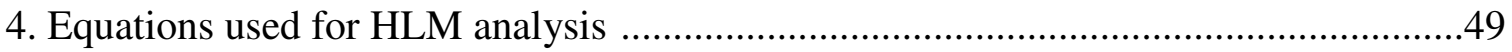




\section{CHAPTER I}

\section{INTRODUCTION}

\section{Background}

African American girls have the highest prevalence of overweight and obesity status among their racial counterparts with the exception of Hispanic girls (117). Approximately, 36.9\% of 6-11 year old African American girls are considered either overweight or obese [body mass index $(\mathrm{BMI}) \geq 85$ th percentile for their age and gender] compared to only $32.7 \%$ of 6-11 year old Caucasian girls (117). The greater prevalence of obesity in African American girls is problematic due to the link between obesity and several diseases [i.e., precursors to cardiovascular disease (CVD) and type 2 diabetes mellitus (T2DM)] (154) and disease risk factors [i.e., hyperinsulimia, hypertension, and mental health disorders (i.e., depression, low self-esteem)] both in childhood and in adult life $(26,53,137)$. In addition, the unhealthy effects of pediatric obesity are likely to serve as antecedents of adult disease $(9,53,153)$ highlighting the need to intervene at an early age. Development of overweight and obesity in the pediatric population has been associated with decreased physical activity (PA) levels and increased sedentary behavior $(74,132,134)$. Not only is low PA level associated with obesity, but it also appears to be associated with mental health outcomes such as depressive symptoms, self-esteem, and body image dissatisfaction (160).

Currently, it is recommended that school-age ( $>5$ years) children should engage in 60 minutes or more of PA every day (177). While any type of activity counts towards the 60 minutes, it is recommended that most of the PA be either moderate or vigorous 
intensity. According to the most recent Youth Risk Behavior Surveillance Summary (YRBSS, 2013), only $27.1 \%$ of high school students (grades 9-12) met the current PA recommendation based on a self-report survey (87). Only 16.0\% of African American girls reported being physically active for at least 60 minutes per day compared to $18.7 \%$ of Caucasian girls (87). In addition, 27.3\% of African American girls reported not participating in any form of PA on any day of the week, compared to $16.1 \%$ of Caucasian girls (87). It is also well known that children spend a large amount of their day engaging in sedentary behaviors such as watching television, playing video games, and using a computer. Increased sedentary behavior is related to a higher BMI in children (4). Objectively measured NHANES data indicated that 6-11 year old children spent an average of 6.07 of their waking hours engaging in sedentary behavior (103). Like PA, there is also a marked change during adolescence that shows girls are more sedentary than boys; however, in this case it has been shown to increase (103).

Several intervention studies have been conducted to improve the PA level of children $(11,162)$. However, the majority of these studies have not been successful in altering the PA level of African American girls (17). The lack of improvement in the PA level of African American girls has been linked to two factors; the lack of 1) culturaltailoring of the PA intervention and 2) the involvement of the mother (the primary role model) $(96,126,135)$.

Evidence suggests that health behaviors are learned from the family dynamic in early childhood and remain relatively stable through adolescence and adulthood (98). Mothers' health behaviors specifically can have a substantial impact on the development of the daughter's mental health outcomes (i.e., self-esteem, PA self-efficacy, depression, 
body image dissatisfaction) and physical health (PA, nutritional) behaviors $(105,171)$.

The impact of the mother's health cognitions and behaviors on a child's health behaviors has been linked to the mother-daughter relationship $(8,120,135)$. Researchers have reported that the mother-daughter relationship could impact the daughter's PA and related mental health outcome variables (2). Parents can impact their child's health behaviors through modeling, rewarding, ignoring, implementing or eliminating barriers, and providing resources for these behaviors (174). When developing these attitudes towards PA, studies have shown that a child's behaviors are related to their perceptions of their parents' attitudes toward PA $(98,105)$. Parental encouragement, social support, positive beliefs towards PA, and self-efficacy are all positively correlated with a child's PA level, which emphasizes the importance of the mother-daughter relationship (105). For example, a mother's PA self-efficacy, defined as her confidence in her ability to be physically active, has been reported to impact the level of social support that she provides to her daughter for PA pursuits (2). Self-efficacy is the underlying construct for the social cognitive theory (SCT) $(12,13)$. These same underlying constructs also play a role in the modeling of behaviors by the mother for her daughter.

Social cognitive theory and mother-daughter relationship encompass various factors that are interwoven and influence the daughters' predilection for health behaviors including PA. The theoretical framework for this secondary analysis is depicted in Figure 1. According to SCT, behavior is learned by observing and modeling the behavior of others (12). The daughter will observe her mother's behaviors whether they are positive or negative health behaviors and adopt the behavior as her own. The strength of the mother-daughter relationship can be impacted by the daughter's mental health outcome 
variables, such as her self-esteem, depressive symptoms, and body image dissatisfaction, which are known to impact PA levels $(55,160,166)$.

Figure 1. Theoretical framework.

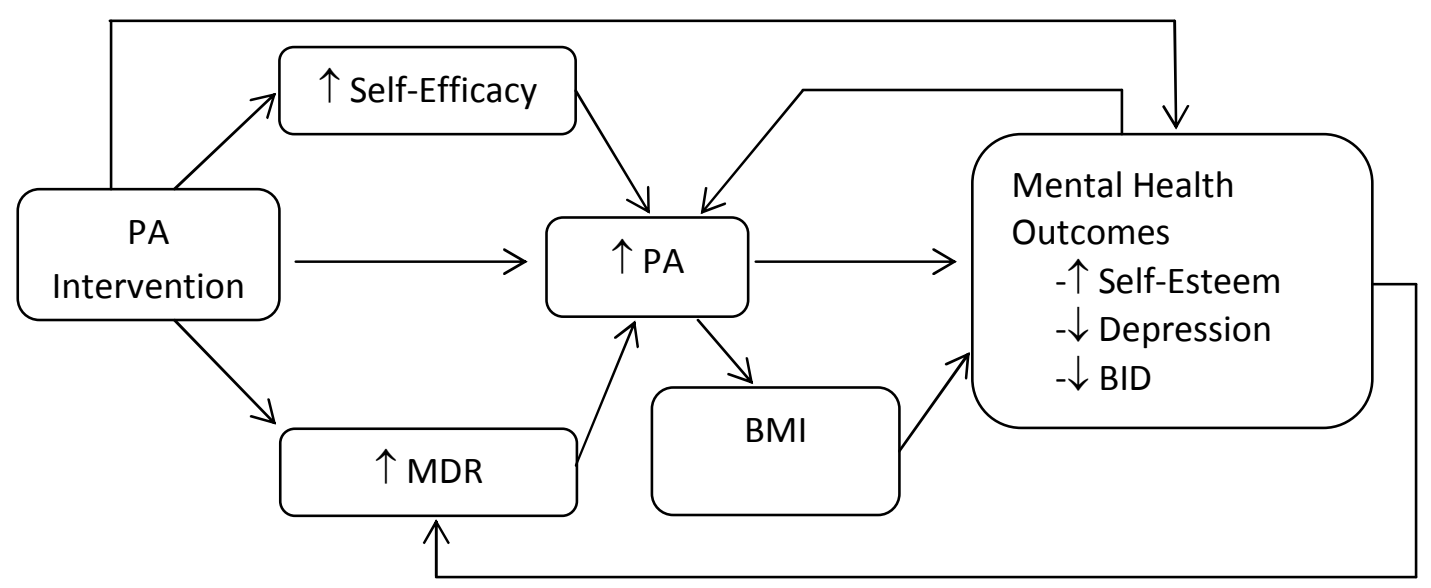

Research has shown that mental health outcome variables are not only associated with each other, but also associated to PA in children. SCT variables (i.e., self-efficacy) have been reported to mediate PA change in pre-adolescent children (33). Additionally, self-efficacy has been shown to be a correlate of PA, and is the mediating variable most commonly observed in PA interventions (145). Researchers have shown that participating in PA interventions can lead to improvements in children's PA self-efficacy, PA level, and self-esteem (55). High self-esteem is positively correlated with increased PA, whereas low self-esteem is correlated with reduced PA (158). Depressive symptoms are inversely related to PA in children and youth $(111,184)$. Low self-esteem is predictive of depressive symptoms, specifically in adolescent girls (54). In addition, body image dissatisfaction, which can be defined as subjective unhappiness with some aspect of one's 
appearance, can lead to disordered eating habits, which are also associated with depressive symptoms (184). However, BMI can also have a moderating effect on children's PA level and mental health outcome variables. The use of SCT framework and related mental health outcome variables may provide an understanding of mechanisms behind behavior change, and thereby promote maintenance of these positive behaviors later in life. For African American girls, the role of the mother may enhance the effectiveness of the PA intervention.

\section{Purpose of the Study}

Currently, very little is known about the role of mother-daughter relationship on African American girls' PA levels and mental health outcome variables. It is wellestablished that overweight and obesity status is problematic in African American girls, and a culturally-tailored mother-daughter intervention may provide a means for increasing PA and enhancing mental health outcome variables. Mental health outcome variables have been shown to not only be related to each other, but to PA level as well. Therefore, the purpose of this study is to examine if the change in PA following a 12week culturally tailored mother-daughter PA intervention predicts change in mental health outcome variables (self-esteem, depressive symptoms, and body image dissatisfaction) and the mother-daughter relationship in pre-adolescent African American girls. For the scope of this study, change in PA will encompass sedentary time, light PA, and MVPA. This study is a secondary data analysis project stemming from a larger randomized controlled trial. 


\section{Hypotheses}

$\mathrm{H}_{1}$ : Participation in a culturally-tailored mother-daughter PA dance intervention will increase the daughters' objectively measured percent time spent in light PA, MVPA, and total daily PA and decrease percent time spent in sedentary behavior.

$\mathrm{H}_{2}$ : Participation in a culturally-tailored mother-daughter PA dance intervention will improve the mother-daughter relationship.

$\mathrm{H}_{3}$ : Increases in PA levels will be mediated by increases in PA self-efficacy and mother-daughter relationship.

$\mathrm{H}_{4}$ : Change in PA variables will predict change in daughter's mental health outcome variables of interest (self-esteem, body dissatisfaction, depressive symptoms).

\section{Summary}

Pediatric obesity is a significant clinical and public health issue for African American girls. This population suffers disproportionately from obesity and related risk factors compared to their Caucasian counterparts. The rise of pediatric overweight and obesity status has been associated with decreased PA and increased sedentary behavior $(74,132,134)$. Low PA levels have also been associated to several mental health outcome variables including self-esteem, depressive symptoms, and body image dissatisfaction (160). Because PA behaviors exhibited in childhood tend to track into adulthood, it is important to form positive health behaviors early in adolescent development $(88,164)$. Physical activity levels tend to decline as children reach adolescence. The reduction in PA has been shown to occur at a greater rate in girls (92). African American girls in particular face an even greater rate of decline in PA through 
adolescence (90). This marked decline highlights the critical need to examine and understand variables that predict and/or moderate PA behaviors within this population. Mothers' health behaviors can impact the development of daughters' physical health and mental health outcomes $(105,109,171)$. The role of the mother-daughter relationship is a factor that has rarely been examined as a viable route for changing health behaviors, and was examined in this study with the implementation of an after-school PA intervention. The strength of the mother-daughter relationship could also serve as a mediating variable where intervention exposure would result in a change in mother-daughter relationship and thus increasing PA levels. Developing a better understanding of the factors that moderate an increase in PA in African American girls could lead to more effective means of increasing PA within this population. 


\section{CHAPTER II}

\section{LITERATURE REVIEW}

\section{$\underline{\text { Overview }}$}

African American girls suffer disproportionately from overweight and obesity status compared to other groups (117). These rates are alarming due to the fact that pediatric obesity leads to a multitude of health consequences and serves as a predictor for disease in later life. The rise in pediatric obesity can be attributed to physical inactivity, which is also associated with mental health outcome variables (i.e., self-efficacy, selfesteem, body image dissatisfaction, depressive symptoms) $(58,107,158)$. Currently, it is recommended that school-aged children ( $>5$ years) should engage in 60 minutes or more of PA on every day of the week (177). The majority of African American girls are not meeting this recommendation, which indicates that effective interventions are needed to increase time spent in MVPA $(4,75)$. One way to develop effective interventions in this specific population could be to make it culturally relevant and include the girl's mother, who serves as her primary role model. Since a mother's health behaviors can impact her child's, it is plausible that the mother-daughter relationship could have a mediating effect on the success of a physical activity (PA) intervention. Very little is known regarding the influence of the mother-daughter relationship on African American girls' PA levels and related mental health outcome variables. The present study examined the impact of a 12week culturally-tailored mother-daughter PA intervention on pre-adolescent African American girls' PA levels and if the change in PA predicted a change in related mental health outcome variables. 
This review of literature is separated into four sections. The first section reviews the prevalence of pediatric obesity and associated health consequences. The second section discusses PA levels in children. The third section provides an overview on the current body of literature on PA interventions in children. Finally, the last section describes mental health outcome variables, determinants of PA and the impact of the mother-daughter relationship.

\section{Prevalence of Pediatric Obesity and Health Consequences}

The prevalence of overweight $(\mathrm{BMI} \geq 85$ th percentile but $<95$ th percentile for age and gender) and obesity (BMI $\geq 95$ th percentile for age and gender) in American children has doubled in the last three decades $(50,117)$. Current National Health and Nutrition Examination Survey (NHANES) data indicates that African American girls have the highest prevalence of overweight and obesity compared to all racial/ethnic groups with the exception of Hispanic girls. Currently, 36.9\% of African American girls ages 6-11 are considered overweight compared to $32.7 \%$ of their Caucasian counterparts (117). In addition, $21.7 \%$ of African American girls are obese, while only $17.9 \%$ of Caucasian girls fell within that range (117). The increased prevalence of pediatric obesity is not only alarming because obesity status has been shown to track from childhood into adulthood $(53,102,149)$ but also because obesity has been linked to several health consequences $(26,53,133,137,153,154)$.

Pediatric obesity is a risk factor for several diseases such as type 2 diabetes mellitus (T2DM), hyperinsulimia, hypertension, cardiovascular disease (CVD), and mental health conditions (i.e., depression, low self-esteem) $(58,107,158)$. The risks associated with pediatric obesity are likely to serve as antecedents of adult disease (53). 
Since 1970, T2DM has increased 9-10 fold in American children (45). African American children, especially girls, have one of the highest prevalence of T2DM compared to all other racial/ethnic groups (139). These increased risk factors highlight the need to identify viable methods for decreasing the prevalence of pediatric obesity in preadolescent African American girls.

\section{Physical Activity Levels in Children and Adolescents}

Lack of physical activity (PA) and excess sedentary behavior (i.e., screen time, media usage) are among the major contributors to pediatric obesity (58). Currently, it is recommended that school-aged children ( $>5$ years of age) should engage in 60 minutes or more of PA every day (177). While any type of activity counts towards the 60 minutes, it is recommended that most of the PA be either moderate or vigorous intensity. According to the most recent Youth Risk Behavior Surveillance Summary (YRBSS, 2013), only $27.1 \%$ of high school students (grades 9-12) meet the current PA recommendation (87). In addition, $15.2 \%$ of students reported not participating in any kind of PA during the previous week (87). Similar to obesity, there appears to be a disparity in PA in US children. NHANES self-report data demonstrated similar findings with respect to the racial gap in PA levels where 31\% of African American girls reported two or fewer bouts of vigorous PA each week, compared to only $20 \%$ of Caucasian girls (4). However, self-report data from national surveillance studies tends to be overestimated especially in children, as a result of social desirability bias and the difficulty associated with estimating both frequency and duration of PA (48). Objectively 
measured NHANES data indicated that 35\% of 6-11 year old girls recorded at least 60 minutes of moderate PA on 5 of 7 days of the week (168).

In all racial groups, PA has been shown to decrease with age as children progress from childhood to adolescence $(4,90,113,114)$. In order to combat the lower PA levels in adolescence and adulthood, pre-adolescent interventions are crucial to forming positive health behaviors.

\section{Sedentary Behavior Levels in Children}

It has been reported that children spend approximately $75 \%$ of their day being inactive (158). Sedentary behaviors can include events such as sitting, watching television and playing video games and are related to a higher BMI in children (4). According to NHANES data using objective measures of sedentary behavior, 6-11 year old children spend approximately 6.07 hours (about $42 \%$ of waking hours) in sedentary activity per day (103). The amount of time spent in sedentary activity has been shown to be greater in girls and increases as children reach puberty to approximately 8.13 hours per day (103). However, when stratified by race, 6-11 year old African American girls were less sedentary than Caucasian girls (103). Pate et al. found that sixth grade girls spent approximately 7.7 hours (55.6\% of waking hours) in sedentary behavior, which is consistent with NHANES data (122). A study by Treuth et al. also found a two hour increase in sedentary time when comparing elementary, middle, and high school students, which indicated that sedentary time increases as children age (167). Researchers attributed this increase in sedentary behavior to a reduction in percent time spent in light PA (167). 


\section{$\underline{\text { Sedentary Behavior Interventions }}$}

Obese children tend to spend a larger part of their day in sedentary behavior (185). When given the choice of active games or sedentary activities, obese children chose sedentary activities (63). Epstein et al. conducted an intervention in 55 children (age $=10.1$ years $)$ and their parents to compare the effects of reducing time spent in sedentary behavior, reinforcing children for increasing PA, or a combination of both on childhood weight status (64). Children and a parent attended weekly meetings for four months, and two monthly meetings for one year. Researchers reported a significant decrease in overweight prevalence in the sedentary reduction group after four months of reinforcing a decrease in sedentary behaviors (64). At one-year follow-up, the sedentary reduction group also exhibited a greater decrease in overweight prevalence (-18.7 vs. 10.3, and -8.7) and percent body fat (-4.7 vs. -1.3$)$ when compared to the increased PA group and the combined group (64). This study is critical in providing support for the concept that decreasing sedentary behavior can improve weight status. Similar results were seen in a later study by the same research group in 8-12 year old children $(n=90)$ and their families (62).

Spruijt-Metz et al. conducted a culturally-tailored school-based intervention in minority girls $(\mathrm{n}=459$, age $=12.5$ years, $73 \%$ Latina $)$ designed to increase PA and decrease sedentary behaviors (152). The intervention consisted of an interactive mediabased component that was delivered in 5-7 sessions per week, each lasting two hours during the spring semester. Girls also created public service announcements showing increased PA and decreased sedentary behavior for girls their age. Researchers reported that girls in the intervention group had a significant reduction in time spent in sedentary 
behavior $(\beta \pm \mathrm{SE}=-0.27 \pm 0.14, p<0.05)$, but had no significant effect on PA or body fat (152). While not significant, the intervention group did experience a smaller absolute increase in BMI and body fat compared to the control group (152). This was one of a limited number of studies that used a theory-based intervention to target sedentary behavior and test for mediating variables. A review by DeMattia et al. examined interventions targeting reducing sedentary behaviors in children and adolescents and its effect on both behavior change and weight status (52). Twelve studies were included, six of which were population-based prevention, and six were in overweight/obese populations. While these interventions embodied several approaches, they all were successful in reducing sedentary behavior and improving weight status (52). This shows that interventions aiming to reduce sedentary behavior are effective in controlling weight and reducing sedentary time in both children and adolescents (52).

\section{Physical Activity Interventions}

Because of the high prevalence of pediatric obesity and known risk factors, the need to develop effective interventions is critical. Schools have been a common environment for intervention because virtually all children attend school for the majority of the day (151). Several difficulties lie within this setting including policies, curriculum requirements, teacher cooperation, and administration approval just to name a few (148). In 2009, Brown et al. published a systematic review paper of 38 intervention studies published from 1990-2007. Authors concluded that school-based interventions that utilized PA and/or diet to reduce pediatric obesity were generally not effective (36). However, the interventions did generally increase PA and reduce sedentary time, but the 
effect was only seen short term (36). School-based interventions work well during the day, but there is a disconnect once the children go home at the end of the day. There is conflicting evidence to support long term prevention of obesity through a combined PA and diet school-based intervention (36). This could partially be due to the lack of alteration in the home environment and family dynamic as an added component to the school intervention.

Since school-based interventions have produced equivocal data, after-school PA interventions are emerging as an important setting to boost daily PA. Approximately 6.6 million children participate in an after-school program (23), making this a promising option for reaching a large amount of children. These programs have been shown to engage children in as much as one-third of their recommended 60 minutes per day of MVPA (173). Trost et al. indicated that after-school PA programs can be effective in improving PA levels, fitness, BMI, and blood lipids (173). However, limitations to these programs include transportation needs and low attendance rates (173).

The Stanford GEMS intervention used an after-school dance program and a home-based screen time reduction program for low socioeconomic status (SES) African American girls (142). Two hundred sixty-one 8-10 year old African American girls and their parents/guardians participated in a 2-year community-based intervention. The treatment intervention consisted of after-school dance classes (African, hip-hop, and step) offered 5 days per week, 12 months per year at community centers in neighborhoods in the Oakland, CA, area. A typical intervention day consisted of a healthy snack, one hour of homework tutoring, and 45-60 minutes of dance. The screen time reduction program was administered in each participant's home and included an African American history 
lesson and the screen time reduction model. The health education active-control group received monthly newsletters with culturally tailored health information. Results yielded no change in BMI between groups, with the exception of a subset of high-risk girls who demonstrated a reduced increase in excessive BMI (142). However, between group differences were found in depressive symptoms, lipid levels, and insulin levels (142). The lack of change in BMI could be due to the interventions' low attendance rates, as participants only attended an average of $21 \%$ of dance classes (142).

The Memphis GEMS pilot intervention had similar objectives as Stanford GEMS, but included a child-targeted program, a separate parent-targeted program, and a control group. Sixty 8-10 year old African American girls and their parents participated in this 12-week intervention (22). The child-targeted intervention was 90 minutes in length and consisted of 30 minutes of hip-hop aerobics, 30 minutes of nutrition education, and 15 minutes of welcome and recap segments (22). Parent-targeted sessions were 90 minutes and consisted of dance, nutrition lectures, and a food preparation segment (22). One year results demonstrated that girls in the intervention group also increased objectively measured MVPA by 12\% (22). Results also indicated non-significant trends in both the child- and parent-targeted interventions towards reduced BMI and waist circumference when compared to the control group (22).

The Medical College of Georgia FitKid project instituted an eight month program for three years to reduce adiposity in children in grades 3-5, of which $61 \%$ were African American (188). The intervention took place after-school and consisted of 80 minutes of MVPA and 40 minutes of academic enrichment (188). After one year, results indicated an increase in after-school MVPA and a decrease in body fat percentage in the 
participants that attend at least $40 \%$ of the program (55). Three year post-intervention results showed that children in the intervention group improved in body fat percentage and cardiorespiratory fitness during the 8-month intervention, but returned to control group levels during the summer months (77). Each of these after-school programs show promise for improving health risk factors, but the effectiveness tends to dissipate at postintervention. This emphasizes the need to identify mediating variables that will increase the effectiveness of PA interventions in children and produce lasting effects.

\section{$\underline{\text { Social Cognitive Theory }}$}

The use of SCT as a theoretical framework for developing pediatric PA interventions allows researchers to identify mediating variables that affect choices and behaviors such as PA. SCT states that behavior is learned, at least partially, through modeling and observation of peers and role models (12). This process involves attention, retention, production and motivation. Cognitive processes involved with SCT include self-efficacy, goal-setting, outcome expectancy, and satisfaction with the behavior (13). These cognitive processes directly impact PA behaviors. Enhancing one's self-efficacy can be accomplished through mastery experiences, modeling behavior, social persuasion, and reducing stress response to the behavior (13). When the model is similar to the individual, there is a greater effect of the model's successes. For example, a daughter who identifies similarly to her mother would be more likely to model her health behaviors. The formation of self-efficacy begins in the family dynamic as early as infancy and develops into adolescence when peers tend to take on that role (13). PA selfefficacy has been classified as a correlate of PA in children, and low levels of self- 
efficacy are associated with depressive symptoms $(13,145)$. Social cognitive theory has formed a background for several intervention studies to examine the role of parental behaviors in relation to the PA self-efficacy of the child.

\section{Determinants of Physical Activity}

Understanding the factors that influence a child's likelihood to be physically active is necessary in developing effective interventions. Determinants of PA can be stratified into four categories - biological, psychological, behavioral, and socioenvironmental. When examining behavioral determinants as causal factors for outcome variables such as PA, it is unlikely that these causal factors will be absolute (19). With respect to the present study, there could be multiple causal factors or reverse causality in which the causal pathway is bidirectional. For example, improvements in mental health outcomes could predict change in PA levels, which is the opposite of the aforementioned hypothesis. These complex bidirectional relationships, often involving mediating pathways, are common to behavior research as the relationships between mental health outcome variables and PA are multifaceted $(19,49)$. While difficulty lies in understanding mediating pathways in behavioral research, it is a necessary first step to inform more effective interventions and tailor them to specific groups of people.

\section{Parental Behaviors}

It is well established that parents have an influential role in the development of the child's health behaviors, but the exact mechanisms are still unclear $(123,163,174)$. 
Baranowski et al. stated that parental influence could result from modeling, rewarding/punishing behaviors, the use of barriers, providing resources, and employing authoritative practices to develop self-control in the child (16). Parents play a significant role in the lives of their children, as most form the primary social support system in the home environment especially during pre-adolescence (76). Parents' health behaviors can either enhance or compromise those of their children. A child's health behaviors can be fostered through social support. Parental social support is a broad term that encompasses providing opportunities to be active, transportation to activities, verbal encouragement and praise, co-participation, and financial support among others and has been associated with children PA level (25). For example, involvement in PA has been positively correlated with parental social support in children and adolescents $(105,145)$. Therefore, enhancing parental social support can lead to increased PA. According to a review by Gustafson et al., the three forms of support that have the greatest impact on children are parental involvement, encouragement, and facilitation (76). Support may mediate any relationship between active parents and active children (76). It has been reported that when parents are physically active, their children are six times more likely to be active compared to inactive parents (109).

Parental support can either directly or indirectly predict a child's PA level (76). In a study done by Trost et al. that examined 380 students (age, 14.0 \pm 1.6 years) and their parents, researchers found that parental PA behavior, parental enjoyment of PA and perceived importance of PA were positively correlated with parental support (174). They found that parental support was associated with the child's PA levels both directly and indirectly through self-efficacy (174). Therefore, it is possible that the child's self- 
efficacy mediates the relationship between parental support and the child's PA (174). These data highlight the significance of SCT variables, specifically learning through observation and self-efficacy, and children forming their own behaviors through observing those around them. Girls may be especially susceptible to the behaviors of their mothers (171). It is crucial to understand the role of parental behaviors on the child when developing effective family-based PA interventions.

\section{Mother-Daughter Relationship}

Mothers' health behaviors have a strong influence on their child's health behavior, especially in African American culture (8, 39, 40, 61, 101, 131, 135). It appears that mothers may have a greater influence on their daughters as opposed to their sons (76). In a review of maternal PA relationships, six of the 11 studies showed a significant relationship between mothers' support and daughters' PA levels, while only three demonstrated a significant relationship between mothers' support and sons' PA levels (76). This study also showed that fathers' influence their sons' PA more than their daughters' (76). While there are several constructs that encompass a mother-daughter relationship, role-modeling and connectedness was the focus of the current study. Moore et al. reported that children of active mothers are twice as likely to be active $(95 \% \mathrm{CI}=$ $0.9,4.5)$ when compared to children of inactive mothers (109). Yin et al. found that daughters' PA levels correlated with that of their mothers from pre-adolescence through the start of adolescence (ages 9-15) (186). Finally, Davison et al. demonstrated a strong association $(\beta=0.21, p<0.01)$ between mothers' support and the PA levels of the daughters (47). While these associations have been examined briefly in the literature, 
little data exists on the strength of the parent-child relationship associated to the child's PA level specifically in the African American culture.

It has been reported that maternal connectedness can influence a child's resilience to risky behaviors $(1,8)$. Aronowitz et al. defines resilience as an adolescent's ability to resist risky behaviors or hazardous situations (8). Risky behaviors encompass any unhealthy or self-destructive behavior and include unhealthy diet, low PA, substance use, violence, and sexual behaviors (8). Researchers examined the role of maternal connectedness on resilience to risky behaviors in early adolescent African American girls $(\mathrm{n}=443$; age $=11-15$ years $)$. Results indicated that girls who felt more connected to their mothers were less likely to engage in risky behaviors during adolescence (8). These results also stated that "connectedness" was based on the daughter's perception of her relationship with her mother and not simply maternal presence. Additionally, Ackard et al. reported that girls who felt less connected to their mothers had a higher prevalence of unhealthy weight control, low self-esteem, and depression (1). Increased parental influence can function as a protective factor for adolescents engaging in unhealthy behaviors (32). In African Americans specifically, a strong mother-daughter relationship fosters empowerment and socialization and can also lead to high self-esteem, strong ethnic identity, and successful coping strategies (32).

Mother-daughter PA interventions are sparse within the literature, and the few that exist are not specific to African Americans (127, 128, 170). A study by O'Loughlin et al. examined the prevalence and correlates of PA in 2285 multiethnic children ages 913 years in 24 inner-city elementary schools in Montreal (120). Baseline data from this 5year school-based study indicated that direct modeling of PA by mothers was found to be 
a correlate of girl's PA (120). Mothers participating with their daughter in PA were positively correlated with increased PA levels in the girls and they were less likely to be active if their mothers never encouraged them (120). Ransdell et al. were the first to implement a mother and daughter exercising together program with mostly Caucasian participants (127). Adolescent girls and their moms were randomized into either a homebased intervention or community-based intervention. The community-based program involved exercise occurring at a facility with trained staff and other mother-daughter dyads, while the home-based intervention asked the dyads to exercise together in their home at a convenient time. Both mothers and daughters increased their PA levels. Mothers and daughters in both groups had significant fitness improvements, and in mothers, this was coupled with positive changes in CVD risk factors with blood pressure (127). Researchers cited the success of the intervention to high adherence rates, which they believed was the result of mother-daughter bonding (127).

Currently, there have only been four mother-daughter PA interventions that targeted African Americans $(22,142,156,180)$. None of these studies included a motherdaughter PA component where they were engaging in the activity together, but one in particular highlighted this as a future recommendation. In the Memphis GEMS study, researchers implemented a 12 week randomized controlled after-school dance program for 8-10 year old African American girls and their mothers (22). This intervention was comprised of 60 dyads in a daughter only dancing group, a parent only dancing group, or a control group. Results yielded a 12\% increase in self-reported MVPA for the girls in the daughter-only dancing group (22). However, one of the biggest critiques expressed by the mothers was their wish to engage in the PA portion of the program with their daughters. 


\section{Self-Efficacy}

Bandura defines self-efficacy as one's belief in their own ability to organize and execute the necessary course of action required to accomplish a given task (13). Selfefficacy is a correlate of PA in children, and is the mediating variable most commonly examined in PA interventions $(145,179)$. A mediating variable is one that intervenes in a causal pathway and is necessary to complete the pathway from intervention to the targeted behavioral outcome (19). Trost et al. conducted a study to compare the determinants of PA in active and low-active African American sixth graders (172). Approximately half of the 119 participants were female and had an average age of $11.4 \pm 0.5$ years. Participants were considered to be active if they engaged in three or more 20-minute bouts of MVPA during a one week period (172). When compared to the lowactive group, active girls and boys demonstrated significantly higher levels of selfefficacy (172). This study provided key evidence for the positive relationship between self-efficacy and PA in the African American pre-adolescents. In a later study, Trost et al. compared PA levels and determinants of PA in an ethnically diverse sample of 11 year old non-obese $(\mathrm{n}=133)$ and obese $(\mathrm{n}=54)$ middle school students $(169)$. PA was measured objectively with accelerometers while all mental health outcome variables were assessed by self-report. Obese children in this study participated in significantly less daily MVPA and had lower self-efficacy than their non-obese classmates (169). This outcome suggests that obese children were less confident in their abilities to be physically active, which could have influenced their PA levels. Self-efficacy has also been shown to be a correlate of adolescent girl's sedentary behaviors (115). However, a systematic review by Van der Horst et al. found no evidence for this relationship in younger children (179). 
Dishman et al. used variables from SCT (i.e., self-efficacy, outcome-expectancy value, goal-setting, and satisfaction) as mediators of change in PA in a school-based intervention, in order to increase PA in African American and Caucasian adolescent girls (55). The purpose of the two-year program was to increase self-efficacy through positive PA experiences, develop behavioral skills that will to transition into adulthood, and encourage age and gender appropriate PA (55). The multicomponent randomized controlled trial used health education, PE classes, and extracurricular activities to enhance self-efficacy, and develop behavioral skills necessary for change in health behaviors (55). Results of this study indicated that the intervention not only had a direct effect on increasing PA, but also had a direct effect on self-efficacy (55). This was the first study to produce outcomes that indicated increased self-efficacy can lead to increased PA (55).

\section{Self-Esteem}

Some of the greatest concerns related to pediatric obesity are mental health outcome variables such as self-esteem and depressive symptoms (53). Low self-esteem is predictive of depressive symptoms specifically in girls during adolescence (54). In addition, PA has been positively correlated with self-esteem in adolescence (189). In a study by Strauss et al. that examined the relationship between PA and self-esteem in 92 children (ages 10-16 years), regression analysis indicated that increased self-esteem scores predicted increased PA and adolescents with low levels of PA had significantly lower self-esteem scores (158). 
A recent study by Witherspoon et al. examined how mental health factors vary by body weight and gender among African Americans $(\mathrm{n}=235)$ adolescents' ages 11-16 years. Researchers reported that female, obese African American adolescents had significantly lower self-esteem scores when compared to males or overweight individuals (184). This raises the important issue of studies that have combined overweight and obesity status into one category and revealed little to no change in mental health variables. The difference in the self-esteem of overweight girls and the obese girls could be due to a higher ideal body weight that is evident in African American culture in which overweight seems normal (184).

Self-esteem is critical in a child's development as it serves as a core factor leading to personal motivation, persistence, and academic achievement (166). A study by Tremblay et al. assessed the relationship between children's self-reported PA levels, BMI, and self-esteem as part of a larger study of elementary schools in New Brunswick, Canada (166). A sub-cohort consisting of 5,146 sixth-grade students was drawn from a larger study examining the effect of the home and school environment on children's attitudes and behaviors. Results indicated that PA levels were significantly associated with self-esteem (166). More importantly, this data suggests that females with higher levels of PA are less likely to have low self-esteem, a condition commonly seen in preadolescent females (166).

With respect to the African American population, there are mixed results regarding self-esteem, BMI, and PA levels. Strauss et al. reported that African American girls were less likely to have low self-esteem based on BMI when compared to Caucasian or Hispanic girls (157). Stockton et al. confirmed this in their study that indicated no 
significant difference in the self-esteem levels of African American girls based on weight status (155). Because of these inconsistencies, it is clear that self-esteem not only varies by age and gender, but also by race/ethnicity (124). In a study by Brown et al. that examined changes in self-esteem and physical appearance competence in Caucasian $(\mathrm{n}=$ $1166)$ and African American $(n=1213)$ girls ages 9-10, results indicated that self-esteem level is more consistent between the ages of 9-14 years in African American girls, while they declined at 11 years in Caucasian girls (34). Since self-esteem is highly variable within African American girls, it is important to understand the underlying mechanisms responsible for this behavior and how it can impact PA.

\section{Body Image Dissatisfaction}

Body image dissatisfaction can be defined as subjective unhappiness with some aspect of one's appearance (99). According to Ricciardelli et al., BMI is strongly correlated to body dissatisfaction in pre-adolescent and adolescent girls (136). Overweight status in young girls has consistently predicted body dissatisfaction and the development eating disorders, depression, low self-esteem, and emotional distress (27, 99). Kelly et al. examined racial differences in body image dissatisfaction using silhouette measures in girls enrolled in an overweight treatment intervention (89). Results showed that $99 \%$ of girls enrolled in the program preferred a smaller body size, regardless of race (89). This is particularly alarming as body dissatisfaction is a risk factor for eating disorders and other psychological distress (99). African American girls in this study indicated a larger preferred body size than their Caucasian counterparts, which is consistent with previous findings (13). African American girls also reported an 
ideal body image significantly smaller than that reported by their peers in a validation study (86). This indicated that compared to non-treatment seeking individuals, African American girls in this intervention had a greater aspiration to be thin which can lead to further dissatisfaction among other psychological issues (136). In contrast, the Stanford GEMS pilot study found the opposite effect within the treatment group (141). This, however, was an obesity prevention intervention as opposed to obesity treatment. This intervention involved after-school dance classes and health lessons at home aimed to reduce time spent watching television in low SES African American girls (141). The girls in the intervention group exhibited a statistically significant decrease in concerns about their weight and trended towards lower body dissatisfaction scores compared to the control group (141). This indicates a reduced risk of developing eating disorders can be seen in as little as a 12 week intervention.

\section{Depressive Symptoms}

Depressive symptoms in children are categorized as perceived peer rejection, loneliness, lack of support, difficulty trusting individuals, helplessness, perceived negative daily experiences, blaming oneself, and having a negative view of oneself (42, 125). Bandura et al. examined self-efficacy pathways as they led to childhood depression in a sample of 282 children. Research suggests that an individual's self-efficacy is critical in adapting their own functioning and providing control over the events that affect their lives (15). If an individual does not believe in their ability to achieve success, or perceives low self-efficacy, he or she will have trouble when faced with difficulties.

Adolescence is a common time of difficulty as physically, socially and academically transitions are occurring. Children who have low self-efficacy prior to entering 
adolescence will be more vulnerable to new demands, making them more prone to depression (15). Bandura et al. reported that perceived low self-efficacy contributed more profoundly to depression in girls than boys (15).

In the adolescent population, depressive symptoms have been inversely related to PA (111). Possible mechanisms for the association between PA and depression include the distraction hypothesis, the mastery hypothesis, increased social interaction, and improvement in self-esteem $(69,70)$. The mastery hypothesis is directly related to SCT in that an individual feels a sense of accomplishment resulting in improved mood.

Participating in a PA program provides opportunities for increased social interaction relating to social support, which also improves mood $(69,70)$. Finally, being physically active may improve mood through increasing self-esteem (143). Using these hypotheses, it is evident that a PA intervention highlighting the use of SCT mediating variables can be used to improve mood in adolescence.

The exact relationship between obesity and depression is unclear. It has been said that obesity causes depression (81), but studies have shown the opposite pathway as well (73). Goodman et al. found that a depressed mood in normal and overweight adolescents at baseline predicted obesity at follow-up one year later (73). However, in this study baseline obesity was not a predictor for depression at follow-up indicating that depressed adolescents are at increased risk for becoming obese.

With respect to sedentary behavior, Schmitz et al. found a higher level of depressive symptoms was associated with more time spent in sedentary behavior in 3,798 seventh grade students (146). Research has shown a strong positive influence of PA and improvements in depressive symptoms in adults and adolescents (160). Dunn et al. 
examined whether exercise was an effective treatment for mild to moderate depression in 80 adults (mean age $=35.9 \pm 6.4$ years) $(57)$. Participants were either randomized into an exercise treatment group or control group. Results demonstrated that the recommended dose of exercise was an effective therapy for mild to moderate depression, and half of the recommended amount produced no effect (57). This is an important finding and is comparable to responses elicited by cognitive behavioral therapy and medications (57), (60). When comparing this to children and adolescents, there is much less evidence for this relationship; however, effects are being seen. A review by Larun et al. in children under 20 years old found a significant moderate effect in PA intervention in comparison to no intervention (97). Moreover, when comparing vigorous and light PA in adolescents to a control group where no PA intervention was implemented, no significant effect was found. This information suggests that PA, regardless of intensity, may be appropriate for reducing depressive symptoms in children and adolescents (97). However, due to the limited amount of studies in this area, there is not sufficient evidence to prove that vigorous PA is more effective than light PA when comparing to control groups in children and adolescents (97). The lack of data is even greater for children under 16 years old, especially in diverse populations.

\section{$\underline{\text { Summary }}$}

Pediatric obesity prevalence has increased tremendously over the past 30-40 years, resulting in earlier onset and indicators of adult disease such as T2DM $(45,53$, 107). African American girls are suffering disproportionally from obesity and related diseases compared to their Caucasian counterparts. This review of literature suggested that traditional school-based and after-school PA interventions are not producing 
sustained results. Therefore, it is essential to identify mediating factors for increasing PA among African American girls in order to develop effective interventions. The use of SCT framework and related mental health outcome variables may provide an understanding of mechanisms behind behavior change, which can in turn promote maintenance of these positive behaviors in later life. For African American girls, the role of the mother may mediate the effectiveness of the PA intervention. The resulting PA level may be used to predict change in mental health outcome variables. This study will contribute to the gaps in the literature by providing insight into the relationship between PA and several mental health outcome variables, a pathway that is relatively unexplored in pre-adolescent African American girls. 


\section{CHAPTER III}

\section{METHODS}

\section{Introduction}

This study was a secondary data analysis project that stemmed from a larger randomized controlled trial. The purpose of this study was to examine if change in PA following a 12-week culturally tailored mother-daughter PA intervention predicted change in mental health outcome variables (self-esteem, depressive symptoms, body image dissatisfaction) in pre-adolescent African American girls. The sample for this study was drawn from an after-school PA program, [Mothers and Girls Dancing Together Trial (MAGNET)]. Upon a successful screening procedure, a baseline visit was scheduled in the participant's home. Baseline visits included completion of informed consent documents, physical measures, and surveys. Physical activity was assessed with accelerometers for seven consecutive days including two weekend days. Following baseline, mother-daughter dyads were randomly assigned to one of three [motherdaughter $(\mathrm{CH}-\mathrm{M})$, daughter only $(\mathrm{CH})$, or the control $(\mathrm{CON})]$ groups. Participants in the $\mathrm{CH}-\mathrm{M}$ (mother and daughter) and $\mathrm{CH}$ (daughter only) groups attended dance classes. Participants in the $\mathrm{CON}$ (mother and daughter) group and mothers in the $\mathrm{CH}$ group participated in the information-based health education program. The dance intervention was implemented three days per week for 12 weeks. The outcome and predictor variables were assessed at baseline, midpoint (6 weeks), and post-intervention (12 weeks). Only data from the CH-M group was utilized for this analysis. Study design is presented Figure 2. 
Figure 2. Study design.

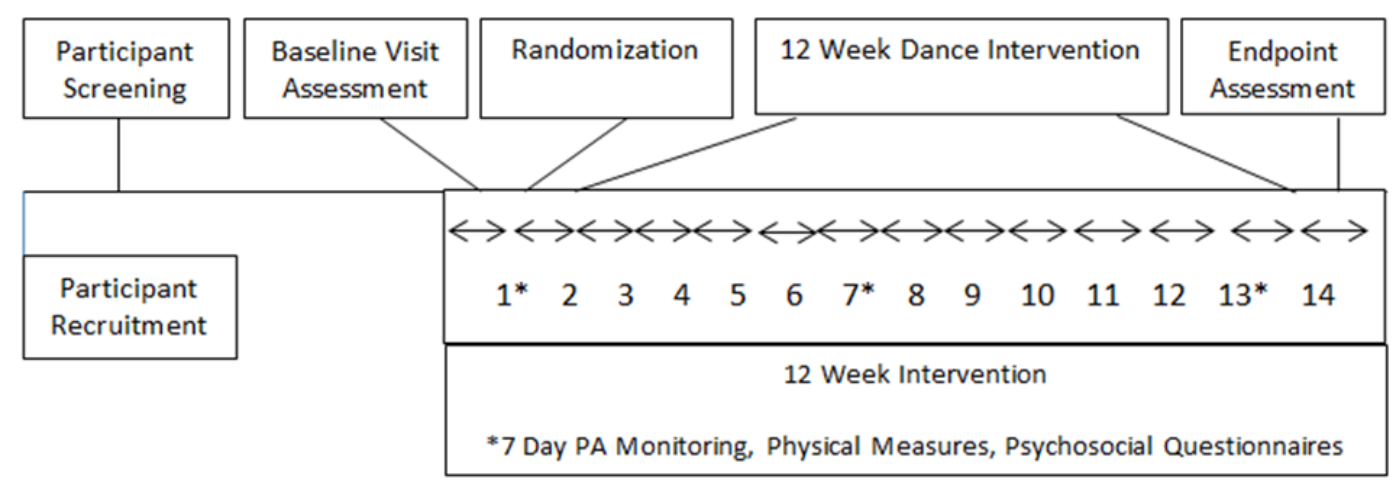

\section{Participants and Randomization}

\section{Participants}

This study consisted of low socioeconomic status (SES) African American mother-daughter dyads from the greater Springfield, MA, area. Girls were eligible for this study if they were between 7-10 years of age. A girl was defined as African American or Black if her parent/guardian self-identified her as either African American or Black. For this study, "mother" was broadly defined as the maternal figure that resided with the girl. There was no set age requirement for the maternal figures. Participants (mother and daughter) were excluded from the study if they 1) were not able to read and write in English, or 2) had any condition limiting their ability to participate in assessment (unable to wear accelerometer) or intervention (unable to participate in PA). Their inability to participate in PA could have resulted from developmental or physical disabilities, the inability to increase PA levels for any reason, uncorrected structural heart disease, or musculoskeletal injury or disorder. In addition, girls were excluded if they had any medical condition affecting growth (type 1 diabetes, T2DM, renal disease, eating 
disorders, pregnancy) or if they were taking any medications affecting growth (insulin, anti-diabetic oral hypoglycemic drug, thyroid hormone). All eligible mothers and daughters who were enrolled into the study were required to complete an informed consent and assent form, respectively, during the baseline visit. This study protocol was approved by the University of Massachusetts Amherst Institutional Review Board (Appendix C \& D).

\section{Recruitment and Screening}

Participants were recruited through recruitment strategies that have been previously employed by the Pediatric Physical Activity Laboratory. Flyers (Appendix A) were distributed to all elementary schools and churches within the greater Springfield, MA, area with the instructions to contact the lab if interested in participating in the program. Face to face recruitment was conducted at local YMCAs, Boys and Girls Clubs, and community events (i.e., Stone Soul Festival, Back to School Celebration, Bay State Health Fair). In addition, study information was also announced on local radio shows and in newspapers. All participants who provided their contact information were contacted and screened for eligibility. A copy of the screening document can be found in Appendix B. All participants that successfully completed the screening procedure and were eligible for the study were asked to schedule a baseline visit at the time and location convenient for them. After a successful screening procedure, ID numbers were assigned to the mother-daughter dyad. 


\section{Randomization}

Mother-daughter dyads were randomized into one of three (CH-M, $\mathrm{CH}$, or $\mathrm{CON})$ groups after the completion of all baseline measures. In children, researchers have reported that BMI can influence PA level (85). Due to the influence of BMI on PA level, it was important that girls' BMI be taken into account during the randomization process. BMI was calculated from height and weight obtained at the baseline visit. From that, BMI percentile was determined and dyads were separated into normal weight and overweight groups. Normal weight was categorized as the 5th-85th percentile and overweight was categorized by $\geq 85$ th percentile (118). Within the normal weight and overweight group, dyads were randomized using a random number generator into the three groups (CH-M, $\mathrm{CH}$, and $\mathrm{CON})$. Households with multiple daughters were randomized into the same group; however, only one daughter was chosen randomly to be included in the analysis. Participants were informed of their group assignment within 48 hours of the randomization procedure. Twenty-eight mother-daughter dyads were randomized into the $\mathrm{CH}-\mathrm{M}$ group, 10 of which were considered overweight.

\section{$\underline{\text { Experimental Intervention }}$}

\section{Intervention Theoretical Framework}

The PA intervention was based on SCT. According to SCT, human behavior is learned through observation and modeling including attention, retention, production, and motivation $(13,14)$. The development of these behaviors is attributed to personal (interest in dance, outcome expectation), behavioral (skills needed), and environmental (mother 
attendance) factors $(13,14)$. Outcome expectation is defined as a judgment of a likely consequence that the behavior will produce. With respect to this intervention, outcome expectations included having fun, praise, approval, and feeling good about themselves. The primary moderator in SCT is self-efficacy. An individual with higher self-efficacy will be more likely to view challenging tasks as attainable, develop a deeper interest in the activity, form a stronger commitment to the behavior, and recover quickly from potential setbacks (13). According to SCT, enhancing self-efficacy is attributed to four sources of influence (13). These factors include mastery experiences (teaching the dances in chunks to increase success), social modeling (witnessing mothers and peers experience success in learning the dance steps), social persuasion (verbal encouragement from instructors and mothers), and psychological response (reducing stress and improving mood by creating a positive learning environment). Similarities between the modeler (i.e., daughter) and model (i.e., mother) have a great effect on the success of the adaptation of the behavior. For example, when a daughter feels that she is similar to, and has a good relationship with her mother, she will be more likely to be influenced by her mother's attitudes/behaviors and more likely to adapt a new behavior.

A child's initial self-efficacy is modeled from experiences in the family (13). This starts as early as infancy when parents are responsive to behaviors and create an environment encouraging freedom of movement and exploration (11). This increased responsiveness by the parent aids in social and cognitive development of the child. As the child develops, they learn about their capabilities through what others tell them they can and cannot do. This newly formed self-knowledge forms the basis of a child's core beliefs with respect to their confidence and efficacy. 
Because parents play an important role in the development of a child's selfefficacy, it is important to incorporate them into interventions targeting heath behavior change. This intervention had the potential to enhance PA self-efficacy by providing participants with mastery experiences, social modeling, social persuasion, and a reduced stress response. The environment created by interventionists was conducive to learning the dance steps in small chunks, positive reinforcement (verbal, small incentives, opportunity to showcase dance routines to family members), and the encouragement to model the behaviors of their mothers. New health behaviors were learned by selectively observing the dance steps and their mother's behaviors, retaining those events as memory, producing those concepts into their own actions, which in turn can increase motivation to perform the action which is linked to positive outcome expectations.

\section{Experimental Intervention Overview}

The study intervention was implemented three days per week (Monday, Wednesday, and Thursday) over a 12-week time period. The experimental intervention was held from 4:00-6:30 pm at Rebecca M. Johnson Elementary School in Springfield, MA. A depiction of a typical intervention day is illustrated in Figure 3. A typical intervention day lasted for 2.5 hours. Each day consisted of 90 minutes of healthy snacks and homework tutoring and 60 minutes of MVPA dance class (for $\mathrm{CH}-\mathrm{M}$ and $\mathrm{CH}$ group).

All girls were given a healthy snack upon arrival and time to change into appropriate clothes if necessary. As part of the intervention, all girls were provided with homework tutoring by college undergraduate and graduate students. 
Figure 3. Daily intervention schedule.

\begin{tabular}{|c|c|c|c|}
\hline $\mathrm{CH}-\mathrm{M}$ & $\longleftrightarrow$ Snack & Tutored Homework Time & Dance Class \\
\hline \multirow[t]{2}{*}{$\mathrm{CH}$} & & & \\
\hline & Snack & Dance Class & Tutored Homework Time \\
\hline \multirow[t]{2}{*}{ CON } & & & \\
\hline & Snack & Tutored Homework Time & \\
\hline 4:00 & $4: 30$ & $5: 30$ & $6: 30$ \\
\hline
\end{tabular}

\section{Treatment (Dance) Intervention}

The treatment intervention groups consisted of the $\mathrm{CH}-\mathrm{M}$ (mothers and daughters) and the $\mathrm{CH}$ (daughters only) groups. Mothers and daughters assigned to the $\mathrm{CH}-\mathrm{M}$ group participated in the after-school dance intervention together. For the $\mathrm{CH}$ group, daughters participated in the dance intervention and their mothers participated in the control intervention. Although girls in the $\mathrm{CH}-\mathrm{M}$ and $\mathrm{CH}$ group participated in the same PA program, they did so at different times. Offering two separate dance classes for the $\mathrm{CH}$ and $\mathrm{CH}-\mathrm{M}$ groups would allow for a better understanding of the role of the mother at the intervention. During a typical intervention day, the $\mathrm{CH}$ group participated in the dance intervention first, followed by the homework tutoring time. The dance time of the $\mathrm{CH}-\mathrm{M}$ group $(5: 30 \mathrm{pm})$ was designed to allow maternal figures enough time after work to come participate in the program with their daughters.

\section{Dance Intervention Development}

In the African American community, dance has been used to show pride, involvement, and connection to culture (141). Dance is a feasible method for increasing 
PA as it is accessible for all ability levels and has been shown to provide a sustained amount of self-reported MVPA during a dance class (141). Only Robinson et al. used afro-centric dance (i.e. traditional African, Hip Hop, and step) as a PA intervention method in African American girls, and this led to a 12\% increase in self-reported PA during the dance intervention (141).

The dance styles that were used (African, Jazz, and Hip Hop) in the current study were chosen based on a focus group study from a representative sample of African American mother-daughter dyads in Springfield, MA (3). Experienced professional dancers were hired to develop two dances for each style and instructional DVDs were created. The intensity of the dance was targeted at the daughters' intensity levels. Each dance routine was approximately seven minutes in duration. The first minute was a brief warm-up, followed by the dance steps, and a one-minute cool down.

Each dance style routine was taught for four weeks. The first routine was taught for each style, followed by the second routine as shown in Table 1. A student dance instructor was hired to learn the dance routines and teach them during the intervention. Within each two-week period of a specific dance style, the dance instructor broke down the routine into chunks and taught those parts up until the second Monday. The second Wednesday of the two-week period was used as rehearsal time. Part of the final Thursday of the dance style was used as a dance showcase in which family and friends were invited to view the girls perform the routine they had learned. 
Table 1. Dance style intervention schedule.

\begin{tabular}{lcc}
\hline Dance Style & $\underline{\text { Routine 1 }}$ & Routine 2 \\
\hline Jazz & Week 1 \& 2 & Week 7 \& 8 \\
African & Week 3 \& 4 & Week 9 \& 10 \\
Hip Hop & Week 5 \& 6 & Week 11 \& 12
\end{tabular}

\section{Control Intervention}

Both mothers and daughters in the $\mathrm{CON}$ group and mothers in the $\mathrm{CH}$ group participated in the CON intervention. This intervention consisted of weekly newsletters (separate for mothers and daughters) that were mailed to the participants' home. The newsletters were developed from a focus group from a representative sample of African American mother-daughter dyads in Springfield, MA (3). Weekly topics that were covered in the newsletters are listed in Table 2. In addition, participants in the $\mathrm{CH}-\mathrm{M}$ (mothers and daughters) and girls in the $\mathrm{CH}$ group also received the weekly newsletter. 
Table 2. Mother and daughter weekly newsletter topics.

\begin{tabular}{ccc}
\hline Week & Daughter's Topic & Mother's Topic \\
\hline 1 & Physical Activity & Physical Activity \\
3 & Physical Activity & Physical Activity \\
4 & Physical Activity & Nutrition \\
5 & Nutrition & Nutrition \\
6 & Nutrition & Nutrition \\
7 & Nutrition & Obesity \\
8 & Nutrition & Cardiovascular Disease \\
9 & Sleep \& Water & High Blood Pressure \\
10 & Hygiene, Hair \& Skin Care & Diabetes \\
11 & Communication & Breast Cancer \\
\hline 12 & School Items \& Screen Time & Commication \\
\hline & & Bental Health \& Sleep \\
\hline
\end{tabular}

\section{$\underline{\text { Measurements }}$}

All assessments took place at participants' homes or at Rebecca Johnson Elementary School (site of the intervention). Trained data collectors completed all data collection. Cohort 1 data collection took place during the 2012-2013 academic year, while Cohort 2 data collection took place during the 2013-2014 academic year. Table 3 provides a list of all variables of interest and the time point when each was assessed. The informed consent and assent procedure was completed at the beginning of all baseline 
data collection. During each data collection time point, the order of data collection was as follows: physical measures, mental health outcome variables, and PA assessment.

Table 3. Assessment time points of variables of interest.

\begin{tabular}{lccc}
\hline Variables & Baseline & 6-week & 12-week \\
\hline PA (Accelerometer) & $\mathrm{X}$ & $\mathrm{X}$ & $\mathrm{X}$ \\
PA (Self-Report) & $\mathrm{X}$ & $\mathrm{X}$ & $\mathrm{X}$ \\
Height \& Weight (BMI) & $\mathrm{X}$ & $\mathrm{X}$ & $\mathrm{X}$ \\
Self-Esteem & $\mathrm{X}$ & & $\mathrm{X}$ \\
PA Self-Efficacy & $\mathrm{X}$ & $\mathrm{X}$ & $\mathrm{X}$ \\
Mother-Daughter Relationship & $\mathrm{X}$ & & $\mathrm{X}$ \\
Depressive Symptoms & $\mathrm{X}$ & & $\mathrm{X}$ \\
Body Image Dissatisfaction & $\mathrm{X}$ & & $\mathrm{X}$ \\
Demographics \& SES & $\mathrm{X}$ & & \\
\hline
\end{tabular}

Physical Measures

\section{$\underline{\text { Height and Weight }}$}

Height and weight were assessed for both mother and daughter. To assess height and weight, participants were asked to remove their shoes and excess clothing (i.e. jackets or house coats). Height was measured twice using a portable stadiometer (Shorr Height Measuring Board, Olney, MD) to the nearest $0.1 \mathrm{~cm}$. A third measurement was recorded if the two values differed by $>0.5 \mathrm{~cm}$. Weight was measured using a digital 
scale (Scaletronix 5125, White Plains, NY) on an uncarpeted floor. If the only option was carpeted flooring in the house, a $2 \times 2$ piece of plywood was placed underneath the scale to ensure accuracy. A third measurement was recorded if the two values differed by $>0.3$ $\mathrm{kg}$. For both height and weight, the mean of the recorded values was used for data analysis. BMI was calculated as weight $(\mathrm{kg}) /[\text { height }(\mathrm{m})]^{2}$. For daughters, calculated BMI was used to determine their CDC age and gender predicted BMI percentile (119).

\section{Physical Activity}

\section{Objective Assessment}

The GT3X+ Actigraph accelerometer (Actigraph, LLC, Pensacola, FL) was used to objectively measure participants' (mothers and daughters) PA levels. This triaxial accelerometer measured and recorded accelerations ranging in magnitude from 0.05-2.00 $\mathrm{G}$ and a band limited frequency response from $0.05-2 \mathrm{G}$ 's. Within these parameters, the Actigraph GT3X+ is capable of detecting normal human motion and eliminates high frequency vibrations with an electronic filter. The accelerometer was initialized prior to each use and results were downloaded to a computer using Actilife software (Version 6.9.1). Accelerometers were programmed to store data in 60-second epochs.

Initialization was completed at least two days prior to data collection. The accelerometer started collecting data on the first day of data collection (baseline, midpoint, or postintervention) at 7:00 a.m.

Accelerometers were worn on an elastic belt placed over the participant's right hip. Participants were asked to wear the accelerometers for seven days including two weekend days. They were instructed to wear the accelerometer at all times except when 
the unit could become completely wet (i.e. swimming or bathing). While wearing the accelerometer, participants were asked to maintain a PA logbook. Any time a participant removed the accelerometer belt, they were instructed to record the time they removed the unit and the time they put it back on. Participants received reminder calls throughout the week to ensure proper wear time, correct recordings in the PA logbook, and instructions regarding when to stop wearing the accelerometer. After wearing the accelerometer for seven consecutive days, participants were instructed to place the accelerometers and their PA log in a pre-paid addressed envelope (provided to them during data collection visit) to mail it back to the Pediatric PA Lab at UMass Amherst. Physical activity variables assessed included percent time spent in sedentary behavior, light PA, MVPA, total daily PA, and counts per minute (CPM). The analysis included CPM as this measure does not rely on cut points and provided information about participants' total movement. The Choi algorithm was used to confirm sufficient wear time which was defined as wear time for at least 480 minutes for three days $(41,104,138)$. Evenson et al. CPM cut points were used to process the daughter's accelerometer data into PA intensity categories [sedentary PA (SPA; 0-100 CPM), light PA (LPA; 101-2295 CPM), moderate PA (MPA; 2296-4011 CPM), and vigorous PA (VPA; $\geq 4012 \mathrm{CPM})]$ (65). Troiano et al. cut points for adults were to process the mother's accelerometer data into PA intensity categories (SPA; 0-99 CPM, LPA; 100-2019 CPM, MPA; 2020-5998 CPM, VPA; \5999 CPM) (168).

\section{$\underline{\text { Self-Report Assessment }}$}

Participants' PA was also assessed using a questionnaire. Daughters' PA was assessed with the Physical Activity Questionnaire for Younger Children (PAQ-C), which 
has been validated against accelerometry $(\mathrm{r}=0.39)(95)$. The PAQ-C was designed to assess general levels of PA (Appendix E). It asked the daughter to identify how many days in the past week she participated in a list of activities, average length of each session, and if it was organized. A study examining the reliability of the PAQ-C found that the internal consistency of the measure was relatively stable in females $(r=0.82)$ (43). Mothers' self-reported PA was assessed with the International Physical Activity Questionnaire (Short Form IPAQ, Appendix F). The IPAQ was developed as a selfreported measure of PA appropriate for assessing population levels of PA of adults 18-65 years of age (30). A modified short form version of the IPAQ that was used in this study can be found in Appendix F. A validation study conducted in 14 centers across 12 countries yielded a criterion validity of $r=0.30$ and Spearman's correlation coefficient $r$ $=0.8(79)$. The results indicated that the self-report tool had support for test-retest reliability and also was sensitive to change in PA levels and gender differences.

\section{Mental Health Outcome Variables}

Demographic variables were assessed from the mother. Mother-daughter relationship was assessed from both the mothers' and daughters' perspective. Motherdaughter relationship from the mother's perspective was assessed using the Adolescent Openness to Parental Socialization form and the Parental Responsiveness form (adapted from the Inventory of Parent-Adolescent Attachment). The Adolescent Openness to Parental Socialization form (Appendix G) was adapted from the Inventory of ParentAdolescent Attachment and contained seven items that described the child's behaviors and willingness to discuss issues with her mother (7). Participants were asked to rate how 
often these situations (i.e., mother and child discuss the reasons for rules in the family, child tells her mother that she loves her, child tells her mother about her plans with friends) occurred in a family from never to always. For mothers, the reliability coefficient was $r=0.84(29)$.

The Parental Responsiveness form (Appendix H) consists of six statements that measured parental affection and behavioral responses (28). Mothers were asked to rate how often these events occurred within their family. The child form (Appendix I) contained the same statements, but they were rephrased from the child perspective. Researchers reported a Cronbach's alpha of 0.82 and 0.83 for mothers and daughters, respectively (24). Enhanced mother-daughter relationship may increase social support, resulting in increased PA.

Self-efficacy is one of the main contributing factors in SCT and has been shown to impact one's ability to participate in PA (55). Mothers' and daughters' PA selfefficacy was assessed with the PA Self-Efficacy Scale (144) and the Children's SelfPerceptions of Adequacy in and Predilection for Physical Activity (CSAPPA) scale (80), respectively. The PA Self-Efficacy scale (Appendix J) contains 12 statements that assessed the participant's confidence in their ability to be physically active under several conditions. Test-retest reliability for this questionnaire in adults was $r=0.68$ and internal consistency was approximately $r=0.84$ (144). The CSAPPA (Appendix K) contained 20 items and assessed a child's perception of their ability and desire to participate in PA. It presented the participant with two scenarios and asked the child to identify which statement was most like them and the degree to which that statement was true. Test-retest reliability ranges from $r=0.84-0.90$ and had strong construct validity (38). 
Daughter's self-esteem was assessed with the Rosenberg Self-Esteem (RSE; Appendix L) scale. This questionnaire contained 10 statements and participants were asked to rate their level of agreement or disagreement with each statement. Internal consistency of this scale in adolescents reported at $r=0.77$ and test-retest reliability ranges from $r=0.85-0.88$ (147). Mother and daughter depressive symptoms were assessed with the Beck Depression Inventory (BDI; Appendix M) and the Child Depression Inventory (CDI; Appendix N), respectively $(21,94)$. The BDI contained 21 questions and covered topics such as appetite and sleep loss, thoughts about suicide, and interest in other people and activities. This questionnaire had a high one-week test-retest reliability using $r=0.93$ and a high internal consistency that was $\alpha=0.91$ (21). The short form CDI contained 10 items and was used to assess a child's depressive symptoms. The two week test-retest reliability of the CDI was 0.82 (67) and the internal consistency ranges from $r=0.71-0.94$ (24). Girls' body image dissatisfaction was assessed with a modified version of the Body Dissatisfaction Scale which contained silhouettes originally developed by Stunkard et al. (161) that consisted of eight pictures of African American girls ranging from underweight to obese (91). Girls were asked to choose which picture best represented them currently, and which picture they wished to look like (Appendix O). While the girls' depiction of her current body image may differ from actual body size, any smaller body size chosen was considered to be dissatisfaction.

\section{$\underline{\text { Statistical Analysis }}$}

Spearman correlations were utilized to examine associations between the variables of interest at baseline and post-intervention. In addition, due to the impact of 
BMI on PA and BID, the interaction between BMI on PA and body image dissatisfaction were examined to determine if BMI should be included in the analysis as a moderator. A two-way alpha of $<0.05$ was used to determine significance. All statistical analyses were performed using SAS version 9.3 and HLM software. The univariate procedure in SAS was used to test for normality of the data. All PA variables and the CSAPPA scores were not normally distributed. Due to this, a log transformation of the data was used for the analysis. The purpose of this study was to examine if change in PA following a 12-week culturally tailored mother-daughter PA intervention predicted mental health outcome variables in pre-adolescent African American girls. Based on this purpose statement, the following hypotheses will be tested.

$\mathrm{H}_{1}$ : Participation in a culturally-tailored mother-daughter PA dance intervention will increase the daughters' objectively measured percent time spent in light PA, MVPA, and total daily PA and decrease percent time spent in sedentary behavior. Analysis plan for $\mathrm{H}_{1}$ : A MANOVA was used to assess difference in daughters' percent time spent in light PA, MVPA, total PA and sedentary time at all three time points (baseline, 6-week, and 12-week). A MANOVA was used to account for the correlation between the PA variables of interest.

$\mathrm{H}_{2}$ : Participation in a culturally-tailored mother-daughter PA dance intervention will improve the mother-daughter relationship. 
$\underline{\text { Analysis plan for } \mathrm{H}_{2}}$ : A repeated measures ANOVA was used to assess a difference in mother-daughter relationship at each time point (baseline, 6-weeks, and 12-weeks).

$\mathrm{H}_{3}$ : Increases in PA levels will be mediated by increases in PA self-efficacy and mother-daughter relationship.

Analysis plan for $\mathrm{H}_{3}$ : A simple regression analysis was used to assess if change in PA self-efficacy or mother-daughter relationship mediated any change in PA.

$\mathrm{H}_{4}$ : Change in PA variables will predict change in daughter's mental health outcome variables of interest (self-esteem, body dissatisfaction, depressive symptoms). Analysis plan for $\mathrm{H}_{4}$ : The primary analysis used to test the research question was Hierarchical Linear Modeling (HLM). HLM was chosen as an analysis tool in answering the research question as to if changes in PA variables can predict a change in mental health outcome variables for several reasons. First, HLM was used in examining rate of change in longitudinal data. Second, it is used for datasets involving longitudinal nested data, which in this case a participant's repeated measures are nested within the individual. For instance with respect to mental health outcome variables, each daughter had mental health outcome variables at multiple time points. Therefore, her 12-week (post-intervention) outcome measurements will be influenced by her baseline measures. Third, HLM can work with small sample sizes across multiple time points using a multi-model change value to predict outcome variables of interest. At the time of analysis, it 
can also account for participants with different numbers of data at each time point. For example, if a daughter was missing PA data at 6-week time point (midpoint), it would be removed from the model, but her other measures at baseline and 12weeks (post-intervention) would be used in the model. Fourth, the HLM model can also reduce variation by controlling for participants' characteristics such as daughters' BMI percentile. Fifth, HLM is preferred over simple regression models as HLM can account for random effects including effects of grouping and clustering observations (72). Sixth, HLM has the ability to compute change scores for PA variables (Level 1 model). These change scores were then input as predictor variables in the next model (Level 2 model).

In the present study, the first set of models examined change in PA variables (\% sedentary, \% light, \% MVPA, self-reported activity score) over time (baseline, 6-week, and 12-week). For each of these models, the empirical Bayesian estimate of each daughter's change in PA over time was obtained from the model's residual files. These values were then included as predictors in the Level 2 file for the next series of models. The next series of models evaluated the effect of change PA over time predictors on change in mental health outcome variables. To account for reverse causality (i.e., change in mental health outcome variables predicting change in PA), HLM models were run in the opposite direction. In this series of analysis, change scores were calculated for each mental health outcome variable (Level 1 model). The change scores were then used in a subsequent model (Level 2 model) to predict changes in PA levels. Average BMI 
percentile was also included as a Level 2 predictor to control for daughters' BMI.

Equations used to generate these models can be found in Figure 4.

Figure 4. Equations used for hierarchical linear models.

$$
\begin{gathered}
\frac{\text { Conditional Model }}{\text { Level-1 Model }} \\
Y_{i j}=\beta_{0 j}+\beta_{1 j} *\left(T I M E \_2_{i j}\right)+r_{i j} \\
\text { Level-2 Model } \\
\beta_{0 j}=\gamma_{00}+\gamma_{01} *\left(d \_P A\right)_{j}+\gamma_{02} *\left(A V G \_B M I P\right)_{j}+u_{0 j} \\
\beta_{1 j}=\gamma_{10}+\gamma_{11} *\left(d \_P A\right)_{j}+\gamma_{12} *\left(A V G_{-} B M I P\right)_{j}+u_{1 j}
\end{gathered}
$$

Where the following are fixed effects:

$\boldsymbol{Y}_{i j}$ is the outcome variable

$\boldsymbol{\beta}_{0}$ is the Level-1 intercept, which is being predicted with an intercept, change in a physical activity variable $\left(d \_P A\right)$, and an average BMI (AVG_BMIP) percentile variable

$\gamma_{00}$ is the intercept for the Level-1 intercept equation, or the average value of $\boldsymbol{Y}_{i j}$ at time $=0$ (Time 2 , Week 6$)$ for each girl

$\gamma_{01}$ is the effect of $d_{-} P A$ on the Level- 1 intercept at time $=0$

$\gamma_{02}$ is the effect of AVG_BMIP on the Level-1 intercept at time $=0$

$\boldsymbol{\beta}_{\boldsymbol{1}}$ is the Level-1 linear component of the trajectory, also being predicted by its intercept, $d_{-} P A$, and $\mathrm{AVG} \_\mathrm{BMIP}$

$\gamma_{10}$ is the intercept for the linear component. This is the instantaneous rate of change for every increase in unit of $\boldsymbol{Y}_{i j}$ for each girl

$\gamma_{11}$ is the effect of $d_{-} P A$ on the linear component

$\gamma_{12}$ is the effect of AVG_BMIP on the linear component 


\section{CHAPTER IV}

\section{RESULTS}

\section{$\underline{\text { Baseline characteristics }}$}

The purpose of this study was to examine if changes in PA levels following a 12week culturally-tailored mother-daughter PA intervention predicted change in mental health outcome variables in pre-adolescent African American girls. OF the 28 motherdaughter dyads randomized into the $\mathrm{CH}-\mathrm{M}$ group, 10 were considered overweight. There were 27 dyads at baseline, 18 at midpoint, and 18 at post-intervention assessment. During the course of the intervention, nine dyads dropped out of the program (1 due to time commitment, 1 due to transportation issues, the rest unknown). Daughters' accelerometer data were excluded (baseline, $n=2$; midpoint, $n=2$; post-intervention, $n=3$ ) if they did not meet the wear time criterion of at least 480 minutes for three days using the Choi algorithm $(41,104,138)$. With respect to the mothers' accelerometer data, one was excluded at baseline, while two were excluded at midpoint and post-intervention assessments for not meeting the wear time criteria. Participants who did not meet wear time criteria were coded as missing data for PA variables. Mothers and daughters wore the accelerometer for an average of 6.0 and 5.4 days, respectively.

Participant baseline characteristics are reported in Table 4. Daughters' mean BMI percentile placed them within the normal weight range (between $5-85^{\text {th }} \%$ ) for their age and gender. Mothers' mean BMI placed them in the obese category $\left(\mathrm{BMI}>30 \mathrm{~kg} / \mathrm{m}^{2)}\right.$ for their weight status. Accelerometer data revealed that both mothers and daughters spent 
the majority of their day in sedentary activity. Daughters' self-reported PA activity score indicated that the girls spent most of their time in sedentary pursuits (based on a scale of 1 to 5 , with 5 being the more active score). Mothers' PA self-efficacy score indicated that they had above average scores (based on a scale of 1 to 5 with higher scores indicating greater PA self-efficacy). Daughters' CSAPPA scores range from 19-76, with higher scores indicating greater PA self-efficacy. The mean values of these surveys indicated that daughters were somewhat confident in their abilities to be physically active. Daughters' mean self-esteem scores fell within the normal range (based on a scale where values less than 15 determine low self-esteem). A lower body image dissatisfaction score (or more negative) indicated a desire to be thinner, zero indicated neutral feelings, and a positive number indicated a desire to be heavier. Daughters' mean body image dissatisfaction scores indicated that they expressed a desire to have a smaller body size. Both mothers' and daughters' scores for depression placed them within the normal range for non-depressive symptoms. Parental Responsiveness scores can range from 4-24, with higher scores indicating more connectedness for mothers. Daughters' Parental Responsiveness scores range between 10 and 40, with higher scores indicating greater connectedness. Higher scores on the Adolescent Openness to Parental Socialization indicated more openness. Mothers' reported a high perception of mother-daughter relationship with respect to both questionnaires and daughters reported a somewhat high perception of mother-daughter relationship. 
Table 4. Participant's baseline characteristics

\begin{tabular}{|c|c|c|c|c|}
\hline \multirow{2}{*}{ Variable } & \multicolumn{3}{|c|}{ Daughter } & \multirow{2}{*}{$\begin{array}{c}\text { Mother } \\
\text { Mean } \pm S D\end{array}$} \\
\hline & $N$ & Mean $\pm S D$ & $N$ & \\
\hline \multicolumn{5}{|l|}{ Physiological } \\
\hline Age (years) & 25 & $9.0 \pm 1.4$ & 21 & $36.0 \pm 17.0$ \\
\hline $\operatorname{BMI}\left(\mathrm{kg} / \mathrm{m}^{2}\right)$ & 27 & $20.3 \pm 5.7$ & 26 & $34.0 \pm 7.4$ \\
\hline BMI percentile & 25 & $73.3 \pm 28.9$ & & $\mathrm{n} / \mathrm{a}$ \\
\hline \multicolumn{5}{|c|}{ Physical Activity (Accelerometer) } \\
\hline Sedentary activity (\% time) & 22 & $60.8 \pm 9.1$ & 21 & $71.3 \pm 7.3$ \\
\hline Light PA (\% time) & 22 & $36.3 \pm 7.6$ & 21 & $27.1 \pm 6.9$ \\
\hline MVPA (\% time) & 22 & $2.8 \pm 2.0$ & 21 & $1.6 \pm 0.9$ \\
\hline Total PA (\% time) & 22 & $39.2 \pm 9.1$ & & $\mathrm{n} / \mathrm{a}$ \\
\hline Counts per minute (CPM) & 22 & $340.9 \pm 136.7$ & & $\mathrm{n} / \mathrm{a}$ \\
\hline Wear time (days) & 22 & $5.4 \pm 2.0$ & 21 & $6.00 \pm 2.0$ \\
\hline \multicolumn{5}{|l|}{ Physical Activity (Self-report) } \\
\hline Sedentary activity (min/day) & & $\mathrm{n} / \mathrm{a}$ & 27 & $291.1 \pm 96.6$ \\
\hline Light PA (min/day) & & $\mathrm{n} / \mathrm{a}$ & 25 & $32.8 \pm 15.7$ \\
\hline MVPA (min/day) & & $\mathrm{n} / \mathrm{a}$ & 24 & $55.8 \pm 35.9$ \\
\hline Activity score & 22 & $2.7 \pm 0.5$ & & $\mathrm{n} / \mathrm{a}$ \\
\hline \multicolumn{5}{|l|}{ Mental Health Outcomes } \\
\hline PA self-efficacy & 23 & $57.0 \pm 14.5$ & 27 & $3.8 \pm 0.6$ \\
\hline Self-esteem & 24 & $23.1 \pm 5.5$ & & $\mathrm{n} / \mathrm{a}$ \\
\hline Body image dissatisfaction & 24 & $-1.1 \pm 2.1$ & & $\mathrm{n} / \mathrm{a}$ \\
\hline Depressive symptoms & 25 & $50.0 \pm 10.0$ & 24 & $9.7 \pm 7.5$ \\
\hline Parental responsiveness & 22 & $30.3 \pm 4.5$ & 27 & $21.5 \pm 2.8$ \\
\hline Parental socialization & & $\mathrm{n} / \mathrm{a}$ & 27 & $23.1 \pm 5.4$ \\
\hline
\end{tabular}

$\mathrm{BMI}=$ body mass index, $\mathrm{PA}=$ physical activity, $\mathrm{MVPA}=$ moderate to vigorous physical activity, $\mathrm{SR}=$ self-report data. 


\section{$\underline{\text { Baseline correlations }}$}

Spearman correlations revealed several significant relationships between daughters' outcome variables of interest. BMI was positively associated with self-esteem $(\mathrm{r}=0.41, p=0.049)$. BMI was negatively associated with body image dissatisfaction $(\mathrm{r}=$ $-0.62, p=0.001)$. BMI percentile was also negatively associated with body image dissatisfaction $(\mathrm{r}=-0.58, p=0.005)$. Daughters' self-reported PA score, but not objectively measured PA, was positively associated to their PA self-efficacy $(r=0.44, p$ $=0.04)$. Among the mental health outcome variables, daughters' self-esteem was positively associated to her perception of her mother-daughter relationship $(\mathrm{r}=0.44, p=$ 0.041). Baseline correlations for mothers' variables were also examined. The only significant positive correlation was found between their self-reported MVPA and their PA self-efficacy $(\mathrm{r}=0.46, p=0.02)$.

Correlations between mother and daughter variables were examined (Table 5). Mothers' self-reported light PA min/day was positively related to daughters' BMI, BMI z-score, and self-esteem. Daughters' self-esteem was also positively related to mothers' BMI. Daughters' PA self-efficacy was negatively related to mothers' depressive symptoms and PA self-efficacy. Daughters' perception of mother-daughter relationship was positively correlated to mothers' view of their relationship. The strength of the correlation ( $\mathrm{r}$ value) is denoted in Table 5. 
Table 5. Baseline correlation (r values) between mother-daughter variables

\begin{tabular}{|c|c|c|c|c|c|c|c|}
\hline & \multicolumn{7}{|c|}{ Mothers' Variable } \\
\hline \multirow{6}{*}{ 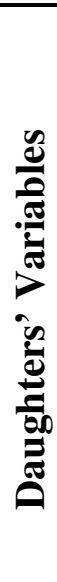 } & Measure & $\begin{array}{l}\text { SR SED } \\
\mathrm{min} / \mathrm{day}\end{array}$ & $\begin{array}{l}\text { SR LPA } \\
\text { min/day }\end{array}$ & $\begin{array}{l}\text { Depressive } \\
\text { symptoms }\end{array}$ & $\begin{array}{l}\text { PA Self- } \\
\text { Efficacy }\end{array}$ & $\mathrm{PR}$ & BMI \\
\hline & $\begin{array}{l}\text { BMI z- } \\
\text { score }\end{array}$ & 0.10 & $0.45^{*}$ & -0.22 & 0.23 & -0.16 & 0.18 \\
\hline & BMI & 0.10 & $0.45^{*}$ & -0.22 & 0.23 & -0.16 & 0.17 \\
\hline & $\begin{array}{l}\text { Self- } \\
\text { esteem }\end{array}$ & 0.25 & $0.52 * *$ & -0.03 & 0.15 & 0.14 & $0.66 * *$ \\
\hline & $\begin{array}{l}\text { PA Self- } \\
\text { efficacy }\end{array}$ & 0.10 & 0.05 & $-0.50 *$ & $-0.45^{*}$ & 0.24 & -0.10 \\
\hline & PR & 0.12 & 0.01 & -0.19 & 0.12 & $0.45^{*}$ & 0.38 \\
\hline
\end{tabular}

Values represent the strength of correlation ( $\mathrm{r}$ value). $\mathrm{BMI}=$ body mass index, $\mathrm{PA}=$ physical activity, MVPA = moderate to vigorous physical activity, $\mathrm{SR}=$ self-report data, $\mathrm{SED}=$ sedentary behavior, LPA = light physical activity, $\mathrm{PR}=$ Parental Responsiveness. $* \mathrm{p}<0.05$

$* * \mathrm{p} \leq 0.01$

\section{$\underline{\text { Post-intervention correlations }}$}

Several relationships changed or emerged following the 12-week culturallytailored mother-daughter PA intervention. Daughters' BMI percentile was still negatively associated with her body image dissatisfaction $(r=-0.64, p=0.01)$. Daughters' percent time spent in light PA was negatively associated with depressive symptoms $(\mathrm{r}=-0.62, p$ $=0.03)$. Daughters' self-esteem was negatively associated with depressive symptoms $(\mathrm{r}=$ $-0.61, p=0.02$ ). Daughters' PA self-efficacy was negatively associated with depressive symptoms $(\mathrm{r}=-0.54, p=0.04)$ and positively associated with body image dissatisfaction $(\mathrm{r}=0.57, p=0.03)$. This indicated that higher levels of PA self-efficacy were associated 
with less desire to be thin. No significant associations existed among mothers' postintervention variables.

Correlations between mother and daughter post-intervention variables were examined. The strength of the correlation ( $\mathrm{r}$ value) is denoted in Table 6. Baseline association observed in the mothers' variables between self-reported MVPA and PA selfefficacy was lost at 12-week assessment. Mother and daughter perception of motherdaughter relationship was no longer associated at post-intervention. The association between daughters' BMI percentile and body image dissatisfaction was maintained throughout the intervention, with the relationship getting stronger at post-intervention. Several associations among daughters' variables emerged at post-intervention including the relationship between percent time spent in light PA, self-esteem, and PA self-efficacy with depressive symptoms and body image dissatisfaction.

Table 6. Post-intervention correlation ( $\mathrm{r}$ values) between mother-daughter variables

\begin{tabular}{|c|c|c|c|c|c|}
\hline & & \multicolumn{4}{|c|}{ Mothers' Variable } \\
\hline \multirow{5}{*}{ 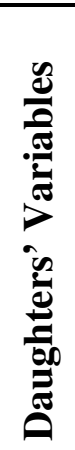 } & Measure & $\begin{array}{l}\text { Light PA (\% } \\
\text { time) }\end{array}$ & BMI & $\begin{array}{l}\text { PA Self- } \\
\text { efficacy }\end{array}$ & PR \\
\hline & LPA (\% time) & 0.31 & $-0.66^{*}$ & $-0.68 *$ & -0.10 \\
\hline & $\begin{array}{l}\text { MVPA (\% } \\
\text { time) }\end{array}$ & -0.01 & -0.14 & -0.17 & $-0.84 * *$ \\
\hline & $\begin{array}{l}\text { Depressive } \\
\text { symptoms }\end{array}$ & 0.14 & -0.00 & $0.55^{*}$ & $\begin{array}{l}-0.08 \\
\end{array}$ \\
\hline & Self-esteem & $-0.65^{*}$ & 0.47 & -0.47 & -0.02 \\
\hline
\end{tabular}

$\mathrm{BMI}=$ body mass index, $\mathrm{PA}=$ physical activity, $\mathrm{MVPA}=$ moderate to vigorous physical activity, $\mathrm{SR}=$ self-report data, SED = sedentary behavior, LPA = light physical activity, $\mathrm{PR}=$ Parental Responsiveness.

$* \mathrm{p}<0.05$

$* * \mathrm{p} \leq 0.01$ 


\section{Changes in physical activity (Hypothesis 1)}

A 1x3 MANOVA was used to assess the change in PA variables across three time points (baseline, 6-week, and 12-week). Because the data was skewed, a log transformation of the data was completed prior to analysis. Changes in PA are reported in Table 4. There were no significant changes in daughters' objectively measured PA. Because BMI has been shown to impact PA levels, a MANCOVA was used to assess all PA variables with BMI as the covariate. Results indicated that there was no effect of BMI on the change in PA levels (objective or self-reported). Secondary analysis was performed in participants who attended at least $40 \%$ of the dance intervention (Table 7). There were no significant changes in PA variables among the girls who attended at least $40 \%$ of the dance intervention. 
Table 7. Change in PA variables across three time points.

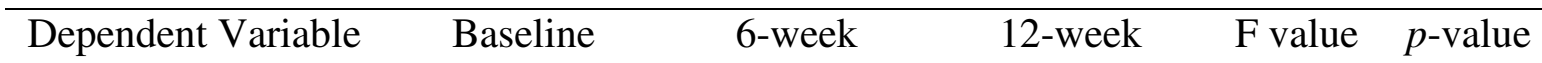

\section{All Participants}

\begin{tabular}{llllll}
\hline SED (\% time) & $60.8 \pm 9.1$ & $63.2 \pm 12.4$ & $63.7 \pm 8.2$ & 0.34 & 0.72 \\
Light PA (\% time) & $36.3 \pm 7.6$ & $34.3 \pm 11.4$ & $33.6 \pm 7.1$ & 0.69 & 0.51 \\
MVPA (\% time) & $2.8 \pm 2.0$ & $2.6 \pm 1.4$ & $2.8 \pm 1.3$ & 0.12 & 0.88 \\
Total PA (\% time) & $39.2 \pm 9.1$ & $36.9 \pm 12.4$ & $36.4 \pm 8.2$ & 0.63 & 0.54 \\
CPM & $340.9 \pm 136.7$ & $305.3 \pm 105.5$ & $318.2 \pm 98.5$ & 0.61 & 0.55 \\
SR Activity Score & $2.7 \pm 0.5$ & $2.5 \pm 0.7$ & $2.2 \pm 0.6$ & 3.19 & 0.04 \\
\hline & Participants with $>40 \%$ Intervention Attendance & & 0.58 \\
\hline SED (\% time) & $61.1 \pm 6.6$ & $59.5 \pm 10.6$ & $63.6 \pm 9.1$ & 0.55 & 0.45 \\
Light PA (\% time) & $36.4 \pm 6.1$ & $37.7 \pm 9.4$ & $33.5 \pm 7.8$ & 0.82 & 0.71 \\
MVPA (\% time) & $2.5 \pm 1.0$ & $2.8 \pm 1.3$ & $2.9 \pm 1.4$ & 0.34 & 0.71 \\
Total PA (\% time) & $38.9 \pm 9.1$ & $40.5 \pm 10.6$ & $36.4 \pm 9.0$ & 0.59 & 0.56 \\
CPM & $325.1 \pm 85.4$ & $337.4 \pm 84.6$ & $318.7 \pm 103.8$ & 0.20 & 0.82 \\
SR Activity Score & $2.7 \pm 0.6$ & $2.5 \pm 0.8$ & $2.2 \pm 0.6$ & 1.43 & 0.25 \\
\hline
\end{tabular}

$\mathrm{SED}=$ sedentary activity, $\mathrm{PA}=$ physical activity, MVPA = moderate to vigorous physical activity, $\mathrm{CPM}=$ counts per minute, $\mathrm{SR}=$ self-reported data, $(\%$ time $)=$ percent time spent engaging in that level of intensity.

\section{Change in mother-daughter relationship (Hypothesis 2)}

A 1x3 ANOVA was used to assess change in mother-daughter relationship across the three time points (baseline, 6-week, and 12-week). There were no significant changes in daughters' perception of their mother-daughter relationship $(p=0.21)$. Secondary 
analysis was performed in those who attended at least $40 \%$ of the dance intervention. Similarly, there was no change in the daughters' perception of their mother-daughter relationship ( $p=0.11)$. Daughters were split into tertiles based on their perception of their mother-daughter relationship based on the Parental Responsiveness questionnaire. There were no significant changes in PA in either the high mother-daughter relationship tertile or the low mother-daughter relationship tertile.

\section{Effects of mediators on increases in physical activity (Hypothesis 3)}

Simple regression analysis was used to examine if an increase in PA self-efficacy and mother-daughter relationship mediated any increase in PA. Results indicated that neither objectively assessed percent time spent in PA (sedentary behavior, light PA, MVPA, total PA) nor self-reported activity were mediated by PA self-efficacy in preadolescent African American girls. Additionally, mother-daughter relationship did not mediate any change in objectively measured (sedentary behavior, light PA, MVPA, total PA) or self-reported PA.

\section{Change in mental health outcome (Hypothesis 4)}

Paired $t$-tests were used to examine change in mental health outcome variables across the two time points (baseline and 12-week). PA self-efficacy was not normally distributed, so a log transformation of the data was used in the analysis. As shown in Table 5, there was no significant change in any of the mental health outcome variables over time. A second analysis was performed in only the daughters who attended at least 
$40 \%$ of the dance intervention (Table 8 ). Similar to the whole sample, no significant changes were observed in any mental health outcome variables.

Table 8. Change in mental health outcome variables over two time points.

\begin{tabular}{lcccc}
\hline $\begin{array}{l}\text { Mental Health Outcome } \\
\text { Variables }\end{array}$ & Baseline & 12-week & t value & $p$-value \\
\hline \multicolumn{2}{c}{ All Participants } & & \\
\hline Depressive symptoms & $51.1 \pm 9.3$ & $47.9 \pm 11.5$ & 0.74 & 0.47 \\
BID & $-0.7 \pm 2.1$ & $-1.0 \pm 1.5$ & 0.34 & 0.74 \\
PA Self-Efficacy & $56.9 \pm 14.5$ & $55.3 \pm 19.2$ & 0.30 & 0.77 \\
Self-esteem & $22.8 \pm 4.5$ & $25.8 \pm 4.8$ & -1.45 & 0.16 \\
\hline & Participants with $>40 \%$ Intervention Attendance & \\
\hline Depressive symptoms & $48.9 \pm 5.3$ & $51.1 \pm 13.4$ & -0.49 & 0.63 \\
BID & $-1.8 \pm 2.0$ & $-1.5 \pm 1.8$ & -0.48 & 0.66 \\
PA Self-Efficacy & $55.8 \pm 18.6$ & $60.0 \pm 12.6$ & -0.85 & 0.40 \\
Self-esteem & $25.5 \pm 4.2$ & $26.6 \pm 3.4$ & -0.68 & 0.51 \\
\hline
\end{tabular}

$\mathrm{BID}=$ body image dissatisfaction, $\mathrm{PA}=$ physical activity.

Hierarchical linear modeling was used to examine if change in PA variables could predict a change in daughters' mental health outcome variables. The first model (Level 1 model) examined change in PA variables (\% sedentary, \% light, \% MVPA, self-reported activity score) over time (baseline, 6-week, and 12-week). Computed PA change scores from this model were used as predictor variables in the second model (Level 2 model) to 
examine if change in PA predicted change in mental health outcome variables. Results are presented in Tables 9, 10, and 11 . 
Table 9. HLM results for the PA predictor variables on the outcome variable self-esteem.

\begin{tabular}{|c|c|c|c|c|c|c|c|c|c|}
\hline \multicolumn{10}{|c|}{ Fixed Effects - Self-Esteem (RSE) } \\
\hline & Coef & SE & $\begin{array}{l}\text { T (20 } \\
d f)\end{array}$ & $\begin{array}{l}p \text { - } \\
\text { value }\end{array}$ & & Coef & SE & $\begin{array}{l}\text { T (20 } \\
d f)\end{array}$ & $\begin{array}{l}p- \\
\text { value }\end{array}$ \\
\hline$\%$ SED & & & & & \% Light & & & & \\
\hline Intercept, $\beta_{0}$ & & & & & Intercept, $\beta_{0}$ & & & & \\
\hline Intercept $2, \gamma_{00}$ & 24.25 & 0.87 & 27.82 & $<0.01$ & Intercept $2, \gamma_{00}$ & 24.25 & 0.87 & 27.88 & $<0.01$ \\
\hline BMI $\%, \gamma_{01}$ & 0.04 & 0.03 & 1.14 & 0.27 & $\mathrm{BMI} \%, \gamma_{01}$ & 0.04 & 0.03 & 1.14 & 0.26 \\
\hline$\Delta \mathrm{SED}, \gamma_{02}$ & 6.52 & 11.18 & 0.58 & 0.57 & $\Delta$ Light, $\gamma_{02}$ & -19.74 & 29.55 & -0.67 & 0.51 \\
\hline Slope, $\beta_{l}$ & & & & & Slope, $\beta_{1}$ & & & & \\
\hline Intercept $2, \gamma_{10}$ & 0.19 & 0.10 & 1.90 & 0.07 & Intercept $2, \gamma_{10}$ & 0.19 & 0.10 & 1.90 & 0.07 \\
\hline $\mathrm{BMI} \%, \gamma_{11}$ & -0.01 & 0.00 & -2.61 & 0.02 & BMI $\%, \gamma_{11}$ & -0.01 & 0.00 & -2.61 & 0.02 \\
\hline$\Delta \mathrm{SED}, \gamma_{12}$ & -0.57 & 1.51 & -0.38 & 0.71 & $\Delta$ Light, $\gamma_{12}$ & 1.51 & 3.98 & 0.38 & 0.71 \\
\hline \% MVPA & & & & & ACT & & & & \\
\hline Intercept, $\beta_{0}$ & & & & & Intercept, $\beta_{0}$ & & & & \\
\hline Intercept $2, \gamma_{00}$ & 24.20 & 0.86 & 28.07 & $<0.01$ & Intercept $2, \gamma_{00}$ & 24.09 & 0.88 & 27.48 & $<0.01$ \\
\hline BMI $\%, \gamma_{01}$ & 0.04 & 0.03 & 1.07 & 0.30 & BMI $\%, \gamma_{01}$ & 0.04 & 0.03 & 1.22 & 0.24 \\
\hline$\Delta \mathrm{MVPA}, \gamma_{02}$ & -1.88 & 26.58 & -0.07 & 0.94 & $\Delta \mathrm{ACT}, \gamma_{02}$ & 26.32 & 100.24 & 0.26 & 0.80 \\
\hline Slope, $\beta_{1}$ & & & & & Slope, $\beta_{1}$ & & & & \\
\hline Intercept $2, \gamma_{10}$ & 0.20 & 0.10 & 2.01 & 0.06 & Intercept $2, \gamma_{10}$ & 0.20 & 0.09 & 2.11 & 0.04 \\
\hline $\mathrm{BMI} \%, \gamma_{11}$ & -0.01 & 0.00 & -2.61 & 0.02 & BMI $\%, \gamma_{11}$ & -0.01 & 0.00 & -2.68 & 0.01 \\
\hline$\Delta \mathrm{MVPA}, \gamma_{12}$ & 0.17 & 3.35 & 0.05 & 0.96 & $\Delta \mathrm{ACT}, \gamma_{12}$ & -9.95 & 10.96 & -0.91 & 0.37 \\
\hline
\end{tabular}

Coef $=$ coefficient, $\mathrm{SE}=$ standard error, $\mathrm{T}=\mathrm{t}$-ratio, $\mathrm{df}=$ degrees of freedom, $\% \mathrm{SED}=$ percent time spent in sedentary activity, BMI $\%=$ average BMI percentile, $\triangle \mathrm{SED}=$ change in percent time spent in sedentary behavior, $\%$ light $=$ percent time spent in light activity, $\Delta$ Light $=$ change in percent time spent in light activity, $\%$ MVPA $=$ percent time spent in moderate to vigorous physical activity, $\triangle \mathrm{MVPA}=$ change in percent time spent in moderate to vigorous physical activity, ACT $=$ self-reported activity score, $\triangle \mathrm{ACT}=$ change in self-reported activity score. 
Table 10. HLM results for the PA predictor variables on the outcome variable body image dissatisfaction.

\begin{tabular}{|c|c|c|c|c|c|c|c|c|c|}
\hline \multicolumn{10}{|c|}{ Fixed Effects - Body Image Dissatisfaction (BID) } \\
\hline & Coef & SE & $\begin{array}{l}\text { T (20 } \\
d f)\end{array}$ & $\begin{array}{l}p- \\
\text { value }\end{array}$ & & Coef & SE & $\begin{array}{l}\text { T (20 } \\
d f)\end{array}$ & $\begin{array}{l}p- \\
\text { value }\end{array}$ \\
\hline$\%$ SED & & & & & $\%$ Light & & & & \\
\hline Intercept, $\beta_{0}$ & & & & & Intercept, $\beta_{0}$ & & & & \\
\hline Intercept $2, \gamma_{00}$ & -1.50 & 0.27 & -5.59 & $<0.01$ & Intercept $2, \gamma_{00}$ & -1.49 & 0.27 & -5.55 & $<0.01$ \\
\hline BMI $\%, \gamma_{01}$ & -0.04 & 0.01 & -3.80 & $<0.01$ & $\mathrm{BMI} \%, \gamma_{01}$ & -0.04 & 0.01 & -3.81 & $<0.01$ \\
\hline$\Delta \mathrm{SED}, \gamma_{02}$ & -2.39 & 3.51 & -0.68 & 0.50 & $\Delta$ Light, $\gamma_{02}$ & 4.30 & 9.28 & 0.46 & 0.65 \\
\hline Slope, $\beta_{1}$ & & & & & Slope, $\beta_{1}$ & & & & \\
\hline Intercept $2, \gamma_{10}$ & 0.02 & 0.03 & 0.80 & 0.43 & Intercept $2, \gamma_{10}$ & 0.02 & 0.03 & 0.73 & 0.47 \\
\hline $\mathrm{BMI} \%, \gamma_{11}$ & -0.00 & 0.00 & -0.41 & 0.69 & BMI $\%, \gamma_{11}$ & -0.00 & 0.00 & -0.38 & 0.71 \\
\hline$\Delta \mathrm{SED}, \gamma_{12}$ & 0.52 & 0.47 & 1.12 & 0.27 & $\Delta$ Light, $\gamma_{12}$ & -1.14 & 1.23 & -0.93 & 0.36 \\
\hline \% MVPA & & & & & ACT & & & & \\
\hline Intercept, $\beta_{0}$ & & & & & Intercept, $\beta_{0}$ & & & & \\
\hline Intercept $2, \gamma_{00}$ & -1.46 & 0.26 & -5.66 & $<0.01$ & Intercept $2, \gamma_{00}$ & -1.41 & 0.26 & -5.46 & $<0.01$ \\
\hline $\mathrm{BMI} \%, \gamma_{01}$ & -0.04 & 0.01 & -3.58 & $<0.01$ & $\mathrm{BMI} \%, \gamma_{01}$ & -0.04 & 0.01 & -3.96 & $<0.01$ \\
\hline$\Delta \mathrm{MVPA}, \gamma_{02}$ & 8.43 & 8.08 & 1.04 & 0.31 & $\Delta \mathrm{ACT}, \gamma_{02}$ & -6.10 & 30.22 & -0.20 & 0.84 \\
\hline Slope, $\beta_{1}$ & & & & & Slope, $\beta_{1}$ & & & & \\
\hline Intercept $2, \gamma_{10}$ & 0.02 & 0.03 & 0.79 & 0.44 & Intercept $2, \gamma_{10}$ & 0.02 & 0.03 & 0.51 & 0.62 \\
\hline BMI $\%, \gamma_{11}$ & -0.00 & 0.00 & -0.54 & 0.59 & BMI $\%, \gamma_{11}$ & -0.00 & 0.00 & -0.29 & 0.78 \\
\hline$\Delta \mathrm{MVPA}, \gamma_{12}$ & -1.07 & 1.02 & -1.06 & 0.30 & $\Delta \mathrm{ACT}, \gamma_{12}$ & 3.01 & 3.57 & 0.84 & 0.41 \\
\hline
\end{tabular}

Coef $=$ coefficient, $\mathrm{SE}=$ standard error, $\mathrm{T}=\mathrm{t}$-ratio, $\mathrm{df}=$ degrees of freedom, $\% \mathrm{SED}=$ percent time spent in sedentary activity, BMI $\%=$ average BMI percentile, $\Delta \mathrm{SED}=$ change in percent time spent in sedentary behavior, $\%$ light $=$ percent time spent in light activity, $\Delta$ Light $=$ change in percent time spent in light activity, $\%$ MVPA $=$ percent time spent in moderate to vigorous physical activity, $\triangle \mathrm{MVPA}=$ change in percent time spent in moderate to vigorous physical activity, ACT $=$ self-reported activity score, $\triangle \mathrm{ACT}=$ change in self-reported activity score. 
Table 11. HLM results for the PA predictor variables on the outcome variable depressive symptoms.

\begin{tabular}{|c|c|c|c|c|c|c|c|c|c|}
\hline \multicolumn{10}{|c|}{ Fixed Effects - Depressive Symptoms (CDI) } \\
\hline & Coef & $\mathrm{SE}$ & $\begin{array}{l}\text { T (20 } \\
d f)\end{array}$ & $\begin{array}{l}p- \\
\text { value }\end{array}$ & & Coef & $\mathrm{SE}$ & $\begin{array}{l}\text { T (20 } \\
d f)\end{array}$ & $\begin{array}{l}p- \\
\text { value }\end{array}$ \\
\hline$\%$ SED & & & & & \% Light & & & & \\
\hline Intercept, $\beta_{0}$ & & & & & Intercept, $\beta_{0}$ & & & & \\
\hline Intercept $2, \gamma_{00}$ & 1.78 & 0.49 & 3.62 & $<0.01$ & Intercept $2, \gamma_{00}$ & 1.79 & 0.49 & 3.67 & $<0.01$ \\
\hline $\mathrm{BMI} \%, \gamma_{01}$ & 0.02 & 0.02 & 1.27 & 0.22 & $\mathrm{BMI} \%, \gamma_{01}$ & 0.02 & 0.02 & 1.27 & 0.22 \\
\hline$\Delta \mathrm{SED}, \gamma_{02}$ & -7.54 & 5.91 & -1.28 & 0.22 & $\Delta$ Light, $\gamma_{02}$ & 22.40 & 15.75 & 1.42 & 0.17 \\
\hline Slope, $\beta_{1}$ & & & & & Slope, $\beta_{1}$ & & & & \\
\hline Intercept $2, \gamma_{10}$ & 0.03 & 0.07 & 0.46 & 0.65 & Intercept $2, \gamma_{10}$ & 0.04 & 0.07 & 0.48 & 0.63 \\
\hline BMI $\%, \gamma_{11}$ & 0.01 & 0.00 & 1.69 & 0.11 & $\mathrm{BMI} \%, \gamma_{11}$ & 0.01 & 0.00 & 1.71 & 0.10 \\
\hline$\Delta \mathrm{SED}, \gamma_{12}$ & -0.22 & 0.94 & -0.24 & 0.82 & $\Delta$ Light, $\gamma_{12}$ & 0.82 & 2.51 & 0.33 & 0.75 \\
\hline \% MVPA & & & & & ACT & & & & \\
\hline Intercept, $\beta_{0}$ & & & & & Intercept, $\beta_{0}$ & & & & \\
\hline Intercept $2, \gamma_{00}$ & 1.74 & 0.49 & 3.56 & $<0.01$ & Intercept $2, \gamma_{00}$ & 1.80 & 0.50 & 3.63 & $<0.01$ \\
\hline $\mathrm{BMI} \%, \gamma_{01}$ & 0.03 & 0.02 & 1.53 & 0.14 & $\mathrm{BMI} \%, \gamma_{01}$ & 0.03 & 0.02 & 1.26 & 0.22 \\
\hline$\Delta \mathrm{MVPA}, \gamma_{02}$ & 16.39 & 14.33 & 1.14 & 0.27 & $\Delta \mathrm{ACT}, \gamma_{02}$ & -44.92 & 54.09 & -0.83 & 0.42 \\
\hline Slope, $\beta_{1}$ & & & & & Slope, $\beta_{1}$ & & & & \\
\hline Intercept $2, \gamma_{10}$ & 0.03 & 0.07 & 0.37 & 0.72 & Intercept $2, \gamma_{10}$ & 0.01 & 0.07 & 0.13 & 0.90 \\
\hline BMI $\%, \gamma_{11}$ & 0.01 & 0.00 & 1.66 & 0.11 & $\mathrm{BMI} \%, \gamma_{11}$ & 0.01 & 0.00 & 1.89 & 0.07 \\
\hline$\Delta \mathrm{MVPA}, \gamma_{12}$ & -0.83 & 2.19 & -0.38 & 0.71 & $\Delta \mathrm{ACT}, \gamma_{12}$ & 5.95 & 7.65 & 0.78 & 0.45 \\
\hline
\end{tabular}

Coef $=$ coefficient, $\mathrm{SE}=$ standard error, $\mathrm{T}=\mathrm{t}$-ratio, $\mathrm{df}=$ degrees of freedom, $\% \mathrm{SED}=$ percent time spent in sedentary activity, BMI $\%=$ average BMI percentile, $\triangle \mathrm{SED}=$ change in percent time spent in sedentary behavior, $\%$ light $=$ percent time spent in light activity, $\Delta$ Light $=$ change in percent time spent in light activity, $\%$ MVPA $=$ percent time spent in moderate to vigorous physical activity, $\triangle \mathrm{MVPA}=$ change in percent time spent in moderate to vigorous physical activity, ACT $=$ self-reported activity score, $\triangle \mathrm{ACT}=$ change in self-reported activity score. 
Results indicated that when there was an effect on the outcome variables, it was due to BMI rather than the predictor PA variables. The change in slope for girls with average change in percent time spent in sedentary activity was significant $(p=0.017)$. This indicates that for every increase in average BMI percentile of girls with average percent time spent in sedentary behavior, BMI had a significant decrease on self-esteem. However, the effect on the change in percent time spent in sedentary activity was not significant $(p=0.709)$, indicating that BMI is responsible for the significant decrease in self-esteem rather than change in percent time spent in sedentary activity. The same was also true for change in percent time spent in light PA $(p=0.017)$, change in percent time spent in MVPA $(p=0.017)$, and change in self-reported activity score $(p=0.014)$.

With respect to body image dissatisfaction, results showed that the intercept due to the effect of BMI was significant for change in percent time spent in sedentary activity $(p=0.001)$, light PA $(p=0.001)$, MVPA $(p=0.002)$, and self-reported activity score $(p<$ 0.001). This indicated that for every increase in BMI percentile, girls felt more dissatisfaction towards their bodies. Results did not indicate any significant effects either from BMI or PA variables on depressive symptoms. Overall, HLM analysis demonstrated that change in the predictor variables did not have an effect on mental health variables, but increased BMI did have some effect on the change in mental health outcome variables.

Because reverse causality could have played a role in this analysis, appropriate HLM models were run in the opposite direction (change in mental health outcome variables predicting a change in PA variables). Results showed that neither mental health 
outcome variables nor BMI had any effects on changes in PA levels. With respect to change in sedentary behavior, results indicated that there was no predictive effect of selfesteem $(p=0.34)$, body image dissatisfaction $(p=0.86)$, or depressive symptoms $(p=$ 0.45). With respect to change in light PA, there was no predictive effect of self-esteem ( $p$ $=0.29)$, body image dissatisfaction $(p=0.76)$, or depressive symptoms $(p=0.62)$. With respect to change in MVPA, there was no predictive effect of self-esteem $(p=0.77)$, body image dissatisfaction $(p=0.61)$, or depressive symptoms $(p=0.98)$. Finally, with respect to daughters' self-reported activity score, there was no predictive effect of selfesteem $(p=0.59)$, body image dissatisfaction $(p=0.99)$, or depressive symptoms $(p=$ $0.65)$. 


\section{CHAPTER V}

\section{DISCUSSION}

\section{Introduction}

Studies have shown that obesity is a public health problem in African American girls. The development of pediatric obesity has been associated with reductions in PA levels and increased time spent in sedentary behaviors $(74,132,134)$. Current traditional PA programs in this population have proven ineffective due to the lack of cultural relevance (i.e., Afro-centric dance, inclusion of mother, African American history lessons $)(17,96,126)$. It has also been reported that mothers' health behaviors can impact the development of their daughters' health behaviors, including PA and mental health outcomes (PA self-efficacy, self-esteem, depressive symptoms, and body image dissatisfaction) $(2,8,120,135)$. These mental health outcome variables are not only associated to each other, but also to PA levels in children $(55,111,158,184)$. Therefore, it is possible that a PA intervention that utilizes the African American culture (i.e., culturally-tailored mother-daughter dance) may provide a feasible means of improving African American girls' PA levels and mental health outcome variables. Currently, there are very little data on the impact of mother-daughter relationship on African American girls' PA levels and mental health outcome variables (self-esteem, depressive symptoms, and body image dissatisfaction). Thus, the purpose of this study was to examine if the changes in PA following a 12-week culturally-tailored mother-daughter dance intervention predicted changes in mother-daughter relationship and mental health outcome variables in pre-adolescent African American girls. 


\section{$\underline{\text { Daughters' correlations }}$}

There were several significant correlations found in this study. At baseline, daughters' BMI was positively associated with self-esteem indicating that girls who had higher BMI also had higher levels of self-esteem. This finding is not consistent with what other researchers have reported. For example, in the Memphis GEMS study (61), researchers found no difference in self-esteem of 8-10 year old African American girls (n $=303$ ) based on weight status (155). A review of obesity and psychological well-being literature indicate a modest relationship between obesity and self-esteem (181). However, this result could be confounded by age, as the same relationship was not found with BMI percentile. Studies have shown that perception of body size rather than actual BMI was a better predictor of self-esteem $(84,106)$. In the present study, BMI percentile was also negatively associated to body image dissatisfaction, indicating that girls with a higher BMI had lower scores on the Body Image Dissatisfaction Scale indicating a desire to be thinner. This finding is consistent with previous literature in pre-adolescent and adolescent girls demonstrating that overweight girls experienced greater feelings of dissatisfaction towards their bodies and express a desire to be thinner $(89,136)$.

Daughters' self-reported PA was positively associated to PA self-efficacy. In the literature, both objective and subjective reports of PA have been correlated to PA selfefficacy $(55,112,184)$, yet the present study only found this relationship in the subjective measure. The observed association between self-reported PA and PA self-efficacy in the present study could be the due to an overestimation of PA. Girls with higher self-esteem seem to have a more positive perception of their mother-daughter relationship. This finding is similar to what has been reported in $16-18$ year old $(n=105)$ adolescent African 
American girls, where there was a significant positive association between daughters' self-esteem and their perception of trust in their mother (176). A similar relationship has also been reported in pre-adolescent Caucasian and Latina girls and their mothers (78, 100). This is the first study to report a similar association in pre-adolescent African American girls.

Post intervention 12-week assessment yielded new correlations. Daughters' percent time spent in light PA was negatively associated with depressive symptoms, which demonstrates that girls who spent more time engaging in light PA had lower depressive symptoms. The reported association is consistent with what has been previously reported in adolescents $(6,35,111,116,160)$. Data describing pre-adolescent depression is sparse in the literature, as most studies focus on adolescents or adults. The TEENS study (seventh and eighth grade students, $n=3,558$ ) showed that changes in PA over a two-year period were inversely associated with changes in depressive symptoms (111). However, unlike the present study, the TEENS study did not implement a PA intervention and based the PA change score on one self-report question, "Do you get some regular physical activity outside of school?"' In contrast, a study of 9-12 year old boys and girls $(\mathrm{n}=90)$ in an afterschool program incorporating PA programming reported a significant decrease in depressive symptoms with an increase in self-reported PA among the treatment group (6).

Although the exact mechanism underlying the anti-depressive effects of PA is still unclear (159), variables such as self-esteem and self-efficacy may provide insight into the complexity of the relationship. Because increased PA has been routinely associated with higher self-esteem, it may serve as part of the equation to understand the relationship 
between PA and depressive symptoms $(54,59,71)$. In the present study, girls with higher self-esteem and PA self-efficacy were less likely to have depressive symptoms, which is consistent with previous findings $(13,18,20,54)$. In a study of $12^{\text {th }}$-grade girls $(\mathrm{n}=$ 1,250), Dishman et al. concluded that self-esteem was inversely related to depressive symptoms, and that physical self-concept mediated the relationship of PA with selfesteem (54). In addition, a cross-sectional study of 62 boys and girls in grades 4-9 demonstrated that self-esteem was strongly associated with depressive symptoms, although measurement tools (Culture-free Self-esteem Inventory for Children and a modified version of the Beck Depression Inventory) varied from those used in the present study (18). The results of the present study contribute to the body of literature that suggests that the need for more pre-adolescent intervention studies to determine if selfesteem can be increased with PA and therefore reduce the risk of depression. Finally, daughters with high self-esteem had lower body image dissatisfaction. This is consistent with Kostanski et al. who found the same inverse relationship in a sample of $516(n=268$ girls) 12-18 year olds (93). Van den Berg et al. conducted an observational study in a large, diverse sample $(n=4,746)$ of 11-18 year old boys and girls. Researchers concluded that the association between self-esteem and body image dissatisfaction was stronger among girls than boys, and weaker but still significant among African American and low SES girls (178). It has been established that the link between body image dissatisfaction and self-esteem is predictive of adolescent eating disorders and depression $(27,99)$, which makes the results of the present study promising. Pre-adolescent behaviors track into adolescence and beyond, so positive self-esteem behaviors during this time period 
may be protective from developing body image issues leading to poor eating habits and mental health issues.

\section{$\underline{\text { Mother-daughter correlations }}$}

\section{Baseline}

In the present study, daughters' self-esteem was positively related to mothers' BMI. Although not intuitive, the literature has established that African American women prefer a larger ideal body size when compared to Caucasian women $(37,51,108,187)$. One study in 134 college women indicated that African American women preferred a larger body size compared to Caucasians and were more likely to have cultural protective factors that prevent lower self-esteem and body dissatisfaction that is often associated with larger body size (108). Daughters' PA self-efficacy was negatively related to mothers' depressive symptoms and PA self-efficacy. Maternal depressive symptoms can significantly impact the child (44). These children could be directly impacted through maternal emotional unavailability, inability to provide physical and emotional resources, and altering parent-child interaction (44). In the present study, mothers with more depressive symptoms may have been unable to provide as much support for their daughters' PA pursuits resulting in a lower PA self-efficacy. However, it was unexpected that daughters' PA self-efficacy would be inversely related to mothers' PA self-efficacy. Perhaps the daughters' did not look to their mothers as role models in developing their PA self-efficacy, but rather had other role models such as other family members, teachers, coaches, or peers $(5,24,47,66,82,150,182)$. A mother's PA self-efficacy impacts the level of support she provides her daughter (2). Since maternal social support 
for PA was not measured in the present study, it is unknown whether it contributed to the relationship observed between mother and daughter PA self-efficacy. It also may be that peers play a larger role in shaping PA self-efficacy in girls than parents. In a sample of 259 adolescent girls (age 15 \pm 1.2 years), Beets et al. found that peer modeling, encouragement, and praise directly influenced girls' PA levels, and that these effects were partially mediated by self-efficacy (24). However, the participants in the Beets et al. study were older than the participants involved in the present study. Therefore, their adolescent stage may have been indicative of the reliance of peer support rather than maternal support. Finally, daughters' perception of her mother-daughter relationship was positively correlated to mothers' view of their relationship. This was a positive outcome in that girls who perceived a better relationship with their mother also had mothers who felt the same way. The importance of this relationship has also been reported in adolescent and adult mother-daughter dyads $(8,31,32,130)$.

\section{Post-intervention}

Mothers with lower BMIs had daughters who spent more time in light PA. Although not observed in the present study, it is possible that mothers with lower BMIs may have had higher activity levels than those with higher BMIs $(68,165,183)$. Daughters may have modeled their mothers' behavior, resulting in greater levels of light PA. Surprisingly, mothers' perception of their mother-daughter relationship was negatively related to daughters' percent time spent in MVPA. This relationship has not yet been established in the literature as few studies have assessed both measures. The result could be indicative of the mother and daughter spending time together, but not in 
moderate to vigorous types of activity. In a study that examined survey responses from 276 mother-daughter dyads, Mosavel et al. found that $94 \%$ of dyads reported having dinner together, $89 \%$ reported watching television together, and 59\% reported attending social affairs such as church together, while only $4 \%$ reported engaging in any healthbased activity (110). It is interesting that the items most frequently reported were mostly sedentary activity. Although, these types of activities could strengthen the motherdaughter relationship, they would have little to no impact on PA levels.

Contrary to baseline correlations, mothers' percent time spent in light PA was negatively related to daughters' self-esteem. Mothers may not be spending a lot of time engaging in light PA, but could still provide their daughters with self-esteem building activities in several ways (20). For example, this could be done through encouragement or enrolling them in a less active type of afterschool program. Mothers' PA self-efficacy was negatively related to daughters' percent time spent in light PA, and positively related to daughters' depressive symptoms. It was unexpected that higher levels of maternal PA self-efficacy would be related to lower levels of daughters' percent time spent in light PA. This could be explained by daughters not relying on their mothers to build their own PA self-efficacy and engaging in active behaviors. However, this notion would be contradictory to the underlying hypothesis about the impact of the mother-daughter relationship. Finally, mothers' PA self-efficacy was positively related to daughters' depressive symptoms. This result seemed counterintuitive, since it indicates that mothers with high PA self-efficacy are related to daughters with more depressive symptoms. It seems that even though mothers' have high levels of PA self-efficacy, they are not modeling that behavior for their daughters in the present study. 


\section{Change in physical activity level}

The first hypothesis of this study, which examined if participation in a culturallytailored mother-daughter intervention would increase percent time spent in light PA, MVPA, and total PA, and decrease sedentary time was rejected, indicating that participation in this intervention did not alter the daughters' PA levels. It is possible that the lack of change in PA could be due to the low attendance rate. During the course of the 12 week interventions ( 36 classes), only $25.9 \%$ of the participants attend at least $75 \%$ of the intervention. The average attendance was $34.7 \%$ for mothers and $43.4 \%$ for daughters. The findings of the present study are consistent with the findings of similar culturally-tailored interventions $(121,142)$. For example, in a sample of 261 preadolescent African American girls participating in Stanford GEMS, researchers observed a decrease in MVPA (142). Researchers attributed the reduction in MVPA to the fact that only one fifth of the intended intervention dose was attained by participants (142). In Latina mother-daughter dyads, Olvera et al. found that participation in a 12 week PA intervention did not lead to any significant change in PA or fitness levels (121). The researchers of that study attributed their results to the use of self-report PA measurement tools and encouraged an objective measure in future studies. However, the researchers failed to report attendance data, which could have also impacted their results.

In the present study, a significant decrease in daughters' self-reported activity was observed at the completion of the 12-week intervention. The decreased activity score indicates that daughters self-reported less PA at the completion of the intervention. Daughters participating in the intervention may not have seen dance as a form of PA, but more of a fun thing to do. Focus group data that contributed to the development of this 
intervention indicated that many daughters did not classify dance as a type of PA (3). If this was the case, an increased amount of dance may not have been perceived as increased PA. This could explain the decrease in self-reported PA. It is also possible that the observed decrease in self-reported PA at the completion of the study could due to an over-reporting of baseline PA due to social desirability bias. Theoretically, one would expect the decreased activity score to accompany an increase in BMI. However, this was not observed in the current study. Pulling from the baseline data of 95 African American girls (age 8-10 years) enrolled in the GEMS studies at Memphis and Baylor, researchers reported that social desirability biased PA self-report and confounded associations between self-report PA and BMI (91). Another possible reason for the decrease in selfreported activity could be due to the timing of PA assessments. Baseline measurements took place from July to the start of intervention in January. Daughters who completed baseline during the warmer months may have reported higher levels of activity due to the opportunity to play outside, whereas 12-week PA assessments took place in April when the weather was colder and therefore less time to play outside. A systematic review of 37 studies consisting of 291,883 participants concluded that the seasons and weather have an important effect on PA levels (175). PA levels were highest from May through August with a peak in July and August (175). Additionally, PA levels tend to decline in the winter months due to shorter days and colder temperatures (175). No change in PA could also be seen as a promising result. Participation in this culturally-tailored motherdaughter dance intervention did not result in a significant decrease in PA levels, so it could be argued that it prevented a decline in PA. 


\section{Mother-Daughter Relationship}

The second hypothesis of this study (intervention would lead to improvements in daughters' perception of their mother-daughter relationship), was rejected. This lack of change could be due to the fact that at baseline, both daughters and mothers already had a relatively high perception of their relationship. It is possible that mother-daughter dyads with a good relationship were the participants who were willing to participate in an intervention like this. This result is not consistent with previous studies. The Daughters and Mothers Exercising Together (DAMET) study randomized 40 mothers and their adolescent daughters (age $=15.5 \pm 1.65$ years) to either a 12 -week university-based or home-based exercise program (129). Both arms of the DAMET intervention led to increased PA participation by mothers and daughters, as well as improvements in motherdaughter relationship (129). Researchers attributed the enhancement of the motherdaughter relationship to increased time spent together such as traveling to and from intervention, as well as exercising together. The DAMET study differs from the present study in that it involved a sample of adolescent Caucasian girls, whereas the present study consisted of pre-adolescent African American girls. Differences in the two study populations make it difficult to compare the study results.

When analyzing only the girls who attended at least $40 \%$ of the intervention, although not significant, daughters' perception of their relationship to their mother improved slightly with the intervention. It is therefore possible that the lack of change in mother-daughter relationship could be attributed to the low intervention attendance. Analyses were run on participants who attended at least $40 \%$ of the intervention, as this is a similar cutoff that researchers have used and deemed an adequate dose of the 
intervention (77). Dyads who attended at least $40 \%$ of the intervention may have seen slight improvements in their relationship due to greater exposure to the intervention activities and to each other. In an attempt to identify changes in PA in daughters who reported better mother-daughter relationship, daughters were split into tertiles based on their perception of their mother-daughter relationship. No significant changes in PA levels were observed in either the high or low perception of mother-daughter relationship groups. Of the four mother-daughter PA interventions that have targeted African Americans, none of these measured mother-daughter relationship, so it is hard to compare the present results to other studies within this population $(22,142,156,180)$.

\section{Effect of mediators on increases in physical activity levels}

The third hypothesis of this study postulated that an increase in PA self-efficacy and mother-daughter relationship would mediate increases in PA levels. Results indicated that PA self-efficacy did not mediate changes in objectively measured or self-reported PA levels. The findings of this study are not consistent with what other researchers have reported (54). For example, Dishman et al. reported that manipulating self-efficacy in African American and Caucasian adolescent girls resulted in increased self-reported PA levels (55). In contrast to the present study, the Dishman et al. study focused on improving self-efficacy in a larger sample size $(n=2,087)$ and examined an older age group (high school girls). In his later work, Dishman et al. reported that regardless of race, high levels of baseline PA self-efficacy in high school girls was correlated to higher baseline PA level, but initial PA self-efficacy did not correlate with change in PA (56). In this case, PA self-efficacy moderated, rather than mediated change in PA. Similar 
findings have been reported in adults who participated in a walking intervention (46). A recent meta-analysis of PA interventions that aimed to enhance PA self-efficacy demonstrated a small effect (10). However, this study had an interesting finding that PA self-efficacy was significantly higher when the individual saw someone they identified

with perform the same task (10). This was one of the underlying rationales for utilizing African American dancers to implement the dance intervention in the present study. Results also indicated that mother-daughter relationship did not mediate any increase in PA. Because there was no significant change, it is possible that mother-daughter relationship may act as a moderator and not a mediator of outcome variables.

\section{Change in physical activity variables predict change in mental health outcomes}

The fourth study hypothesis (changes in PA variables would predict changes in mental health outcome variables) was rejected, as there were no statistically significant changes in mental health outcome variables as a result of participating in the motherdaughter dance intervention. This could also be interpreted as the intervention maintained normal ranges of mental health outcome variables on average. The lack of change could be due to the fact that daughters' baseline depressive symptoms were within normal range. The increase in self-esteem, although non-significant, is a promising result. High self-esteem has been linked to overall happiness, protective against depression, ability to cope with stress, and an ability to be resilient against unhealthy behaviors (i.e. eating disorders, drugs/alcohol, sexual activity) (20). However, it is unknown if the increased self-esteem stemmed from participation in the dance class, spending more time with their mothers, or a combination of both. Similar to this study, a study by Huang et al., reported 
that participation in PA program did not alter adolescent girls' $(n=878)$ self-esteem $(83)$. Self-esteem levels have been shown to remain consistent among African American girls between the ages of 9-14 (34). Since half the present study's age group is represented by that finding, it is possible that the age inclusion criteria prohibited us from seeing a change in self-esteem levels.

Participants who attended at least $40 \%$ of the intervention started with higher baseline body image dissatisfaction than the entire sample. In the Stanford GEMS pilot study $(n=61)$, participants in the treatment group demonstrated a significant decrease in weight concern and trended towards decreased body image dissatisfaction following the 12-week dance intervention (141). This indicates that change in body image dissatisfaction can be seen in this short study duration. It is possible that the present study only observed non-significant improvements in body image dissatisfaction due to small sample size $(n=12)$ used in the subgroup of participants that attended at least $40 \%$ of the intervention.

Hierarchical linear modeling (HLM) was used to examine if changes in PA variables predicted changes in mental health outcome variables. As previously stated, HLM was used because it is able to compute change scores for PA variables of interest. The change scores are then used as predictor variables in subsequent models. However, since there was no change in PA, the HLM Level 2 model could not determine if PA variables predicted overall changes in mental health outcome variables. Results showed that when there was an effect (i.e., BMI predicting change in self-esteem and body image dissatisfaction), it was due to BMI rather than the PA variables. For every increase in average BMI percentile with average percent time spent in sedentary time, BMI had a 
significant effect on self-esteem. This was also true for percent time spent in light PA, MVPA, and change in self-reported activity score. With respect to self-esteem, HLM results indicated that significant changes in self-esteem were observed in girls who exhibited average amounts of sedentary time and had an above average BMI percentile. Results for body image dissatisfaction indicated that the intercept due to the effect of BMI was significant for change in percent time spent in sedentary activity, percent time spent in light PA, percent time spent in MVPA, and change in self-reported activity score. This result occurred in the expected direction as girls who had an above average BMI percentile and sedentary activity also exhibited greater body image dissatisfaction. There was no effect of BMI or PA variables on depressive symptoms. The findings of this study are novel because HLM has not been used to answer this type of question. Due to this, it is difficult to compare the findings of the present study to the literature.

\section{Factors potentially impacting results}

There were several factors that could have impacted the results of the current study. First, this study had a small sample size. The main study, where the present data were drawn from, consisted of only 73 dyads, which were randomized into three groups [mother-daughter (CH-M), child alone, control]. The present study only utilized data from the mother-daughter group $(\mathrm{n}=28)$. Secondly, the intervention suffered from low attendance. Only 12 of 28 dyads (42.9\%) randomized to the CH-M group attended at least $40 \%$ of the dance classes, which translates to about 14 dance classes over the course of 12 weeks ( 1.2 classes/week). Intervention attendance is a common issue in community-based intervention studies. The Stanford GEMS study employed their 
intervention five days per week, provided transportation to the intervention sites, and still had only $21 \%$ average attendance (142). Additionally, the Medical College of Georgia FitKid Project examined the effect of a 3-year afterschool PA program in 617 students (age $=8.5 \pm 0.6$ years) (77). Average attendance over the 3-year intervention was $44 \%$. Because of this, only participants who attended at least $40 \%$ of the intervention were included in the analysis (77).

One of the rationales of the intervention was that participating in the intervention together (mother and daughter) would be the underlying mechanism that would lead to changes in PA, mental health variables, and mother-daughter relationship. Although mothers were supposed to attend the dance class with their daughters, there were some who did not attend as often or at all. Sixteen of 28 mother-daughter dyads did not attend the dance classes together as intended. Daughters' attended an average of $20.8 \%$ more dance classes than their mothers. In dyads that did not attend together, this translated to daughters attending approximately 7.5 dance classes without their mothers over the course of 12 weeks. Therefore, the lack of attending the dance intervention together could have had a direct impact on PA levels, mental health outcome variables for the daughters, and the mother-daughter relationship variable. The study intervention also did not assess whether dyads participated in any other activities at home together that could potentially improve their relationship.

Cohorts 1 and 2 had different dance instructors, which could have led to different dance class environments for the participants. Although there was no significant difference between cohort 1 and 2 PA levels, the cohort 1 instructor did not fully encourage 60 minutes of MVPA during dance class. A seasonal effect could have also 
impacted the results. Baseline measurement for each cohort began as early as August and lasted until the start of the intervention in January; whereas, 12-week (post) data collection took place in April (cooler weather). Baseline data was not seasonally consistent in all participants. As previously stated, research has shown that PA levels peak in July/August and decline in the winter months (175). In addition, it is possible that due to the timing of baseline data collection (August - January), those that had baseline measurements closer to the start of intervention (January) probably represented a more accurate depiction of their true baseline PA levels compared to those that had their baseline PA assessed in August. Finally, the duration of the study may have also impacted the results. This study intervention was only implemented for 12 weeks. These 12 weeks were interrupted by school breaks, holidays, and inclement weather closings. In general, researchers have reported that interventions that have utilized short study durations in African American children and youth are not effective in altering health behaviors such as PA (140). Another factor that could have impacted the study results that was unaccounted for was the timing of state mandated testing. Although there is no evidence to support this claim, it is possible that state standardized testing impacted study results. Mandatory testing took place during the last few weeks of the intervention period. This type of testing typically consists of longer than normal periods of sedentary activity during the school day.

\section{$\underline{\text { Strengths \& Limitations }}$}

Strengths of this study include the use of HLM analysis to address the research question which sought to examine if changes in PA could predict changes in mental 
health outcome variables. This is a unique analysis that has not been used to address this type of question in the literature. It was able to calculate change in PA variable scores and use those values as predictors in the Level-2 model to predict change in mental health outcome variables. While only one group was examined in the present study, the larger study employed a randomized controlled design stratified by BMI which ensured an equal distribution of weight classes in each group. This study design was chosen to test the effectiveness of the mother-daughter dance intervention in pre-adolescent African American girls. This study is also novel in that it involved mother-daughter dyads participating in a culturally-tailored dance intervention together. It has been established that mothers play a significant role in influencing their daughters' health behaviors (105, 109, 171). Mother-daughter relationship with regards to PA has been rarely measured during a PA intervention, and this study was able to shed some light on utilizing this relationship as a method to increase PA. Other strengths include the use of objective PA monitoring and assessments at three time points over the course of the study.

This study was limited by a number of factors. First, the lack of change in PA or mental health outcome variables made it difficult to answer the research questions. Second, the sample size was small and was made even smaller by inconsistent attendance of the dance intervention. Less than half of the mother-daughter dyads attended less than half of the intervention. It is difficult to truly assess the effects of the culturally-tailored dance intervention, when the intended dosage was not attained by the majority of the group. Third, the dance instructor is crucial to the deliverance of the intervention and the motivation of the participants, so the change in instructors from cohort 1 to cohort 2 could have also been a limitation. Fourth, the 12-week duration of the study may not have 
been long enough to see a change in the outcome variables for the present study. Finally, the potential for reverse causality is a limitation to the present study. This is common in studies examining the relationships between physical activity and mental health variables, especially when including mediating pathways $(19,49)$. It is rare for a single variable to be the sole causal factor in a pathway, and it is more common to have a bidirectional relationship. This bidirectional relationship inevitably makes understanding causation more complex. Although the present study did not yield any significant results, reverse causation cannot be ruled out. Models were run in the opposite direction of the original hypothesis (change in mental health outcomes predicting change in PA variables) to provide better understanding of the potential causal pathway. These models also resulted in insignificant findings which indicated that changes did not occur in the opposite direction within this data set. Longer follow-up times may be necessary to adequately address reverse causation among these variables.

\section{Conclusions \& Future Directions}

The purpose of this study was to examine if the changes in PA following a 12week culturally-tailored mother-daughter dance intervention predicted a change in mental health outcome variables and mother-daughter relationship in pre-adolescent African American girls. This study intervention did not result in any significant changes in PA or mental health outcome variables. The lack of significant finding in the present study could be due to the study limitations listed in the above section. Future studies wishing to examine this question should include a larger sample size, longer study duration, and intervention activities that target the mother and daughter at home. Future studies should 
also examine maternal social support provided to the daughter. Research has shown that a mothers' PA self-efficacy can impact the level of support she offers her daughter for PA pursuits (1), so this could influence the pathway between mother-daughter relationship and daughters' PA. One of the key limitations of the present study was the low intervention attendance, which played a significant role in the study findings. Future studies should examine ways to implement this type of intervention in the participants' home to combat the attendance issue. For example, future studies could explore utilizing technology to implement PA interventions in participants' homes to improve intervention adherence. In addition, future studies should examine maternal social support provided to the daughter. Research has shown that a mothers' PA self-efficacy can impact the level of support she offers her daughter for PA pursuits (2), so this could influence the pathway between mother-daughter relationship and daughters' PA. Overall, the current study provides preliminary data on intervention design challenges that should be addressed in future studies seeking to examine the impact of a mother-daughter dance intervention on the PA levels and mental health outcome variables in pre-adolescent African American girls. 


\section{REFERENCES}

1. Ackard DM, Neumark-Sztainer D, Story M, Perry C. Parent-child connectedness and behavioral and emotional health among adolescents. Am J Prev Med. 2006; 30(1):59-66.

2. Adkins S, Sherwood NE, Story M, Davis M. Physical Activity among African-American Girls: The Role of Parents and the Home Environment. Obes Res. 2004; 12(S9):38S-45S.

3. Alhassan, S., Greever, C., Nwaokelemeh, O., Mendoza, A., Barr-Anderson, DJ. Facilitators, barriers, and components of a culturally-tailored afterschool physical activity program in preadolescent African-American girls and their mothers. Ethn Dis. 2014; 24(1):8-13.

4. Andersen RE, Crespo CJ, Bartlett SJ, Cheskin LJ, Pratt M. Relationship of physical activity and television watching with body weight and level of fatness among children. JAMA. 1998; 279(12):938-42.

5. Anderssen N, Wold B. Parental and peer influences on leisure-time physical activity in young adolescents. Res $Q$ Exerc Sport. 1992; 63(4):341-8.

6. Annesi JJ. Correlations of depression and total mood disturbance with physical activity and self-concept in preadolescents enrolled in an after-school exercise program 1. Psychol Rep. 2005; 96(3c):891-8.

7. Armsden GC, Greenberg MT. The inventory of parent and peer attachment: Individual differences and their relationship to psychological well-being in adolescence. $J$ Youth Adolesc. 1987; 16(5):427-54.

8. Aronowitz T, Morrison-Beedy D. Resilience to risk-taking behaviors in impoverished African American girls: The role of mother-daughter connectedness. Res Nurs Health. $2004 ; 27(1): 29-39$.

9. Arslanian S, Suprasongsin C. Insulin sensitivity, lipids, and body composition in childhood: is "syndrome X" present? J Clin Endocrinol Metab. 1996; 81(3):1058-62.

10. Ashford S, Edmunds J, French DP. What is the best way to change self-efficacy to promote lifestyle and recreational physical activity? A systematic review with meta-analysis. Br J Health Psychol. 2010; 15(2):265-88.

11. Baker PR, Francis DP, Soares J, Weightman AL, Foster C. Community wide interventions for increasing physical activity. Sao Paulo Med J. 2011; 129(6):436-7.

12. Bandura A. Health promotion from the perspective of social cognitive theory. Psychol Health. 1998; 13(4):623-49. 
13. Bandura A. Self-efficacy. Wiley Online Library; 1994.

14. Bandura A. Social foundations of thought and action. The Health Psychology Reader. 2002:94.

15. Bandura A, Pastorelli C, Barbaranelli C, Caprara GV. Self-efficacy pathways to childhood depression. J Pers Soc Psychol. 1999; 76(2):258.

16. Baranowski T. Families and Health Actions. In: Handbook of Health Behavior Research I: Personal and Social Determinants. New York: Plenum Press; 1997, p. 179206.

17. Barr-Anderson DJ, Adams-Wynn AW, DiSantis KI, Kumanyika S. Family-focused physical activity, diet and obesity interventions in African-American girls: a systematic review. Obes Rev. 2013; 14(1):29-51.

18. Battle J. Relationship between self-esteem and depression among children. Psychol Rep. 1987; 60(3c):1187-90.

19. Bauman AE, Sallis JF, Dzewaltowski DA, Owen N. Toward a better understanding of the influences on physical activity: the role of determinants, correlates, causal variables, mediators, moderators, and confounders. Am J Prev Med. 2002; 23(2):5-14.

20. Baumeister RF, Campbell JD, Krueger JI, Vohs KD. Does high self-esteem cause better performance, interpersonal success, happiness, or healthier lifestyles? Psychol Sci Public Interest. 2003; 4(1):1-44.

21. Beck AT, Steer RA, Ball R, Ranieri WF. Comparison of Beck Depression Inventories-IA and-II in psychiatric outpatients. J Pers Assess. 1996; 67(3):588-97.

22. Beech BM, Klesges RC, Kumanyika SK, Murray DM, Klesges L, McClanahan B, Slawson D, Nunnally C, Rochon J, McLain-Allen B. Child-and parent-targeted interventions: the Memphis GEMS pilot study. Ethn dis. 2003; 13(1; SUPP/1):S1-40.

23. Beets MW, Beighle A, Erwin HE, Huberty JL. After-school program impact on physical activity and fitness: a meta-analysis. Am J Prev Med. 2009; 36(6):527-37.

24. Beets MW, Pitetti KH, Forlaw L. The role of self-efficacy and referent specific social support in promoting rural adolescent girls' physical activity. Am J Health Behav. 2007; 31(3):227-37.

25. Beets MW, Cardinal BJ, Alderman BL. Parental social support and the physical activity-related behaviors of youth: a review. Health Educ Behav. 2010; 37(5):621-44. 
26. Berenson GS, Srinivasan SR, Bao W, Newman WP, Tracy RE, Wattigney WA. Association between multiple cardiovascular risk factors and atherosclerosis in children and young adults. $N$ Engl J Med. 1998; 338(23):1650-6.

27. Blowers LC, Loxton NJ, Grady-Flesser M, Occhipinti S, Dawe S. The relationship between sociocultural pressure to be thin and body dissatisfaction in preadolescent girls. Eating Behav. 2003; 4(3):229-44.

28. Bogenschneider K, Pallock L. Responsiveness in Parent-Adolescent Relationships: Are Influences Conditional? Does the Reporter Matter? J Marriage Fam. 2008; 70(4):1015-29.

29. Bogenschneider K, Small SA, Tsay JC. Child, parent, and contextual influences on perceived parenting competence among parents of adolescents. J Marriage Fam. 1997:345-62.

30. Booth ML, Ainsworth BE, Pratt M, Ekelund U, Yngve A, Sallis JF, Oja P. International physical activity questionnaire: 12 -country reliability and validity. Med Sci Sports Exerc. 2003; 195(9131/03):3508-1381.

31. Boyd CJ. Mothers and daughters: A discussion of theory and research. J Marriage Fam. 1989:291-301.

32. Boyd K, Ashcraft A, Belgrave FZ. The impact of mother-daughter and fatherdaughter relationships on drug refusal self-efficacy among African American adolescent girls in urban communities. J Black Psychol. 2006; 32(1):29-42.

33. Brown H, Hume C, Pearson N, Salmon J. A systematic review of intervention effects on potential mediators of children's physical activity. BMC Public Health. 2013; 13(1):165.

34. Brown KM, McMahon RP, Biro FM, Crawford P, Schreiber GB, Similo SL, Waclawiw M, Striegel-Moore R. Changes in self-esteem in Black and White girls between the ages of 9 and 14 years: The NHLBI Growth and Health Study. J Adolesc Health. 1998; 23(1):7-19.

35. Brown SW, Welsh MC, Labbé EE, Vitulli WF, Kulkarni P. Aerobic exercise in the psychological treatment of adolescents. Percept Mot Skills. 1992; 74(2):555-60.

36. Brown T, Summerbell C. Systematic review of school-based interventions that focus on changing dietary intake and physical activity levels to prevent childhood obesity: an update to the obesity guidance produced by the National Institute for Health and Clinical Excellence. Obes Rev. 2009; 10(1):110-41.

37. Cachelin FM, Rebeck RM, Chung GH, Pelayo E. Does ethnicity influence body-size preference? A comparison of body image and body size. Obes Res. 2002; 10(3):158-66. 
38. Cairney J, Hay JA, Faught BE, Wade TJ, Corna L, Flouris A. Developmental coordination disorder, generalized self-efficacy toward physical activity, and participation in organized and free play activities. J Pediatr. 2005; 147(4):515-20.

39. Caldwell CH, Zimmerman MA, Bernat DH, Sellers RM, Notaro PC. Racial identity, maternal support, and psychological distress among African American adolescents. Child Dev. 2002; 73(4):1322-36.

40. Cauce AM, Hiraga Y, Graves D, Gonzales N, Ryan-Finn K, Grove K. African American mothers and their adolescent daughters: Closeness, conflict, and control. Urban girls: Resisting stereotypes, creating identities. 1996:100-16.

41. Choi L, Liu Z, Matthews CE, Buchowski MS. Validation of accelerometer wear and nonwear time classification algorithm. Med Sci Sports Exerc. 2011; 43(2):357-64.

42. Cole DA, Martin JM, Peeke LG, Seroczynski A, Hoffman K. Are cognitive errors of underestimation predictive or reflective of depressive symptoms in children: A longitudinal study. J Abnorm Psychol. 1998; 107(3):481.

43. Crocker P, Bailey DA, Faulkner RA, Kowalski KC, McGRATH R. Measuring general levels of physical activity: preliminary evidence for the Physical Activity Questionnaire for Older Children. Med Sci Sports Exerc. 1997; 29(10):1344-9.

44. Cummings EM, Davies PT. Maternal depression and child development. J Child Psychol Psychiatr. 1994; 35(1):73-122.

45. Dabelea D, Bell RA, D'Agostino Jr RB, Imperatore G, Johansen JM, Linder B, Liu LL, Loots B, Marcovina S, Mayer-Davis EJ. Incidence of diabetes in youth in the United States. JAMA. 2007; 297(24):2716-24.

46. Darker C, French D, Eves F, Sniehotta F. An intervention to promote walking amongst the general population based on an 'extended'theory of planned behaviour: a waiting list randomised controlled trial. Psychol Health. 2010; 25(1):71-88.

47. Davison KK, Cutting TM, Birch LL. Parents' activity-related parenting practices predict girls' physical activity. Med Sci Sports Exerc. 2003; 35(9):1589-95.

48. De Leeuw E, Borgers N, Smits A. Pretesting questionnaires for children and adolescents. Methods for testing and evaluating survey questionnaires. 2004:409-29.

49. De Moor M, Beem A, Stubbe J, Boomsma D, De Geus E. Regular exercise, anxiety, depression and personality: a population-based study. Prev Med. 2006; 42(4):273-9.

50. Deckelbaum RJ, Williams CL. Childhood obesity: the health issue. Obes Res. 2001; 9(S11):239S-43S. 
51. Demarest J, Allen R. Body image: Gender, ethnic, and age differences. J Soc Psychol. 2000; 140(4):465-72.

52. DeMattia L, Lemont L, Meurer L. Do interventions to limit sedentary behaviours change behaviour and reduce childhood obesity? A critical review of the literature. Obes Rev. 2007; 8(1):69-81.

53. Dietz WH. Health consequences of obesity in youth: childhood predictors of adult disease. Pediatr. 1998; 101(Supplement 2):518-25.

54. Dishman RK, Hales DP, Pfeiffer KA, Felton GA, Saunders R, Ward DS, Dowda M, Pate RR. Physical self-concept and self-esteem mediate cross-sectional relations of physical activity and sport participation with depression symptoms among adolescent girls. Health Psychol. 2006; 25(3):396.

55. Dishman RK, Motl RW, Saunders R, Felton G, Ward DS, Dowda M, Pate RR. Selfefficacy partially mediates the effect of a school-based physical-activity intervention among adolescent girls. Prev Med. 2004; 38(5):628-36.

56. Dishman RK, Saunders RP, Motl RW, Dowda M, Pate RR. Self-efficacy moderates the relation between declines in physical activity and perceived social support in high school girls. J Pediatr Psychol. 2009; 34(4):441-51.

57. Dunn AL, Trivedi MH, Kampert JB, Clark CG, Chambliss HO. Exercise treatment for depression: efficacy and dose response. Am J Prev Med. 2005; 28(1):1-8.

58. Ebbeling CB, Pawlak DB, Ludwig DS. Childhood obesity: public-health crisis, common sense cure. The Lancet. 2002; 360(9331):473-82.

59. Ekeland E, Heian F, Hagen KB. Can exercise improve self esteem in children and young people? A systematic review of randomised controlled trials. Br J Sports Med. 2005; 39(11):792,8; discussion 792-8.

60. Elkin I, Shea MT, Watkins JT, Imber SD, Sotsky SM, Collins JF, Glass DR, Pilkonis PA, Leber WR, Docherty JP. National Institute of Mental Health Treatment of

Depression Collaborative Research Program. General effectiveness of treatments. Arch Gen Psychiatry. 1989; 46(11):971,82; discussion 983.

61. Emerson E, Donenberg GR, Wilson HW. Health-protective effects of attachment among African American girls in psychiatric care. J Fam Psychol. 2012; 26(1):124-132.

62. Epstein LH, Paluch RA, Gordy CC, Dorn J. Decreasing sedentary behaviors in treating pediatric obesity. Arch Pediatr Adolesc Med. 2000; 154(3):220-6.

63. Epstein LH, Smith JA, Vara LS, Rodefer JS. Behavioral economic analysis of activity choice in obese children. Health Psycholy. 1991; 10(5):311-316. 
64. Epstein LH, Valoski AM, Vara LS, McCurley J, Wisniewski L, Kalarchian MA, Klein KR, Shrager LR. Effects of decreasing sedentary behavior and increasing activity on weight change in obese children. Health Psychol. 1995; 14(2):109-115.

65. Evenson KR, Catellier DJ, Gill K, Ondrak KS, McMurray RG. Calibration of two objective measures of physical activity for children. J Sports Sci. 2008; 26(14):1557-65.

66. Ferrer-Caja E, Weiss MR. Predictors of intrinsic motivation among adolescent students in physical education. Res Q Exerc Sport. 2000; 71(3):267-79.

67. Finch Jr A, Saylor CF, Edwards GL, McIntosh JA. Children's Depression Inventory: Reliability over repeated administrations. J Clin Child Psychol. 1987; 16(4):339-41.

68. Folsom AR, Caspersen CJ, Taylor HL, Jacobs DR,Jr, Luepker RV, Gomez-Marin O, Gillum RF, Blackburn H. Leisure time physical activity and its relationship to coronary risk factors in a population-based sample. The Minnesota Heart Survey. Am J Epidemiol. 1985; 121(4):570-9.

69. Fox KR. The physical self and processes in self-esteem development. From Motivation to Well-Being. 1997.

70. Fox KR. The influence of physical activity on mental well-being. Public Health Nutr. 1999; 2(3a):411-8.

71. Fox KR. The effects of exercise on self-perceptions and self-esteem. Physical activity and psychological well-being. 2000; 13:81-118.

72. Garson GD. Fundamentals of hierarchical linear and multilevel modeling. GD Garson, Hierarchical linear modeling guide and applications.Raleigh, NC: North Carolina State University. Sage. 2013.

73. Goodman E, Whitaker RC. A prospective study of the role of depression in the development and persistence of adolescent obesity. Pediatr. 2002; 110(3):497-504.

74. Goran MI, Reynolds KD, Lindquist $\mathrm{CH}$. Role of physical activity in the prevention of obesity in children. Int J Obes. 1999; 23:S18-33.

75. Gordon-Larsen P, McMurray RG, Popkin BM. Adolescent physical activity and inactivity vary by ethnicity: The National Longitudinal Study of Adolescent Health. $J$ Pediatr. 1999; 135(3):301-6.

76. Gustafson SL, Rhodes RE. Parental correlates of physical activity in children and early adolescents. Sports Med. 2006; 36(1):79-97. 
77. Gutin B, Yin Z, Johnson M, Barbeau P. Preliminary findings of the effect of a 3-year after-school physical activity intervention on fitness and body fat: The Medical College of Georgia Fitkid Project. Int J Pediatr Obes. 2008; 3(S1):3-9.

78. Hahn-Smith AM, Smith JE. The positive influence of maternal identification on body image, eating attitudes, and self-esteem of Hispanic and Anglo girls. Int J Eat Disord. 2001; 29(4):429-40.

79. Hallal PC, Victora CG. Reliability and validity of the international physical activity questionnaire (IPAQ). Med Sci Sports Exerc. 2004; 36(3):556.

80. Hay JA. Adequacy in and predilection for physical activity in children. Clin J Sports Med. 1992; 2(3):192-201.

81. Hayden-Wade HA, Stein RI, Ghaderi A, Saelens BE, Zabinski MF, Wilfley DE. Prevalence, Characteristics, and Correlates of Teasing Experiences among Overweight Children vs. Non-overweight Peers. Obes Res. 2005; 13(8):1381-92.

82. Horn TS. Coaches' feedback and changes in children's perceptions of their physical competence. J Educ Psychol. 1985; 77(2):174.

83. Huang JS, Norman GJ, Zabinski MF, Calfas K, Patrick K. Body image and selfesteem among adolescents undergoing an intervention targeting dietary and physical activity behaviors. J Adolesc Health. 2007; 40(3):245-51.

84. Huang L, Tao FB, Wan YH, Xing C, Hao J, Su PY, Xing XY. Self-reported weight status rather than BMI may be closely related to psychopathological symptoms among Mainland Chinese adolescents. J Trop Pediatr. 2011; 57(4):307-11.

85. Janssen I, Katzmarzyk P, Boyce W, Vereecken C, Mulvihill C, Roberts C, Currie C, Pickett W. Comparison of overweight and obesity prevalence in school-aged youth from 34 countries and their relationships with physical activity and dietary patterns. Obes Rev. 2005; 6(2):123-32.

86. Jorga J, Marinković J, Kentrić B, Hetherington M. Alternative methods of nutritional status assessment in adolescents. Coll Antropol. 2007; 31(2):413-8.

87. Kann L, Kinchen S, Shanklin SL, Flint KH, Kawkins J, Harris WA, Lowry R, Olsen E, McManus T, Chyen D. Youth risk behavior surveillance—United States, 2013. MMWR Surveill Summ. 2014; 63(Suppl 4):1-168.

88. Kelder SH, Perry CL, Klepp KI, Lytle LL. Longitudinal tracking of adolescent smoking, physical activity, and food choice behaviors. Am J Public Health. 1994; 84(7):1121-6. 
89. Kelly N, Bulik C, Mazzeo S. An exploration of body dissatisfaction and perceptions of Black and White girls enrolled in an intervention for overweight children. Body Image. $2011 ; 8(4): 379-84$.

90. Kimm SY, Glynn NW, Kriska AM, Barton BA, Kronsberg SS, Daniels SR, Crawford PB, Sabry ZI, Liu K. Decline in physical activity in black girls and white girls during adolescence. $N$ Engl J Med. 2002; 347(10):709-15.

91. Klesges LM, Baranowski T, Beech B, Cullen K, Murray DM, Rochon J, Pratt C. Social desirability bias in self-reported dietary, physical activity and weight concerns measures in 8-to 10-year-old African-American girls: results from the Girls Health Enrichment Multisite Studies (GEMS). Prev Med. 2004; 38:78-87.

92. Kohl HW, Hobbs KE. Development of physical activity behaviors among children and adolescents. Pediatr. 1998; 101(Supplement 2):549-54.

93. Kostanski M, Gullone E. Adolescent body image dissatisfaction: relationships with self-esteem, anxiety, and depression controlling for body mass. J Child Psychol Psychiatr. 1998; 39(2):255-62.

94. Kovacs M. Rating scales to assess depression in school-aged children. Acta Paedopsychiatrica: International Journal of Child \& Adolescent Psychiatry. 1981.

95. Kowalski KC, Crocker P, Faulkner RA. Validation sf the physical activity questionnaire for older children. Pediatr Exerc Sci. 1997; 9(4):174-86.

96. Kumanyika SK, Morssink CB. Cultural appropriateness of weight management programs. Overweight and Weight Management: The Health Professional's Guide To Understanding and Practice.Gaithersburg, MD: Aspen Publishers. 1997:69-103.

97. Larun L, Nordheim L, Ekeland E, Hagen K, Heian F. Exercise in prevention and treatment of anxiety and de-pression among children and young people. Cochrane Database of Syst Rev. 2006; 4.

98. Lau RR, Quadrel MJ, Hartman KA. Development and change of young adults' preventive health beliefs and behavior: influence from parents and peers. J Health Soc Behav. 1990:240-59.

99. Lawler M, Nixon E. Body dissatisfaction among adolescent boys and girls: the effects of body mass, peer appearance culture and internalization of appearance ideals. $J$ Youth Adolesc. 2011; 40(1):59-71.

100. Loeb RC, Horst L, Horton PJ. Family interaction patterns associated with selfesteem in preadolescent girls and boys. Merrill-Palmer Q Behav Dev. 1980:205-17. 
101. Love KM. Parental attachments and psychological distress among African American college students. J Coll Stud Dev. 2008; 49(1):31-40.

102. Maffeis C, Tato L. Long-term effects of childhood obesity on morbidity and mortality. Horm Res. 2001; 55 Suppl 1:42-5.

103. Matthews CE, Chen KY, Freedson PS, Buchowski MS, Beech BM, Pate RR, Troiano RP. Amount of time spent in sedentary behaviors in the United States, 20032004. Am J Epidemiol. 2008; 167(7):875-81.

104. Mattocks C, Ness AR, Leary SD, Tilling K, Blair SN, Shield J, Deere K, Saunders J, Krikby J, Smith GD. Use of accelerometers in a large field-based study of children: protocols, design issues, and effects on precision. J Phys Act Health. 2008; 5(Supplement 1):S98.

105. Mcguire MT, Hannan PJ, Neumark-Sztainer D, Cossrow NHF, Story M. Parental correlates of physical activity in a racially/ethnically diverse adolescent sample. $J$ Adolesc Health. 2002; 30(4):253-61.

106. Miller CT, Downey KT. A meta-analysis of heavyweight and self-esteem. Pers Soc Psychol Rev. 1999; 3(1):68-84.

107. Mokdad AH, Ford ES, Bowman BA, Dietz WH, Vinicor F, Bales VS, Marks JS. Prevalence of obesity, diabetes, and obesity-related health risk factors, 2001. JAMA. $2003 ; 289(1): 76-9$.

108. Molloy BL, Herzberger SD. Body image and self-esteem: A comparison of AfricanAmerican and Caucasian women. Sex Roles. 1998; 38(7-8):631-43.

109. Moore LL, Lombardi DA, White MJ, Campbell JL, Oliveria SA, Ellison RC. Influence of parents' physical activity levels on activity levels of young children. $J$ Pediatr. 1991; 118(2):215-9.

110. Mosavel M, Simon C, Van Stade D. The Mother-Daughter Relationship: What Is Its Potential as a Locus for Health Promotion? Health Care Women Int. 2006; 27(7):646-64.

111. Motl RW, Birnbaum AS, Kubik MY, Dishman RK. Naturally occurring changes in physical activity are inversely related to depressive symptoms during early adolescence. Psychosom Med. 2004; 66(3):336-42.

112. Motl RW, Dishman RK, Saunders RP, Dowda M, Felton G, Ward DS, Pate RR. Examining social-cognitive determinants of intention and physical activity among black and white adolescent girls using structural equation modeling. Health Psychol. 2002; 21(5):459-467. 
113. Nader PR, Bradley RH, Houts RM, McRitchie SL, O’Brien M. Moderate-tovigorous physical activity from ages 9 to 15 years. JAMA. 2008; 300(3):295-305.

114. Nelson MC, Neumark-Stzainer D, Hannan PJ, Sirard JR, Story M. Longitudinal and secular trends in physical activity and sedentary behavior during adolescence. Pediatr. 2006; 118(6):e1627-34.

115. Norman GJ, Schmid BA, Sallis JF, Calfas KJ, Patrick K. Psychosocial and environmental correlates of adolescent sedentary behaviors. Pediatr. 2005; 116(4):90816.

116. Norris R, Carroll D, Cochrane R. The effects of physical activity and exercise training on psychological stress and well-being in an adolescent population. J Psychosom Res. 1992; 36(1):55-65.

117. Ogden CL, Carroll MD, Kit BK, Flegal KM. Prevalence of childhood and adult obesity in the United States, 2011-2012. JAMA. 2014; 311(8):806-14.

118. Ogden CL, Carroll MD, Kit BK, Flegal KM. Prevalence of obesity and trends in body mass index among US children and adolescents, 1999-2010. JAMA. 2012; 307(5):483-90.

119. Ogden CL, Kuczmarski RJ, Flegal KM, Mei Z, Guo S, Wei R, Grummer-Strawn LM, Curtin LR, Roche AF, Johnson CL. Centers for Disease Control and Prevention 2000 growth charts for the United States: improvements to the 1977 National Center for Health Statistics version. Pediatr. 2002; 109(1):45-60.

120. O'Loughlin J, Paradis G, Kishchuk N, Barnett T, Renaud L. Prevalence and correlates of physical activity behaviors among elementary schoolchildren in multiethnic, low income, inner-city neighborhoods in Montreal, Canada. Ann Epidemiol. 1999; 9(7):397-407.

121. Olvera N, Bush JA, Sharma SV, Knox BB, Scherer RL, Butte NF. BOUNCE: A Community-based Mother-daughter Healthy Lifestyle Intervention for Low-income Latino Families. Obesity. 2010; 18(S1):S102-4.

122. Pate RR, Stevens J, Pratt C, Sallis JF, Schmitz KH, Webber LS, Welk G, Young DR. Objectively measured physical activity in sixth-grade girls. Arch Pediatr Adolesc Med. 2006; 160(12):1262-8.

123. Prochaska JJ, Rodgers MW, Sallis JF. Association of parent and peer support with adolescent physical activity. Res $Q$ Exerc Sport. 2002; 73(2):206-10.

124. Puhl RM, Latner JD. Stigma, obesity, and the health of the nation's children. Psychol Bull. 2007; 133(4):557. 
125. Qualter P, Brown SL, Munn P, Rotenberg KJ. Childhood loneliness as a predictor of adolescent depressive symptoms: an 8-year longitudinal study. Eur Child Adolesc Psychiatry. 2010; 19(6):493-501.

126. Rakowski W. The potential variances of tailoring in health behavior interventions. Annals of Behavioral Medicine. 1999; 21(4):284-9.

127. Ransdell LB, Dratt J, Kennedy C, O'Neill S, DeVoe D. Daughters and mothers exercising together (DAMET): A 12-week pilot project designed to improve physical self-perception and increase recreational physical activity. Women Health. 2001; 33(34):113-29.

128. Ransdell LB, Robertson L, Ornes L, Moyer-Mileur L. Generations exercising together to improve fitness (GET FIT): a pilot study designed to increase physical activity and improve health-related fitness in three generations of women. Women Health. 2005; 40(3):77-94.

129. Ransdell LB, Taylor A, Oakland D, Schmidt J, Moyer-Mileur L, Shultz B. Daughters and mothers exercising together: effects of home-and community-based programs. Med Sci Sports Exerc. 2003; 35(2):286-96.

130. Rastogi M, Wampler KS. Adult daughters' perceptions of the mother-daughter relationship: A cross-cultural comparison. Family Relat. 1999:327-36.

131. Reed M, Dancy B, Holm K, Wilbur J, Fogg L. Eating behaviors among early adolescent African American girls and their mothers. J Sch Nurs. 2013; 29(6):452-63.

132. Rennie KL, Johnson L, Jebb SA. Behavioural determinants of obesity. Best Pract Res Clin Endocrinol Metab. 2005; 19(3):343-58.

133. Rexrode KM, Manson JE, Hennekens $\mathrm{CH}$. Obesity and cardiovascular disease. Curr Opin Cardiol. 1996; 11(5):490-5.

134. Rey-Lopez JP, Vicente-Rodríguez G, Biosca M, Moreno LA. Sedentary behaviour and obesity development in children and adolescents. Nutr Metab Cardiovasc Dis. 2008; 18(3):242-51.

135. Rhee KE, Lumeng JC, Appugliese DP, Kaciroti N, Bradley RH. Parenting styles and overweight status in first grade. Pediatr. 2006; 117(6):2047-54.

136. Ricciardelli LA, McCabe MP. Children's body image concerns and eating disturbance: a review of the literature. Clin Psychol Rev. 2001; 21(3):325-44.

137. Richardson LP, Davis R, Poulton R, McCauley E, Moffitt TE, Caspi A, Connell F. A longitudinal evaluation of adolescent depression and adult obesity. Arch Pediatr Adolesc Med. 2003; 157(8):739-45. 
138. Riddoch CJ, Andersen LB, Wedderkopp N, Harro M, Klasson-Heggebo L, Sardinha LB, Cooper AR, Ekelund U. Physical activity levels and patterns of 9-and 15-yr-old European children. Med Sci Sports Exerc. 2004; 36(1):86-92.

139. Ritchie LD, Sharma S, Ikeda JP, Mitchell RA, Raman A, Green BS, Hudes ML, Fleming SE. Study protocol Taking Action Together: A YMCA-based protocol to prevent Type-2 Diabetes in high-BMI inner-city African American children. Trials. 2010; 11(60).

140. Robinson L, Webster E, Whitt-Glover M, Ceaser T, Alhassan S. Effectiveness of pre-school-and school-based interventions to impact weight-related behaviours in African American children and youth: a literature review. Obes Rev. 2014; 15(S4):5-25.

141. Robinson TN, Killen JD, Kraemer HC, Wilson DM, Matheson DM, Haskell WL, Pruitt LA, Powell TM, Owens A, Thompson N. Dance and reducing television viewing to prevent weight gain in African-American girls: the Stanford GEMS pilot study. Ethn Dis. 2003; 13(1; SUPP/1):S1-65.

142. Robinson TN, Matheson DM, Kraemer HC, Wilson DM, Obarzanek E, Thompson NS, Alhassan S, Spencer TR, Haydel KF, Fujimoto M. A randomized controlled trial of culturally tailored dance and reducing screen time to prevent weight gain in low-income African American girls: Stanford GEMS. Arch Pediatr Adolesc Med. 2010; 164(11):9951004.

143. Rothon C, Edwards P, Bhui K, Viner RM, Taylor S, Stansfeld SA. Physical activity and depressive symptoms in adolescents: a prospective study. BMC Med. 2010; 8(1):32.

144. Sallis JF, Pinski RB, Grossman RM, Patterson TL, Nader PR. The development of self-efficacy scales for healthrelated diet and exercise behaviors. Health Educ Res. 1988; 3(3):283-92.

145. Sallis JF, Prochaska JJ, Taylor WC. A review of correlates of physical activity of children and adolescents. Med Sci Sports Exerc. 2000; 32(5):963-75.

146. Schmitz KH, Lytle LA, Phillips GA, Murray DM, Birnbaum AS, Kubik MY. Psychosocial correlates of physical activity and sedentary leisure habits in young adolescents: the Teens Eating for Energy and Nutrition at School study. Prev Med. 2002; 34(2):266-78.

147. Shisslak CM, Renger R, Sharpe T, Crago M, McKnight KM, Gray N, Bryson S, Estes LS, Parnaby OG, Killen J. Development and evaluation of the McKnight Risk Factor Survey for assessing potential risk and protective factors for disordered eating in preadolescent and adolescent girls. Int J Eat Disord. 1999; 25(2):195-214. 
148. Simons-Morton BG, Parcel GS, Baranowski T, Forthofer R, O'Hara NM. Promoting physical activity and a healthful diet among children: results of a school-based intervention study. Am J Public Health. 1991; 81(8):986-91.

149. Singh AS, Mulder C, Twisk JW, Van Mechelen W, Chinapaw MJ. Tracking of childhood overweight into adulthood: a systematic review of the literature. Obes Rev. 2008; 9(5):474-88.

150. Smith R, Smoll F. The coach as a focus of research and intervention in youth sports. Children and youth in sport: A biopsychosocial perspective. 1996:125-41.

151. Snyder TD, Dillow SA. Digest of Education Statistics 2011. National Center for Education Statistics; 2012.

152. Spruijt-Metz D, Nguyen-Michel ST, Goran MI, Chou C, Huang TT. Reducing sedentary behavior in minority girls via a theory-based, tailored classroom media intervention. Int J Pediatr Obes. 2008; 3(4):240-8.

153. Srinivasan SR, Myers L, Berenson GS. Predictability of childhood adiposity and insulin for developing insulin resistance syndrome (syndrome X) in young adulthood: the Bogalusa Heart Study. Diabetes. 2002; 51(1):204-9.

154. Steinberger J, Daniels SR, American Heart Association Atherosclerosis, Hypertension, and Obesity in the Young Committee (Council on Cardiovascular Disease in the Young), American Heart Association Diabetes Committee (Council on Nutrition, Physical Activity, and Metabolism). Obesity, insulin resistance, diabetes, and cardiovascular risk in children: an American Heart Association scientific statement from the Atherosclerosis, Hypertension, and Obesity in the Young Committee (Council on Cardiovascular Disease in the Young) and the Diabetes Committee (Council on Nutrition, Physical Activity, and Metabolism). Circulation. 2003; 107(10):1448-53.

155. Stockton MB, Lanctot JQ, McClanahan BS, Klesges LM, Klesges RC, Kumanyika S, Sherrill-Mittleman D. Self-perception and body image associations with body mass index among 8-10-year-old African American girls. J Pediatr Psychol. 2009; 34(10):1144-54.

156. Story M, Sherwood NE, Himes JH, Davis M, Jacobs D, Cartwright Y, Smyth M, Rochon J. An after-school obesity prevention program for African-American girls: the Minnesota GEMS pilot study. Ethn Dis. 2003; 13(1; SUPP/1):S1-54.

157. Strauss RS. Childhood obesity and self-esteem. Pediatr. 2000; 105(1):e15.

158. Strauss RS, Rodzilsky D, Burack G, Colin M. Psychosocial correlates of physical activity in healthy children. Arch Pediatr Adolesc Med. 2001; 155(8):897-902. 
159. Ströhle A. Physical activity, exercise, depression and anxiety disorders. J Neural Transm. 2009; 116(6):777-84.

160. Strong WB, Malina RM, Blimkie CJ, Daniels SR, Dishman RK, Gutin B, Hergenroeder AC, Must A, Nixon PA, Pivarnik JM. Evidence based physical activity for school-age youth. J Pediatr. 2005; 146(6):732-7.

161. Stunkard AJ, Sorensen T, Schulsinger F. Use of the Danish Adoption Register for the study of obesity and thinness. Res Publ Assoc Res Nerv Ment Dis. 1983; 60:115-20.

162. Summerbell CD, Waters E, Edmunds L, Kelly S, Brown T, Campbell KJ. Interventions for preventing obesity in children. Cochrane Database Syst Rev. 2005; 3(3).

163. Taylor WC, Baranowski T, Sallis JF. Family determinants of childhood physical activity: a social-cognitive model. Adv Exerc Adher. 1994.

164. Telama R, Yang X, Viikari J, Välimäki I, Wanne O, Raitakari O. Physical activity from childhood to adulthood: a 21-year tracking study. Am J Prev Med. 2005; 28(3):26773.

165. Thompson DL, Rakow J, Perdue SM. Relationship between accumulated walking and body composition in middle-aged women. Med Sci Sports Exerc. 2004; 36(5):911-4.

166. Tremblay MS, Inman JW, Willms JD. The relationship between physical activity, self-esteem, and academic achievement in 12-year-old children. Pediatr Exerc Sci. 2000; 12(3):312-23.

167. Treuth MS, Hou N, Young DR, Maynard LM. Accelerometry-Measured Activity or Sedentary Time and Overweight in Rural Boys and Girls. Obes Res. 2005; 13(9):160614.

168. Troiano RP, Berrigan D, Dodd KW, Mâsse LC, Tilert T, McDowell M. Physical activity in the United States measured by accelerometer. Med Sci Sports Exerc. 2008; 40(1):181-188.

169. Trost SG, Kerr L, Ward DS, Pate RR. Physical activity and determinants of physical activity in obese and non-obese children. Int J Obes Relat Metab Disord. 2001; 25(6):822-9.

170. Trost SG, Loprinzi PD. Parental influences on physical activity behavior in children and adolescents: a brief review. Am J Lifestyle Med. 2011; 5(2):171-81.

171. Trost SG, Pate RR, Saunders R, Ward DS, Dowda M, Felton G. A prospective study of the determinants of physical activity in rural fifth-grade children. Prev Med. 1997; 26(2):257-63. 
172. Trost SG, Pate RR, Ward DS, Saunders R, Riner W. Determinants of Physical Activity in Active and Low-Active, Sixth Grade African-American Youth. J Sch Health. 1999; 69(1):29-34.

173. Trost SG, Rosenkranz RR, Dzewaltowski D. Physical activity levels among children attending after-school programs. Med Sci Sports Exerc. 2011; 40(4) 622-9.

174. Trost SG, Sallis JF, Pate RR, Freedson PS, Taylor WC, Dowda M. Evaluating a model of parental influence on youth physical activity. Am J Prev Med. 2003; 25(4):27782.

175. Tucker P, Gilliland J. The effect of season and weather on physical activity: a systematic review. Public Health. 2007; 121(12):909-22.

176. Turnage BF. African American mother-daughter relationships mediating daughter's self-esteem. Child Adolescent Soc Work J. 2004; 21(2):155-73.

177. US Department of Health and Human Services, US Department of Health and Human Services. Physical activity guidelines for Americans. 2008.

178. van den Berg, Patricia A, Mond J, Eisenberg M, Ackard D, Neumark-Sztainer D. The link between body dissatisfaction and self-esteem in adolescents: Similarities across gender, age, weight status, race/ethnicity, and socioeconomic status. J Adoelsc Health 2010; 47(3):290-6.

179. Van der Horst K, Paw M, Twisk JW, Van Mechelen W. A brief review on correlates of physical activity and sedentariness in youth. Med Sci Sports Exerc. 2007; 39(8):1241.

180. Wadden TA, Stunkard AJ, Rich L, Rubin CJ, Sweidel G, McKinney S. Obesity in black adolescent girls: a controlled clinical trial of treatment by diet, behavior modification, and parental support. Pediatr. 1990; 85(3):345-52.

181. Wardle J, Cooke L. The impact of obesity on psychological well-being. Best Pract Res Clin Endocrinol Metab. 2005; 19(3):421-40.

182. Weiss MR. Motivating kids in physical activity. President's Council on Physical Fitness and Sports Research Digest. 2000.

183. Williamson DF, Madans J, Anda RF, Kleinman JC, Kahn HS, Byers T. Recreational physical activity and ten-year weight change in a US national cohort. Int J Obes Relat Metab Disord. 1993; 17(5):279-86.

184. Witherspoon D, Latta L, Wang Y, Black MM. Do Depression, Self-Esteem, BodyEsteem, and Eating Attitudes Vary by BMI Among African American Adolescents? J Pediatr Psychol. 2013; 38(10):1112-20. 
185. Worsley A, Coonan W, Leitch D, Crawford D. Slim and obese children's perceptions of physical activities. Int J Obes. 1984; 8(3):201-11.

186. Yang XL, Telama R, Laakso L. Parents' physical activity, socioeconomic status and education as predictors of physical activity and sport among children and youths-A 12year follow-up study. Int Rev Social Sport 1996; 31(3):273-91.

187. Yates A, Edman J, Aruguete M. Ethnic differences in BMI and body/selfdissatisfaction among Whites, Asian subgroups, Pacific Islanders, and AfricanAmericans. J Adolesc Health. 2004; 34(4):300-7.

188. Yin Z, Gutin B, Johnson MH, Hanes J, Moore JB, Cavnar M, Thornburg J, Moore D, Barbeau P. An environmental approach to obesity prevention in children: Medical College of Georgia FitKid Project year 1 results. Obes Res. 2005; 13(12):2153-61.

189. Yin Z, Moore JB. RE-EXAMINING THE ROLE OF INTERSCHOLASTIC SPORT PARTICIPATI Re-examining the role of interscholastic sport participation in education 1. Psychol Rep. 2004; 94(3c):1447-54. 


\section{Appendix A}

\section{STUDY FLYER}

\section{Do you like to Dance?}

Join us in a free $\&$ fun after-school dance program for women of color $\&$ their daughter(s)

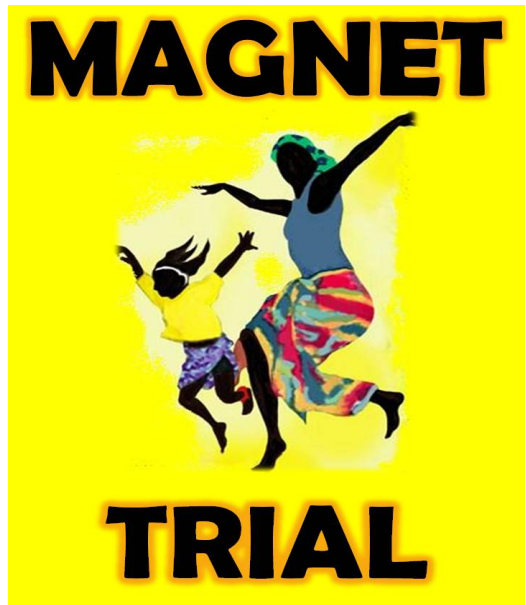

Mothers $\underline{\text { And }}$ Girls DaNcing togETher Program

The 12-week program will start on January 13, 2014 for 3 days per week at Rebecca M. Johnson Elementary School (55 Catherine Street, Springfield, MA).

\section{A fun dance program for girls of color and their moms}

If you and your daughter are interested, please contact us

- Phone: (413) 545-6104

- Email: magnet.trial@gmail.com

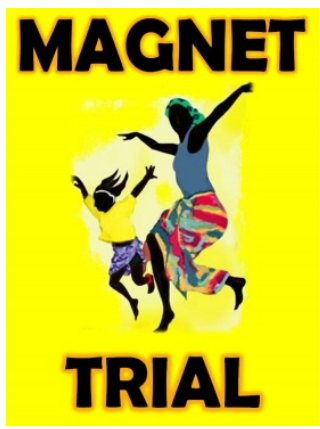

Mothers 므d Girls Da№ing togETher Trial

*MAGNET TRIAL*

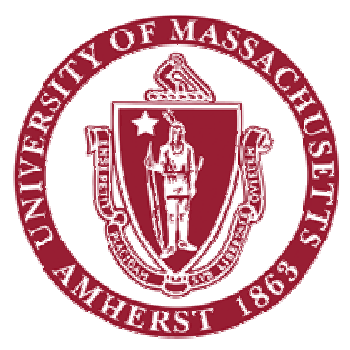


We are studying the use of African style dancing on the health of girls of color (Ages 7 - 10) and their mothers.

We define "mother" as the primary mother figure who lives with the girl.

\section{What is involved......}

1. All girls will receive 1 hour of homework tutoring each day of the 12 -week program.

2. You and your daughter will be assigned randomly (like tossing a coin) to be part of either

a. Mother/guardian - Daughter after school dance program

b. Daughter alone after school dance program

c. Health education program

3. To help us understand how the program works, you and your daughter...

a. Will be asked to complete surveys

b. Will be asked to wear an activity monitor on your waist to measure your physical activity level

c. Will be asked to have your weight and height measured

d. Your daughter's insulin and cholesterol levels will also be measured

4. For taking part of this program you and your daughter will receive a total of $\$ 140$

Parent/Guardian - If you and your daughter are interested, please contact MAGNET Staff by
1. Phone: (413) 545-6104
2. Email: magnet.trial@gmail.com

OR

8

Child's Name: Parent Name:

Phone/Email: Child's Birth Date 


\section{APPENDIX B}

\section{MAGNET SCREENING}

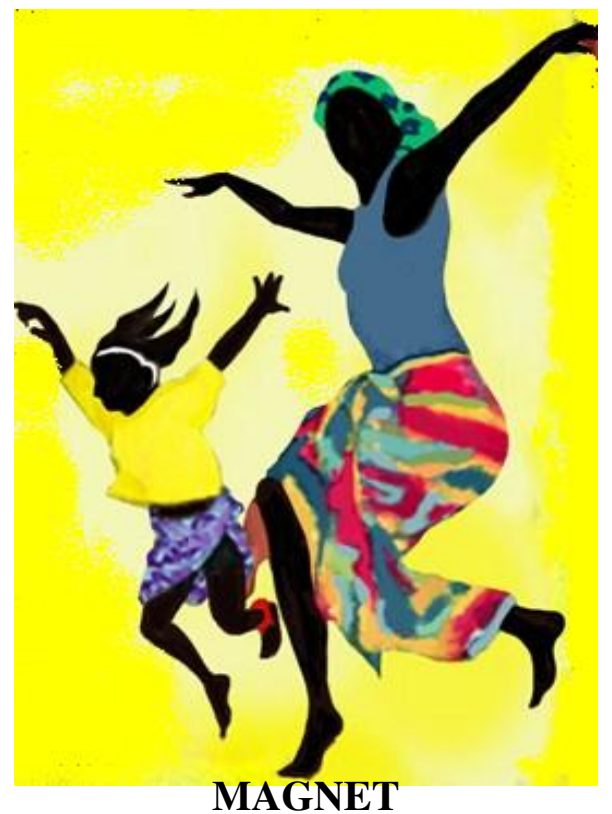

Today's Date: 120

To be eligible for this study, we need to determine the following during the screener.

- Age: Girl is 7 years or older, but has not had her $11^{\text {th }}$ birthday.

- Ethnicity: Parent/caregiver considers girl to be Black or African American.

- No medical conditions that are exclusionary

- No medications that are exclusionary

- Child is able to participate in PE

- Child reads and speaks English

- Parent/Caregiver reads and speaks English

- Mother (primary maternal figure living with the girl has to agree to also participate in study and willing to be randomized into any of 3 groups

If NOT eligible (at any time during screening), read:

"I'm sorry, but based upon your answers to these questions, you and your daughter won't be eligible to participate in this study. Unfortunately, because this study is part of a federally-funded program, we are not allowed to include girls who do not meet all of the 
eligibility requirements. I appreciate your taking the time to answer these questions. Thank you very much."

\section{Opening Script}

Hello, this is <<interviewer name > calling from the UMass MAGNET program. May I please speak with the mother of $<<$ girl's name $>>$ ?

If not home: When would be a good time for me to reach her?

If home: Hello, my name is <<interviewer name>> and I am calling from the UMass MAGNET project. MAGNET stands for Mothers and Girls DaNcing togETher Trial. We are a health education study for girls in grades 2,3 , and 4 . I am calling because you have a daughter who may be eligible for our study. We are we are interested to learn whether an after-school Afro-centric dance program, where girls participate with their mothers, is as effective as a more traditional health education program.

Do you have 5 minutes to talk to me?

Our 12-week study involves completing surveys and taking measures at the beginning, at 6 weeks, and then at 12 weeks. During these 12 weeks, girls and their mother will get to participate in one of three different programs to help them stay healthy. One program includes an Afro-centric after school dance program where girls dance with their mother. In the second program, girls will participate in an after school dance program, while their mother participates in a health education program. In the third program, girls and their mother participate in a health education program together. The dance classes will be held at local venue in the Springfield area. Each family will be randomly selected to participate in one of the groups. This means your chances of being assigned to one of the groups are equal. As part of the program, we will also be taking a small blood sample (about 2 spoonfuls) from your daughter by a trained individual.

Each family participating in UMass MAGNET program will also be paid for their time, effort, and participation for a total of \$100 if all measures are completed over the 12week study. You daughter will also be paid $\$ 40$ for participating in both blood draws.

If you think you might be interested, I have several questions that will help us determine if your daughter is eligible to participate in UMass MAGNET.

Do you think you might be interested?

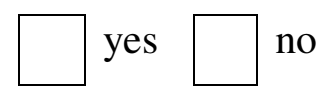

$(\mathrm{Y} / \mathrm{N})$

If NO: Thank you very much for your time. If you change your mind, you can contact our program at (413) 545-6104.

If YES: Great (or some other encouragement.) Your responses to these screening questions are completely voluntary. However, certain questions must be answered to determine your eligibility for the MAGENT program. If you choose not to answer them, it will in no way affect your future associations with other programs at UMass. 
Everything you tell me will be kept confidential and your answers will be seen only by our research staff. These questions take about 10-15 minutes. 


\section{PERSONAL INFORMATION}

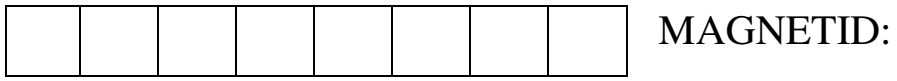

Today's Date: 120

** How many Daughters do you want to enroll in the program?

NOTE: A different screen MUST be used for each daughter.

1. What is $<<$ girl's name $>>$ birthdate? 120

Age? (7 to 10.9 years eligible)

Cohort 1 (11/15/2012) - Born between 11/18/2001 and 11/15/2005

2. To which of the following races do you consider $<<$ girl's name $>>$ to belong? You may choose all that apply.

$\square 1$ Black or African American

$\square 2$ White

$\square 3$ American Indian or Alaska Native

$\square 4$ Asian

$\square 5$ Native Hawaiian or Other Pacific Islander

$\square 6$ Other (Please specify):

3. In addition, do you also consider $<<$ girl's name $>>$ to belong to any of the following ethnic groups? You may choose all that apply.

$\square 1$ Mexican, Mexican American or Chicano

2 Puerto Rican

$\square 3$ Cuban 


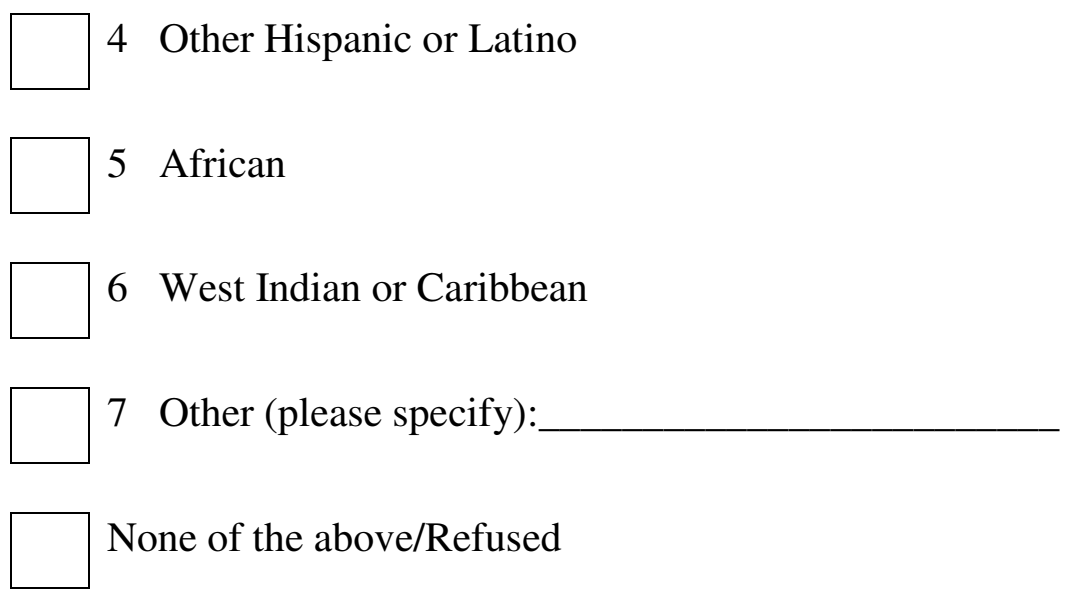

\section{MEDICAL ELIGIBILITY}

\section{Please ask the following questions to the parent or caregiver:}

*Does <<girl's name>> have any past or current medical problems?

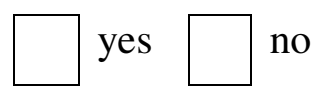

If "yes", can you please tell me what they are?

[Do not read list below, check items if interviewee volunteers them in response to the above question]

a. Diagnosed with a genetic or metabolic disease/syndrome associated with obesity:

$\square$ Alstrom-Hallgren syndrome

Brain

tumor/craniopharyngioma

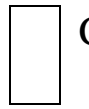

Carpenter syndrome

$\square$ Cohen syndrome

$\square$ Cushing syndrome

Down syndrome

$\square$ Growth hormone deficiency

b. Diabetes
Hypothyroiditis

Insulin secreting pancreatic tumor

Lawrence-Moon-Beidl (Bardet-Biedl) syndrome

Polycystic overy (Stein-Leventhal) syndrome

Prader-Willi syndrome

Pseudo-hypoparathyroidism type 1

Turner syndrome 


\footnotetext{
$\square$ Type 1 (insulin dependent)

$\square$ Type 2 and taking medication

$\square$ Type 2 - NOT taking medication (Eligible)

c. Chronic Kidney (Renal) Diseases:

Nephrotic syndrome

$\square$ Nephritis

$\square$ Kidney transplant

d. Heart Diseases:
}

$\square$ Structural heart disease/Congenital heart disease (uncorrected)

Heart failure

$\square$ Heart transplant

e. Eating Disorders (past or present):

Anorexia nervosa

Bulimia nervosa

Binge eating disorder

f. AIDS and/or HIV infection If, yes, check here

g. Pregnancy

If, yes, check here

Girl is eligible if NONE of the items in a.- g. are checked.

\section{MEDICATION ELIGIBILITY}

Please ask the following questions to the parent or caregiver: 
Has $<<$ girl's name $>>$ taken any medications in the past year?

If "yes", can you list them for me?

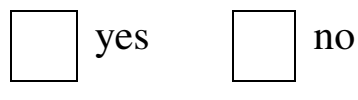

[Do not read list below, check items if interviewee volunteers them in response to the above question]

a. Inhaled

\section{Steroids Eligible}

b. Steroids taken by pills or liquid:

IF YES: How long did she take them, and when?

$\square$ Less than or equal to 2 weeks in past year: Eligible

More than 2 weeks in past year: Ineligible

$\square$ betamethasone (celestone)

$\square \begin{aligned} & \text { methylprednisolone(medrol, solumedrol, depo- } \\ & \text { medrol) }\end{aligned}$

$\square$ cortisone (cortone)

$\square$ prednisolone (prelone, pediapred, deltacortef)

dexamethasone (decadron, dexone, hexadrol)

$\square$ prednisone (deltasone, liquid pred, orasone)

fludrocortisone (florinef)

hydrocortisone (cortef, hydrocortone)

c. Steroids taken by injection (IV,VIM):

IF YES: How long did she take them, and when?

$\square$ Less than or equal to 2 weeks in past year: Eligible

$\square$ More than 2 weeks in past year: Ineligible

$\square$

betamethasone (celestone)

$\square$ cortisone (cortone)

dexamethasone (decadron, dexone, medrol)

$\square$ prednisolone (prelone, pediapred, delta-cortef)

prednisone (deltasone, liquid pred, orasone) 
hexadrol)

$\square$ fludrocortisone (florinef) hydrocortisone (cortef, hydrocortone)

d. Insulin injections:

$\square$ humulin $\square$ humalog $\square$ iletin $\square$ novalin $\square$ velosulin

e. Oral Antidiabetic Drugs:

$\square$ acarbose (precose)

$\square$ metformin (glucophage) $\square$ tolazimide (tolinase)

$\square$ chlorpropamide (diabinese)

$\square$ pioglitazone (Actos) $\square$ tolbutamide (orinase)

$\square$ X glipizide (glucotrol, glucotrol XL, glynase, micronase)

$\square$ r
repaglinide (prandin)

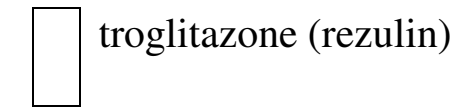

$\square$ glyburide (diabeta) $\square$ rosiglitazone (Avandia)

f. Thyroid hormones:

$\square$ liothronine sodium (cytomel)

$\square$ propylthiouracil

levothyroxine sodium (levothyroid, levoxyl, synthroid)

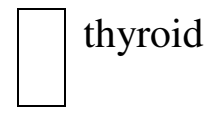

methimazole (tapazole)

g. Growth Hormone Injections:

sermorelin (geref)

somatropin (genotropin, humatrope, norditropin,nutropin, protropin, saizen, serostim)

sumatrem (protropin)

Girl is eligible If all of the below:

- NO steroids (pills, liquids, IV,VIM) have been taken for more than 2 weeks in past year

- NONE of the items in d.-g. are checked 


\section{OTHER ELIGIBILITY CRITERIA}

Is << girl's name>> able to participate in Physical Education (PE) at school?

(If PE is not offered, ask: "Would $<<$ girl's name $>>$ be able to participate in PE if it were offered?")

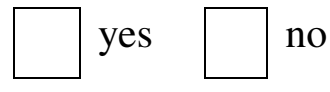

Does <<girl's name >> read and speak English?

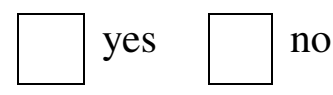

Does the parent read and speak English? (DO NOT READ QUESTION TO

PARENT, ANSWER QUESTION BASE ON PARENT'S INTERACTION WITH DATA COLLECTOR)

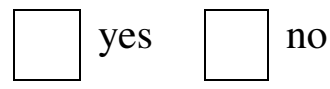




\section{SUMMARY}

Considering only the screening eligibility criteria, does this girl satisfy the MAGNET eligibility requirements?

- Age: Girl is 7 years or older, but has not had her $11^{\text {th }}$ birthday.

- Ethnicity: Parent/caregiver considers girl to be Black or African American.

- No medical conditions that are exclusionary

- No medications that are exclusionary

- Child is able to participate in PE

- Child reads and speaks English

- Parent/Caregiver reads and speaks English

If eligible, read to parent/caregiver (depending on level of eligibility, alter how the first paragraph is read appropriately):

"Based on your answers to these questions, it looks like <<girl's name $>>$ will / MAY be eligible to participate.

The next step in this screening process is to schedule a visit that will take place in a health clinic in Springfield or your home. The purpose of this visit is to get you and your daughter to sign the informed consent and assent documents and to complete the baseline surveys. The visit will take about 2 hours.

We want to make this as easy as possible for you, so we can schedule this next appointment at a time that is most convenient for you and your daughter.

Do you have questions?" 


\section{INFORMED CONSENT \& BASELINE ASSESSMENT VISIT}

Did the girl and her parent/caregiver agree to schedule a visit?

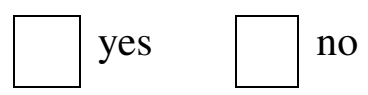

a. If YES, scheduled date for Baseline

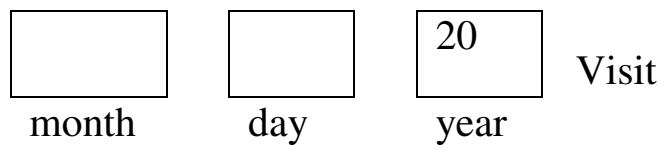

b. Time for Baseline Visit

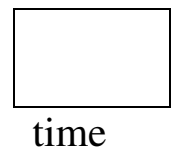

$\mathrm{AM}$

c. Parent First and Last Name:

\begin{tabular}{|l|l|}
\hline First Name & Last Name \\
\hline & \\
\hline
\end{tabular}

d. Girl's Name

\begin{tabular}{|l|l|}
\hline Girl(s) First Name & Girl(s) Last Name \\
\hline & \\
\hline & \\
\hline & \\
\hline
\end{tabular}

e. Relationship to girl(s):

f. Mailing Address:

\begin{tabular}{|l|}
\hline \\
\hline \\
\hline \\
\hline
\end{tabular}

g. Phone numbers:

\begin{tabular}{|l|ll|}
\hline Home number & $(\quad)$ & - \\
\hline Work number & $(\quad)$ & - \\
\hline Cell & $(\quad)$ & - \\
\hline Email address & & \\
\hline
\end{tabular}




\section{APPENDIX C}

\section{ASSENT SCRIPT}

\section{Mothers and Girls DaNcing togETher Trial (Magnet Trial)}

$\mathrm{Hi}<<$ insert child's name >>, my name is <<insert person obtaining Assent name >>. I am here to talk to you about a program to look at how to get girls like yourself and their moms to be more active. We are asking girls like yourself in the second-, third- and fourth-grades at your school to join this study. We have already talked to your mom $<<$ or name of mother-like figure residing with girl $>>$ about this study and she has agreed for you to join. You only have to join this study if you want to. Whether or not you join will not cause you to be treated any differently by your school. Once you join the study you may stop at any time.

If you decide you want to do this study, we will ask you to do a few things.

1. You will be chosen (like flipping a coin) to be in either a mother-daughter after school dance class, a daughter alone after school dance class OR to be in a health club.

a. The dance class will be at your school and will be given 3 days per week for 12 weeks.

b. Dance classes will start right after school and last for about 2 hours 30 minutes. We will want you to attend at least 2 times per week.

c. If you are in the health club, you will get fun things to read in the mail every week for 12 weeks.

2. As part of the program, a person that works for this program will come visit you at your home on three different times to ask questions about your health, how much you play, and how you feel.

3. She will also measure how tall you are, how much you weight, and the size around our waist. 4. We will also ask you to wear a small gadget on a belt around your waist to measure how much you move. This small gadget does not hurt and you can wear it under your clothes.

5. The program person will also take a small amount of blood (about 2 teaspoonful) from your arm, right here $<<$ point to the area of the arm, where blood draw will occur $>>$. This will be like when you go to the doctor's office and have your blood taken. You can still be in this program, if you do not want to have your blood taken.

Joining this study, may be fun and may improve your activity level. We might find out something that will help other children be more active. But we do not promise that this study will be good for you. You and your mom will be given a small amount of money for being a part of this program. We will also give you a T-shirt for being in the study.

I want you to know that only people who are a part of this program and your family will see the information we collect from you. We will not show the information we collect to your school or anyone else. Do you have any questions for me?

\section{Do you want to be in this study?}

\section{YES NO}

If NO --- Thank you very much for listening to me tell you about our program.

If YES --- Great. Now, I need you to read this $<<$ hand child Assent form $>>$ and print and sign your name. As you are reading it, let me know if you have any questions.

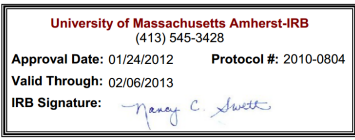




\section{What will happen to me in this program?}

We will like to see if you would like to be in this program. We want to see how your physical activity changes if you participate in an after-school dance program. Only if you want to, you will have to do a few things if you are in this program:

1. We will measure how tall you are, weight, your waist, and your activity level.

2. You will be chosen (like flipping a coin) to be in either a mother-daughter after school dance class, a daughter alone after school dance class OR to be in a health club.

3. The dance class will be at your school and will be given 3 days per week for 12 weeks.

4. We will also take a small amount of blood (about 2 teaspoonful) from your arm. You can still be a part of this program if you do not want to have your blood taken.

\section{Can anything bad happen to me?}

Similar to being involve in your school PE class, you could get hurt during the physical activity program. If you decide to also have your blood taken, the area that we take your blood could feel uncomfortable for a little bit.

\section{Can anything good happen to me?}

Joining this study, may be fun and may improve your activity level. We might find out something that will help other children be more active. But we do not promise that this study will be good for you.

\section{Do I have other choices?}

You can choose not to be in this study.

\section{Who can I talk to about the study?}

You can ask questions any time. You can ask now. You can ask later. Your mom/dad has my phone number.

\section{What if I do not want to do this?}

You don't have to be in this study. No one will be mad at you if you don't want to do this. If you want to or don't want to be in this study, you just have to tell me. And, remember, you can say "yes" now and change your mind later. It's up to you. If you decide you want to be in this study, I need your to write and sign your name.

$\mathrm{I}$, (Print your name here)

(Sign your name here)

Do you want to have your blood taken?

YES NO want to be in this research study.

(Date)

\begin{tabular}{l}
\hline $\begin{array}{l}\text { University of Massachusetts Amherst-IRB } \\
(413) \\
545-3428\end{array}$ \\
Approval Date: 01/24/2012 Protocol \#: 2010-0804 \\
Valid Through: 02/06/2013 \\
IRB Signature: - - namay C. Shete \\
\hline
\end{tabular}




\title{
APPENDIX D \\ INFORMED CONSENT FORM
}

\author{
Mothers and Girls DaNcing togETher Trial (MAGNET Trial) \\ FOR QUESTIONS ABOUT THIS STUDY, CONTACT: \\ Sofiya Alhassan, $\mathrm{PhD}$ \\ University of Massachusetts Amherst \\ Department of Kinesiology \\ Totman Building, Room 150 \\ 30 Eastman Lane \\ Amherst, MA 01003-9258 \\ (413) 545-3475
}

\section{WHAT IS THIS FORM}

This Informed Consent form will give you the information you will need to understand why this study is being done and why you and your daughter are being invited to participate. It will also describe what you and your daughter will need to do to participate and any known risks, inconveniences or discomforts that you and your daughter may have while participating. We encourage you to take some time to think this over and ask questions now and at any other time. If you decide to participate, you will be asked to sign this form and you will be given a copy for your records.

\section{PURPOSE OF RESEARCH PROJECT}

African-American girls (similar to African-American women) have higher rates of obesity and Type 2 diabetes compared to Hispanics or Whites. Physical activity has been shown as a way to lower their obesity and diabetes rates. Unfortunately, low levels of activity are very common in African-American girls. Therefore, it is important for us to find good programs that can improve their activity levels. An important factor in a good activity program is that the girls must enjoy performing the activities. Dancing has been shown to be fun and provide girls with moderate level of activity. In addition, it has been suggested that a way to increase children's activity level is to increase their parents (especially, their mom's) physical activity level. However, we still do not know if exercising with their mom's will further increase girls' physical activity levels.

\section{ELIGIBILITY}

You and your daughter are invited to participate in this study of two different health promotion programs for 7-10 year old African-American girls. African-America girls in the second-, thirdand fourth-grades at your daughter's school are all being asked to participate in this study. For this study we are defining "mother" as the main female figure who lives with the girl.

\section{PROCEDURES}

If you and your daughter decide to participate, you will be asked to do the following things at convenient time for you and your daughter at your home:

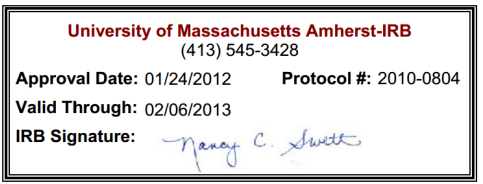

Subject Initials: 
1. We will ask you and your daughter questions about your health, TV habits, and relationship to each other.

2. We will measure you and your daughter's height, weight, and waist size. We will also measure your daughter's blood pressure. We will repeat these measures every 6 weeks (a total of 3 times during the 12-week).

3. You and your daughter will then assigned at random (like flipping a coin) to one of the following groups:

a. A mother-daughter afterschool dance program

b. A daughter alone afterschool dance program

c. A health education program

4. Girls in the mother-daughter group and the daughter alone group will participate in the dance classes but at different times. Only girls in the health education program will participate in the health education program.

5. Mothers in the mother-daughter group will participate in the dance classes with their daughters. However, mothers in the daughter alone or health education group will only participate in the health education program.

6. All girls in the study will receive 1 hour of homework help and health snack for 3 days per week for the 12 weeks.

7. The dance classes and the homework help be provided 3 days per week during the study and will take place at your daughter's school. It will start afterschool and last for about 2.5 hours.

8. The health education program will include weekly health newsletters. The newsletters are designed to provide you and your daughter information on leading a healthy lifestyle.

9. Every 6 weeks from the beginning of the study, your daughter will be asked wear a small beeper-sized motion sensor on a belt around her waist to measure her activity for 7 days in a row.

10. At the first visit and the last visit, we will also collect a small amount of blood (around 2 teaspoons) from your daughter's arm, to test her blood sugar, insulin, and cholesterol levels. Two people will be coming to your home for each blood visit (the researcher and another person to assist).

a. The night prior to your daughter's blood draw, she will be asked to eat a standardized dinner (which we will provide to her base on her food likes and dislikes).

b. After eating this dinner, she will be asked to not eat or drink anything else until she has her blood taken.

c. You and your daughter can still participate in this study if your daughter doesn't want to have her blood taken.

11. At 3 months and 6 months after the dance classes and health education newsletter have ended, you and your daughter will be asked to complete 2 surveys on your activity level and on your relationship to each other. You will be provided with a self-address envelope to return the completed surveys to the research team.

\section{DURATION OF STUDY INVOLVEMENT}

Your participation in this study will last for 14 week. The first meeting will take about 1 hour.

You and your daughter will then meet with a researcher on three other occasions during the study. The second meeting will take about 3 hour (including the blood draw), the third meeting will take about 1 hour and the last meeting will take about 3 hour (including the blood draw). It will take you and your daughter

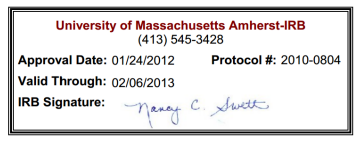

Subject Initials: 
about 30 minutes to complete both the 3- and 6-month surveys. Girls and/or mothers in the dance classes will also take part in the afterschool dance classes for 3 days per week for 12 weeks.

\section{PHOTOGRAPH, FILM, TAPE, AND INTERVIEW}

We will be videotaping and/or photographing some of the dance classes to help us interpret the study findings or for public or scientific presentations. You and your daughter's identity will not be hidden in these videotapes or photographs. By taking part in this study, you and your daughter give us permission to use these images for the above listed purposes. You and your daughter cannot participate in this study if you do not wish to be photographed or filmed.

\section{WITHDRAWAL FROM STUDY}

You and your daughter do not have to be in this study if you do not want to. If you agree to be in the study, but later change your mind, you and your daughter may drop out at any time. There are no penalties or consequences of any kind if you decide that you do not want to participate. You will be notified of all significant new findings during the course of the study that may affect your willingness to continue. The research staff may also withdraw you and your daughter from the study without your permission for one or more of the following reasons:

- Failure to follow the instructions of the research staff

$\circ$ The research staff decides that continuing your participation could be harmful to you and/or your daughter

○ The study is cancelled, other administrative reasons, or unanticipated circumstances

\section{POSSIBLE RISKS, DISCOMFORTS, AND INCONVENIENCES}

You and your daughter may be at increased risk of injury during physical activity (from dance classes or from increased exercise because of the health education program). For mothers and girls in the dance program, instructors will be trained in basic First Aid and to use proper warmup and cool-down routines. For mothers and girls in the health education program, newsletters will include instructions for proper warm-up and cool-down routines. The elastic belts used to the secure the motion sensor in place may rub your daughter's skin and become uncomfortable. No skin damage should result from this and the discomfort level is minimal. Your daughter may also experience temporary discomfort, bleeding and bruising from the area of the blood draw. Your daughter will have the choice of using a numbing cream before each blood draw. All blood draws will be completed by Professor Sofiya Alhassan, who is trained in blood draw procedure and

\section{MEDICAL TREATMENT}

The University of Massachusetts Amherst does not have a program for compensatıng subjects for injury or complications related to human subject research but in the unlikely event of injury resulting directly from being part of this study, researchers will assist you and your daughter in every way to ensure that you and your daughter get proper medical attention.

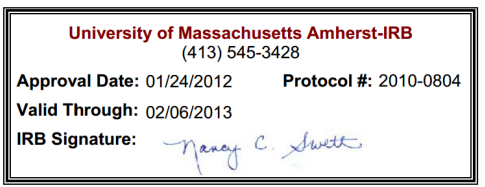

Subject Initials: 


\section{POTENTIAL BENEFITS}

Potential benefits of participating in this study include the possibility of better health for your daughter and yourself, and increasing physical activity levels. Participating in this study may also improve how your daughter feels about herself. In addition, you will receive the results of your daughter's blood pressure readings and blood tests for blood sugar, insulin, and cholesterol, along with what we find out at the end of the study. Finally, what we learn from this study may increase our knowledge about the best ways to help other African-American girls and their mothers improve their physical activity level. We cannot guarantee that you will receive any benefits from this study; however you and your daughter might feel better with the increase in physical activity.

\section{ALTERNATIVES}

The only alternative to being apart of this study is not to participate. You daughter does not have to give blood for you both to be apart of this study.

\section{CONFIDENTIALITY}

The information obtained from this study will be treated as privileged and confidential. It will not be released except upon your written consent. You and your daughter's right to privacy will be maintained at all times. You and your daughter will be assigned a numerical ID number at the beginning of the study and all your data will be identified by ID number only. You and your daughter's name and ID number will be recorded at the beginning of the study and this information will be placed in a file cabinet that will be locked. You daughter's blood sample will be labeled with her ID number and stored in freezers located in locked laboratory space. Only the researchers will have access of you and your daughter's data or your daughter's blood sample. We will use your daughter's blood sample to look at how the program affected her blood sugar, insulin, and cholesterol levels. Your daughter blood sample will not be used for anything else without your permission.

\section{FINANCIAL CONSIDERATIONS}

For your time and effort for participating in this study, your family will receive a total of up to $\$ 100$ for participating in this study (or up to $\$ 140$ if your child participates in the blood draws). You will receive:

1. \$20 for participating in the first set of interview/measures at the beginning of the study

2. \$20 for participating in the 6-week interview/measures

3. $\$ 20$ for participating in the 12 -week interview/measures

4. \$20 for completing and returning the 3-month surveys

5. $\$ 20$ for completing and returning the 6-month surveys

6. $\$ 40$ for your child's participation in the blood draws

a. \$20 for participating in the blood draw at the beginning of the study

b. $\$ 20$ for participating in the blood draw at the end of the study

7. Your daughter will be given a study T-shirt. There is no cost to participate in this study.

\section{REQUEST FOR ADDITIONAL INFORMATION}

Take as long as you like before you make a decision. We will be happy to answer any question you have about this study. If you have further questions about this project or if you have a research-related problem, you may contact the researcher, (Sofiya Alhassan, 413-545-3475). If you have any questions concerning your rights as a research subject, you may contact the University of Massachusetts Amherst.

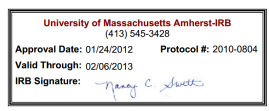

Subject Initials: 
Human Research Protection Office (HRPO) at (413) 545-3428 or humansubjects@ ora.umass.edu

\section{PARTICIPATION STATEMENT OF VOLUNTARY CONSENT}

I have read this form and decided that I will participate in the project described above. The general purposes and particulars of the study as well as possible risks and inconveniences have been explained to my satisfaction. I understand that I can withdraw at any time.

Parent/legal guardian Name (print)

Parent/legal guardian Signature

Date

Child's Name (print)

Child's School

\section{Study Representative Statement}

By signing below I indicate that the participant has read and, to the best of my knowledge, understands the details contained in this document and has been given a copy.

Study Representative Name (Print)

Signature

Date

University of Massachusetts Amherst-IRB
(413) $545-3428$

Approval Date: 01/24/2012 Protocol \#: 2010-0804

Valid Through: 02/06/2013

IRB Signature: - nanay $c$. Swette

Subject Initials: 


\section{APPENDIX E \\ PHYSICAL ACTIVITY QUESTIONNAIRE YOUNGER CHILDREN}

Subject ID:

Date:

We would like to know about the physical activity you have done in the last 7 days. This includes sports or dance that made you sweat or made your legs feel tired, or games that made you huff and puff, like tag, skipping, running, and climbing. REMEMBER: There are no right or wrong answers - this is not a test. It is OK to ask your parents to help you answer the questions. PLEASE ANSWER ALL QUESTIONS AS HONESTLY AND ACCURATE AS YOU CAN - THIS IS VERY IMPORTANT.

1. PHYSICAL ACTIVITY (Do not include P.E. classes)

Have you done any of the following activities in the LAST 7 DAYS? If yes, shade in the circle that matches how many times per week you did each individual activity and write down, on average, how many minutes at a time you did it. Shade "None" if you did not do the activity. Finally, if the activity was organized, that is, a coached sport or lessons, shade in the "Yes, Organized" circle. Start with today and go backwards for seven days total. Note: Shade only one circle per row for "Times in the Last Week."

Times in the Last Week

\begin{tabular}{|c|c|c|c|c|c|c|c|c|}
\hline & $\overline{\text { None }}$ & $\begin{array}{c}\text { to } \\
2\end{array}$ & $\begin{array}{c}3 \text { to } \\
4\end{array}$ & $\begin{array}{c}5 \text { to } \\
6\end{array}$ & $\begin{array}{c}7 \text { or } \\
\text { more }\end{array}$ & $\begin{array}{c}\text { Avg. } \\
\text { Minutes per } \\
\text { session } \\
\end{array}$ & Yes & $\overline{\text { No }}$ \\
\hline Aerobic Dance & 0 & o & 0 & 0 & 0 & $---\cdot$ & 0 & 0 \\
\hline Baseball, Softball & ○ & o & O & ○ & O & $---\cdot$ & O & O \\
\hline Basketball & 0 & ○ & 0 & 0 & 0 & $---\cdot$ & 0 & O \\
\hline Bicycling, Scooter & O & o & 0 & 0 & O & -- & O & O \\
\hline $\begin{array}{l}\text { Cheerleading, } \\
\text { poms }\end{array}$ & 0 & o & O & O & 0 & $---\cdot$ & O & o \\
\hline Creative Play & O & o & 0 & 0 & 0 & $---\cdot-$ & 0 & 0 \\
\hline $\begin{array}{l}\text { Dance (Ballet, } \\
\text { Jazz) }\end{array}$ & O & o & O & O & 0 & $---\cdot-$ & o & O \\
\hline Football & O & o & 0 & ○ & 0 & $---\cdot-$ & 0 & ○ \\
\hline $\begin{array}{l}\text { Four Square, } \\
\text { Tetherball }\end{array}$ & 0 & o & 0 & O & 0 & $---\cdot$ & O & O \\
\hline Golf & 0 & o & 0 & 0 & 0 & & 0 & ○ \\
\hline Gymnastics & O & o & o & O & 0 & --- & O & O \\
\hline Horseback Riding & 0 & 0 & 0 & 0 & 0 & $---\cdot-$ & O & ○ \\
\hline $\begin{array}{l}\text { Ice Hockey, } \\
\text { Skating }\end{array}$ & O & o & O & 0 & 0 & $---\cdot-$ & o & O \\
\hline $\begin{array}{l}\text { Marching Band, } \\
\text { Flags }\end{array}$ & ० & o & 0 & O & ○ & $--\cdot-$ & 0 & 0 \\
\hline $\begin{array}{l}\text { Martial Arts, Tae } \\
\text { Kwon Do }\end{array}$ & 0 & O & O & 0 & 0 & - & 0 & 0 \\
\hline
\end{tabular}

Organized 


\begin{tabular}{|c|c|c|c|c|c|c|c|c|}
\hline $\begin{array}{l}\text { Running, } \\
\text { Track/Field }\end{array}$ & O & o & 0 & O & O & $---\cdot-$ & O & o \\
\hline $\begin{array}{l}\text { Skateboarding, } \\
\text { Rollerblading }\end{array}$ & O & 0 & 0 & O & 0 & $---\cdot-$ & 0 & 0 \\
\hline Sledding, Skiing & ○ & O & ○ & ○ & O & $---\cdot-$ & ○ & ○ \\
\hline Soccer & ० & 0 & 0 & ○ & 0 & $---\cdot-$ & ० & O \\
\hline Swimming & O & ○ & O & ○ & O & $---\cdot-$ & O & ○ \\
\hline Tag, Climbing & 0 & 0 & 0 & O & 0 & $---\cdot-$ & 0 & o \\
\hline $\begin{array}{l}\text { Tennis, } \\
\text { Badminton }\end{array}$ & ० & ○ & ○ & ○ & O & $---\cdot-$ & O & ○ \\
\hline Volleyball & ० & O & o & O & 0 & $---\cdot-$ & O & O \\
\hline $\begin{array}{l}\text { Walking Briskly } \\
\text { for Exercise }\end{array}$ & O & ○ & $\circ$ & O & O & $---\cdot-$ & O & $\circ$ \\
\hline Weight Lifting & ० & O & o & O & 0 & $---\cdot-$ & ○ & O \\
\hline Other & ○ & ○ & O & ○ & O & $---\cdot-$ & O & O \\
\hline Other & $\circ$ & 0 & 0 & 0 & 0 & $---\cdot$ & $\circ$ & 으 \\
\hline
\end{tabular}

2. In the last 7 days, DURING YOUR PHYSICAL EDUCATION (P.E.) CLASSES, how often were you active (playing hard, running, jumping and throwing)? Shade the first one if you did not have P.E. in the last week. Shade only one.

○ I didn't do P.E. in the last seven days

- Hardly ever

- Sometimes

○ Quite often

○ Always

3. In the last 7 days, what did you do most of the time DURING THE MORNING or if you were in school, and had a morning recess, what did you do DURING A MORNING RECESS? Morning means the time after waking and before lunch. Shade only one.

○ Sat down (talking, reading, doing school work)

- Stood around or walked around

- Ran or played a little bit

- Ran around and played quite a bit

- Ran and played hard most of the time

4. In the last 7 days, what did you normally DO AT LUNCH (besides eating lunch)? Shade only one.

○ Sat down (talking, reading, doing school work)

- Stood around or walked around

- Ran or played a little bit

- Ran around and played quite a bit

- Ran and played hard most of the time

5. In the last 7 days, on how many days DURING THE AFTERNOON, did you do sports, dance, or play games in which you were very active? Afternoon means the time after lunch and before dinner. Shade only one. 
○ None

○ 1 afternoon in the last week

- 2 to 3 afternoons in the last week

○ 4 to 5 afternoons in the last week

○ 6 to 7 afternoons in the last week

6. In the last 7 days, on how many EVENINGS did you do sports, dance, or play games in which you were very active? Evenings mean the time after dinner. Shade only one.
○ None
○ 1 evening in the last week
○ 2 to 3 evenings in the last week
○ 4 to 5 evenings in the last week
○ 6 to 7 evenings in the last week

7. How many times did you do sports, dance, or play games in which you were very active LAST WEEKEND (Saturday and Sunday)? Shade only one.

○ None

○ 1 time last weekend

- 2 to 3 times last weekend

- 4 to 5 times last weekend

○ 6 or more times last weekend

8. Which ONE of the following five statements describes you best for the last 7 days? Read all 5 before deciding on the one answer that describes you. Shade only one.

- All or most of my free time was spent doing things that involved little physical effort, for example, watching TV/videos/DVD, doing homework, doing instant messaging/email/internet, or playing video/computer/electronic games

- I sometimes (1 to 2 times in the last week) did physical things in my free time, for example, played sports, went running, swimming, bike riding, did aerobics.

- Ran or played a little bit

- Ran around and played quite a bit

$\circ$ Ran and played hard most of the time

9. How many hours per day did you WATCH TELEVISION in the last week? Include the time you spent watching movies or programs on video or DVD. Do not count television or videos watched in school. Shade only one.

- I watched less than 1 hour/day or not at all

- I watched at least 1 hour/day, but less than 2 hours/day

- I watched at least 2 hours/day, but less than 3 hours/day

- I watched at least 3 hours/day, but less than 4 hours/day

- I watched 4 hours/day or more

10. How many hours per day did you PLAY VIDEO, COMPUTER, OR ELCTRONIC GAMES in the last week? For example, Playstation, Game boy, computer games, or games on the web. Shade only one.

- I did these less than 1 hour/day or not at all 
- I did these at least 1 hour/day, but less than 2 hours/day

- I did these at least 2 hours/day, but less than 3 hours/day

- I did these at least 3 hours/day, but less than 4 hours/day

- I did these 4 hours/day or more

11. How many hours per day did you do instant messaging, email, or browse the Internet in the last week? Do not count school or work-related computer use. Shade only one.

- I did these less than 1 hour/day or not at all

- I did these at least 1 hour/day, but less than 2 hours/day

- I did these at least 2 hours/day, but less than 3 hours/day

- I did these at least 3 hours/day, but less than 4 hours/day

- I did these 4 hours/day or more

12. How many MINUTES PER DAY did you talk on a phone in the last week? Do not count school or work-related phone use. Shade only one.

- I talked on the phone less than 15 minutes/day or not at all

O I talked on the phone at least 15 minutes/day, but less than 30 minutes/day

- I talked on the phone at least 30 minutes/day, but less than 60 minutes/day

- I talked on the phone at least 60 minutes/day, but less than 120 minutes/day

○ I talked on the phone 120 minutes/day or more

13. Were you SICK in the last week, or did anything prevent you from doing your normal physical activities?
○ Yes
○ No

If yes, what prevented you?

14. How often did you participate in physical activity (like playing sports, games, dancing, or any other physical activity) for each day in the last week? Work back 7 days from today and be sure to include spare time, sports teams, and school activities like P.E., recess, and intramurals. Shade only one circle per row. Shade "None" if you did not do any physical activity.

\begin{tabular}{lccccc}
\hline & None & Little Bit & Medium & Often & Very Often \\
\hline Monday & 0 & 0 & 0 & 0 & 0 \\
Tuesday & 0 & 0 & 0 & 0 & 0 \\
Wednesday & 0 & 0 & 0 & 0 & 0 \\
Thursday & 0 & 0 & 0 & 0 & 0 \\
Friday & $\circ$ & 0 & 0 & 0 & 0 \\
Saturday & $\circ$ & 0 & 0 & 0 & 0 \\
Sunday & $\circ$ & $\circ$ & 0 & 0 & 0 \\
\hline Before you stop
\end{tabular}

Before you stop, please go back to page one and make sure that you shaded how many times per week you did each individual activity and THE AVERAGE MINUTES AT A TIME YOU DID IT (people often forget to write down the average minutes), and if the activity was organized. 


\section{APPENDIX F}

\section{PHYSICAL ACTIVITY (IPAQ)}

\section{The following questions are about physical activity. Please read carefully and answer to the best of your knowledge.}

11. When you are at work, which of the following describes what you do? (If you have more than one job, answer for each job.)

\begin{tabular}{|c|c|c|}
\hline$\underline{\text { Job } 1}$ & Job 2 & Job 3 \\
\hline $\begin{array}{l}\square \text { Mostly sitting or } \\
\text { standing }\end{array}$ & $\begin{array}{l}\square \text { Mostly sitting or } \\
\text { standing }\end{array}$ & $\begin{array}{l}\square \text { Mostly sitting or } \\
\text { standing }\end{array}$ \\
\hline$\square$ Mostly walking & $\square$ Mostly walking & $\square$ Mostly walking \\
\hline $\begin{array}{l}\square \text { Mostly heavy labor or } \\
\text { physically demanding } \\
\text { work }\end{array}$ & $\begin{array}{l}\square \text { Mostly heavy labor or } \\
\text { physically demanding } \\
\text { work }\end{array}$ & $\begin{array}{l}\square \text { Mostly heavy labor or } \\
\text { physically demanding } \\
\text { work }\end{array}$ \\
\hline$\square$ Don't know/not sure & $\square$ Don't know/not sure & $\square$ Don't know/not sure \\
\hline
\end{tabular}

The next 3 questions are about vigorous physical activity. Vigorous physical activity causes your heart to beat faster and makes you breathe hard.

12. Now thinking about vigorous physical activities you did in the last 7 days, did you do vigorous activities for at least 10 minutes at a time, such as running, aerobics, sports, heavy yard work, or anything else?

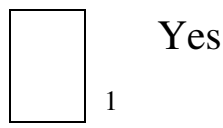

\footnotetext{
$\prod_{0} \mathrm{No} \rightarrow$ Skip to 15 on the next page $\rightarrow$
}

13. How many days per week do you do these vigorous activities for at least 10 minutes at a time?

$\begin{array}{llllllll}\text { Days per week: } & 1 & 2 & 3 & 4 & 5 & 6 & 7\end{array}$


14. On the days when you do vigorous activity for at least 10 minutes, how long do you do those activities?

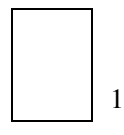

About 10 minutes

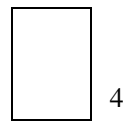

About 40 minutes

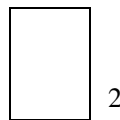

About 20 minutes

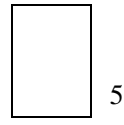

About 50 minutes

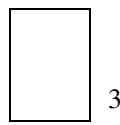

About 30 minutes

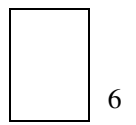

1 hour or more 3

The next 3 questions are about moderate physical activity. Moderate physical activity causes small increases in breathing or heart rate.

15. Now thinking about moderate physical activities you did in the last $\mathbf{7}$ days, did you do moderate activities for at least 10 minutes at a time, such as brisk walking, bicycling at regular pace, vacuuming, gardening, or anything else?

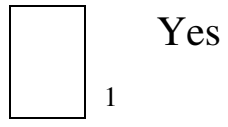

$\prod_{0} \mathrm{No} \rightarrow$ Skip to 18 on the next page $\rightarrow$

16. How many days per week do you do these moderate activities for at least 10 minutes at a time?

$\begin{array}{llllllll}\text { Days per week: } & 1 & 2 & 3 & 4 & 5 & 6 & 7\end{array}$

17. On the days when you do moderate activity for at least 10 minutes, how long do you do those activities?

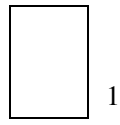

About 10 minutes

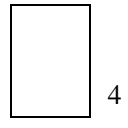

About 40 minutes

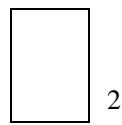

About 20 minutes

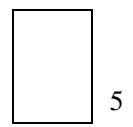

About 50 minutes 


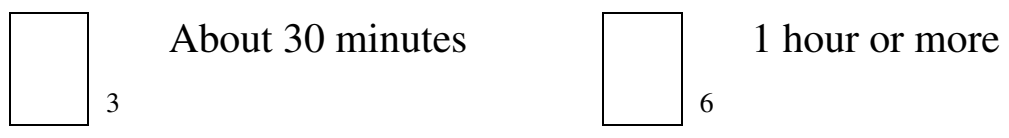

The next 3 questions are about time spent walking.

18. Now thinking about the amount of time you spent walking in the last 7 days that lasted for at least 10 minutes at a time. This includes at work and at home, walking to travel from place to place, and any other walking that you might do solely for recreation, sport, exercise, or leisure.

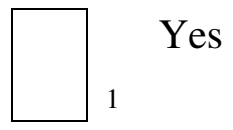

$\int_{0} \mathrm{No} \rightarrow$ Skip to 22 on the next page $\rightarrow$

19. How many days per week do you do spend walking for at least 10 minutes at a time?

$\begin{array}{lllllllll}\text { Days per week: } & 1 & 2 & 3 & 4 & 5 & 6 & 7\end{array}$

20. On the days when you do walk for at least 10 minutes, how long do you do those activities?

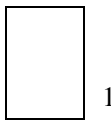

About 10 minutes

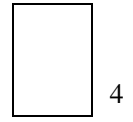

About 40 minutes

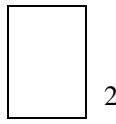

About 20 minutes

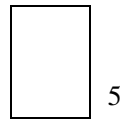

About 50 minutes

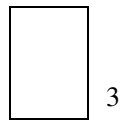

About 30 minutes

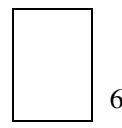

1 hour or more 6

The next 3 questions are about you sitting.

21. Now thinking about the amount of time you spent sitting in the last 7 days. Include time spent at work, at home, while doing course work and during leisure time. This may 
include time spent sitting at a desk, visiting friends, reading, or sitting or lying down to watch television.

22. How many hours per day do you spend sitting?
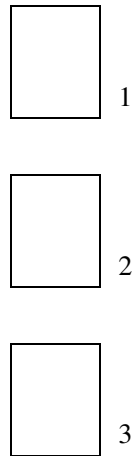

About 30 minutes or less

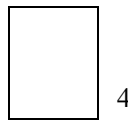

About 3 hour

About 1 hour

About 2 hour

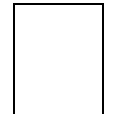

About 4 hour

5

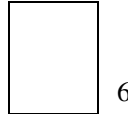

About 5 hour or more 


\section{APPENDIX G}

\section{ADOLESCENT OPENNESS TO PARENTAL SOCIALIZATION PARENT FORM}

Below is a list of things that might happen in a family. Please rate if how often do these things happen in your family.

\begin{tabular}{|c|c|c|c|c|}
\hline $\begin{array}{l}\text { 1. My child tells me who she is going to be with } \\
\text { before she goes out. }\end{array}$ & $\begin{array}{c}\text { Almost } \\
\text { never or } \\
\text { never }\end{array}$ & $\begin{array}{c}\text { Sometimes } \\
\\
\square\end{array}$ & $\begin{array}{l}\text { Often } \\
\\
\square\end{array}$ & $\begin{array}{c}\text { Almost } \\
\text { Always } \\
\text { or } \\
\text { Always } \\
\\
\square\end{array}$ \\
\hline $\begin{array}{l}\text { 2. If my child is going to be home late she calls home } \\
\text { to let me know. }\end{array}$ & $\begin{array}{c}\text { Almost } \\
\text { never or } \\
\text { never } \\
\\
\square\end{array}$ & $\begin{array}{c}\text { Sometimes } \\
\square\end{array}$ & $\begin{array}{c}\text { Often } \\
\\
\square\end{array}$ & $\begin{array}{c}\text { Almost } \\
\text { Always } \\
\text { or } \\
\text { Always } \\
\\
\square\end{array}$ \\
\hline $\begin{array}{l}\text { 3. My child talks with me about the plans she has with } \\
\text { friends. }\end{array}$ & $\begin{array}{c}\text { Almost } \\
\text { never or } \\
\text { never } \\
\square\end{array}$ & $\begin{array}{c}\text { Sometimes } \\
\square\end{array}$ & $\begin{array}{l}\text { Often } \\
\square\end{array}$ & $\begin{array}{c}\text { Almost } \\
\text { Always } \\
\text { or } \\
\text { Always } \\
\\
\square\end{array}$ \\
\hline $\begin{array}{l}\text { 4. My child and I just spend time talking with each } \\
\text { other. }\end{array}$ & $\begin{array}{c}\text { Almost } \\
\text { never or } \\
\text { never } \\
\\
\square\end{array}$ & $\begin{array}{c}\text { Sometimes } \\
\square\end{array}$ & $\begin{array}{c}\text { Often } \\
\\
\square\end{array}$ & $\begin{array}{c}\text { Almost } \\
\text { Always } \\
\text { or } \\
\text { Always } \\
\\
\square\end{array}$ \\
\hline 5. My child comes to me with her problems. & $\begin{array}{c}\text { Almost } \\
\text { never or } \\
\text { never } \\
\\
\square\end{array}$ & $\begin{array}{c}\text { Sometimes } \\
\square\end{array}$ & $\begin{array}{c}\text { Often } \\
\\
\square\end{array}$ & $\begin{array}{c}\text { Almost } \\
\text { Always } \\
\text { or } \\
\text { Always } \\
\\
\square\end{array}$ \\
\hline
\end{tabular}




\begin{tabular}{|l|c|c|c|c|}
\hline $\begin{array}{l}\text { 6. My child and I discuss the reasons for the rules in } \\
\text { our family. }\end{array}$ & $\begin{array}{c}\text { Almost } \\
\text { never or } \\
\text { never }\end{array}$ \\
7. My child tells me she loves me. & $\square$ & $\square$ & $\square$ & Sometimes \\
\hline Often & $\begin{array}{c}\text { Almost } \\
\text { Always } \\
\text { or } \\
\text { Always }\end{array}$ \\
\hline $\begin{array}{c}\text { Almost } \\
\text { never or } \\
\text { never }\end{array}$ & Sometimes & Often & $\begin{array}{c}\text { Almost } \\
\text { Always } \\
\text { or } \\
\text { Always } \\
\square\end{array}$ \\
\hline
\end{tabular}




\section{APPENDIX H}

\section{PARENTAL RESPONSIVENESS - PARENT FORM}

Below is a list of things that might happen in a family. Please rate if how often do these things happen in your family.

\begin{tabular}{|c|c|c|c|c|}
\hline $\begin{array}{l}\text { 1. My child and I just spend time talking with each } \\
\text { other. }\end{array}$ & $\begin{array}{c}\text { Almost } \\
\text { never or } \\
\text { never } \\
\square\end{array}$ & $\begin{array}{c}\text { Sometimes } \\
\\
\square\end{array}$ & $\begin{array}{c}\text { Often } \\
\square\end{array}$ & $\begin{array}{c}\text { Almost } \\
\text { Always } \\
\text { or } \\
\text { Always } \\
\\
\square\end{array}$ \\
\hline 2. I praise my child for things she does well. & $\begin{array}{c}\text { Almost } \\
\text { never or } \\
\text { never } \\
\square\end{array}$ & $\begin{array}{c}\text { Sometimes } \\
\\
\square\end{array}$ & $\begin{array}{c}\text { Often } \\
\\
\square\end{array}$ & $\begin{array}{c}\text { Almost } \\
\text { Always } \\
\text { or } \\
\text { Always } \\
\\
\square\end{array}$ \\
\hline 3. My child comes to me with her problems. & $\begin{array}{c}\text { Almost } \\
\text { never or } \\
\text { never } \\
\square\end{array}$ & $\begin{array}{c}\text { Sometimes } \\
\square\end{array}$ & $\begin{array}{c}\text { Often } \\
\\
\square\end{array}$ & $\begin{array}{c}\text { Almost } \\
\text { Always } \\
\text { or } \\
\text { Always } \\
\\
\square\end{array}$ \\
\hline $\begin{array}{l}\text { 4. My child and I discuss the reasons for rules in our } \\
\text { family. }\end{array}$ & $\begin{array}{c}\text { Almost } \\
\text { never or } \\
\text { never } \\
\square\end{array}$ & $\begin{array}{c}\text { Sometimes } \\
\square\end{array}$ & $\begin{array}{c}\text { Often } \\
\\
\square\end{array}$ & $\begin{array}{c}\text { Almost } \\
\text { Always } \\
\text { or } \\
\text { Always } \\
\square\end{array}$ \\
\hline 5. I tell my child that I love her. & $\begin{array}{c}\text { Almost } \\
\text { never or } \\
\text { never } \\
\square\end{array}$ & $\begin{array}{c}\text { Sometimes } \\
\square\end{array}$ & $\begin{array}{c}\text { Often } \\
\square\end{array}$ & $\begin{array}{c}\text { Almost } \\
\text { Always } \\
\text { or } \\
\text { Always } \\
\square\end{array}$ \\
\hline
\end{tabular}




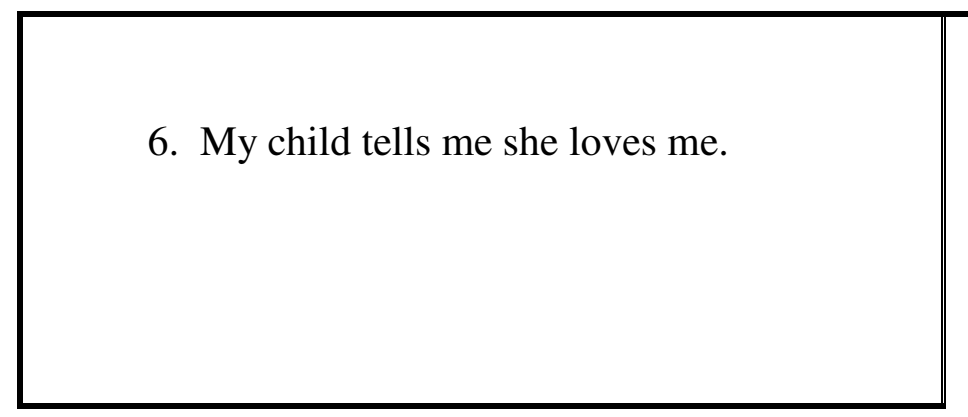

\begin{tabular}{c|c|c|c|}
$\begin{array}{c}\text { Almost } \\
\text { never or } \\
\text { never }\end{array}$ & Sometimes & Often & $\begin{array}{c}\text { Almost } \\
\text { Always } \\
\text { or } \\
\text { Always }\end{array}$ \\
$\square$ & $\square$ & $\square$ & $\square$
\end{tabular}




\section{APPENDIX I}

\section{PARENTAL RESPONSIVENESS - DAUGHTER FORM}

Below is a list of things that might happen in a family. Please rate if how often do these things happen in your family.

\begin{tabular}{|c|c|c|c|c|}
\hline 1. I tell my mom about my problems and troubles. & $\begin{array}{c}\text { Almost } \\
\text { never or } \\
\text { never } \\
\\
\square\end{array}$ & $\begin{array}{c}\text { Sometimes } \\
\\
\square\end{array}$ & $\begin{array}{l}\text { Often } \\
\\
\square\end{array}$ & $\begin{array}{c}\text { Almost } \\
\text { Always } \\
\text { or } \\
\text { Always } \\
\\
\square\end{array}$ \\
\hline 2. My mother helps me to understand myself better. & $\begin{array}{c}\text { Almost } \\
\text { never or } \\
\text { never } \\
\\
\square\end{array}$ & $\begin{array}{c}\text { Sometimes } \\
\square\end{array}$ & $\begin{array}{l}\text { Often } \\
\\
\square\end{array}$ & $\begin{array}{c}\text { Almost } \\
\text { Always } \\
\text { or } \\
\text { Always } \\
\\
\square\end{array}$ \\
\hline $\begin{array}{l}\text { 3. If my mother knows something is bothering } \\
\text { me, she asks me. }\end{array}$ & $\begin{array}{c}\text { Almost } \\
\text { never or } \\
\text { never } \\
\square\end{array}$ & $\begin{array}{c}\text { Sometimes } \\
\square\end{array}$ & $\begin{array}{c}\text { Often } \\
\\
\square\end{array}$ & $\begin{array}{c}\text { Almost } \\
\text { Always } \\
\text { or } \\
\text { Always } \\
\\
\square\end{array}$ \\
\hline $\begin{array}{l}\text { 4. My mother has her own problems, so I don't } \\
\text { bother her with mine. }\end{array}$ & $\begin{array}{c}\text { Almost } \\
\text { never or } \\
\text { never } \\
\\
\square\end{array}$ & $\begin{array}{c}\text { Sometimes } \\
\square\end{array}$ & $\begin{array}{c}\text { Often } \\
\\
\square\end{array}$ & $\begin{array}{c}\text { Almost } \\
\text { Always } \\
\text { or } \\
\text { Always } \\
\\
\square\end{array}$ \\
\hline 5. My mother respects my feelings. & $\begin{array}{c}\text { Almost } \\
\text { never or } \\
\text { never } \\
\\
\square\end{array}$ & $\begin{array}{c}\text { Sometimes } \\
\square\end{array}$ & $\begin{array}{c}\text { Often } \\
\\
\square\end{array}$ & $\begin{array}{c}\text { Almost } \\
\text { Always } \\
\text { or } \\
\text { Always } \\
\\
\square\end{array}$ \\
\hline
\end{tabular}




\begin{tabular}{|c|c|c|c|c|}
\hline $\begin{array}{l}\text { 6. When I'm angry about something my mother tries } \\
\text { to be understanding. }\end{array}$ & $\begin{array}{c}\text { Almost } \\
\text { never or } \\
\text { never } \\
\square\end{array}$ & $\begin{array}{c}\text { Sometimes } \\
\\
\square\end{array}$ & $\begin{array}{c}\text { Often } \\
\\
\square\end{array}$ & $\begin{array}{c}\text { Almost } \\
\text { Always } \\
\text { or } \\
\text { Always } \\
\\
\square\end{array}$ \\
\hline 7. I wish I had a different mother. & $\begin{array}{c}\text { Almost } \\
\text { never or } \\
\text { never } \\
\square\end{array}$ & $\begin{array}{c}\text { Sometimes } \\
\square\end{array}$ & $\begin{array}{c}\text { Often } \\
\square\end{array}$ & $\begin{array}{c}\text { Almost } \\
\text { Always } \\
\text { or } \\
\text { Always } \\
\\
\square\end{array}$ \\
\hline 8. My mother accepts me as I am. & $\begin{array}{c}\text { Almost } \\
\text { never or } \\
\text { never } \\
\square\end{array}$ & $\begin{array}{c}\text { Sometimes } \\
\square\end{array}$ & $\begin{array}{c}\text { Often } \\
\\
\square\end{array}$ & $\begin{array}{c}\text { Almost } \\
\text { Always } \\
\text { or } \\
\text { Always } \\
\square\end{array}$ \\
\hline 9. I don't get much attention at home. & $\begin{array}{c}\text { Almost } \\
\text { never or } \\
\text { never } \\
\square\end{array}$ & $\begin{array}{c}\text { Sometimes } \\
\square\end{array}$ & $\begin{array}{c}\text { Often } \\
\\
\square\end{array}$ & $\begin{array}{c}\text { Almost } \\
\text { Always } \\
\text { or } \\
\text { Always } \\
\\
\square\end{array}$ \\
\hline 10. I get easily upset at home. & $\begin{array}{c}\text { Almost } \\
\text { never or } \\
\text { never } \\
\square\end{array}$ & $\begin{array}{c}\text { Sometimes } \\
\\
\square\end{array}$ & $\begin{array}{c}\text { Often } \\
\\
\square\end{array}$ & $\begin{array}{c}\text { Almost } \\
\text { Always } \\
\text { or } \\
\text { Always } \\
\\
\square\end{array}$ \\
\hline
\end{tabular}




\section{APPENDIX J}

\section{PHYSICAL ACTIVITY SELF EFFICACY}

Below is a list of things people might do while trying to increase or continue regular exercise. We are interested in exercises like running, swimming, brisk walking, bicycle riding, or aerobics classes. Whether you exercise or not, please rate how confident you are that you could really motivate yourself to do things like these consistently, for at least six months.

\begin{tabular}{|l||c|c|c|c|}
\hline 1. Get up early, even on weekends, to exercise. & $\begin{array}{c}\text { I know I } \\
\text { cannot }\end{array}$ & $\begin{array}{c}\text { Maybe I } \\
\text { can }\end{array}$ & $\begin{array}{c}\text { I know I } \\
\text { can }\end{array}$ & $\begin{array}{c}\text { Does not } \\
\text { apply }\end{array}$ \\
\hline $\begin{array}{l}\text { 2. Stick to your exercise program after a long, tiring } \\
\text { day at work. }\end{array}$ & $\begin{array}{c}\text { I know I } \\
\text { cannot }\end{array}$ & $\begin{array}{c}\text { Maybe I } \\
\text { can }\end{array}$ & $\begin{array}{c}\text { I know I } \\
\text { can }\end{array}$ & $\begin{array}{c}\text { Does not } \\
\text { apply }\end{array}$ \\
\hline $\begin{array}{l}\text { 3. Exercise even though you are feeling depressed. } \\
\text { cannot }\end{array}$ & $\begin{array}{c}\text { Maybe I } \\
\text { can }\end{array}$ & $\begin{array}{c}\text { I know I } \\
\text { can }\end{array}$ & $\begin{array}{c}\text { Does not } \\
\text { apply }\end{array}$ \\
\hline $\begin{array}{l}\text { 4. Set aside time for a physical activity program; that } \\
\text { is, walking, jogging, swimming, biking, or other } \\
\text { continuous activities for at least 30 minutes, 3 times } \\
\text { per week. }\end{array}$ & $\begin{array}{c}\text { I know I } \\
\text { cannot }\end{array}$ & $\begin{array}{c}\text { Maybe I } \\
\text { can }\end{array}$ & $\begin{array}{c}\text { I know I } \\
\text { can }\end{array}$ & $\begin{array}{c}\text { Does not } \\
\text { apply }\end{array}$ \\
\hline $\begin{array}{l}\text { 5. Continue to exercise with others even though they } \\
\text { seem too fast or too slow for you. }\end{array}$ & $\begin{array}{c}\text { I know I } \\
\text { cannot }\end{array}$ & $\begin{array}{c}\text { Maybe I } \\
\text { can }\end{array}$ & $\begin{array}{c}\text { I know I } \\
\text { can }\end{array}$ & $\begin{array}{c}\text { Does not } \\
\text { apply }\end{array}$ \\
\hline $\begin{array}{l}\text { 6. Stick to your exercise program when undergoing a } \\
\text { stressful life change (e.g., divorce, death in the } \\
\text { family, moving). }\end{array}$ & $\begin{array}{c}\text { I know I } \\
\text { cannot }\end{array}$ & $\begin{array}{c}\text { Maybe I } \\
\text { can }\end{array}$ & $\begin{array}{c}\text { I know I } \\
\text { can }\end{array}$ & $\begin{array}{c}\text { Does not } \\
\text { apply }\end{array}$ \\
\hline $\begin{array}{l}\text { 7. Attend a party only after exercising. } \\
\square\end{array}$ & $\begin{array}{c}\text { I know I } \\
\text { cannot }\end{array}$ & $\begin{array}{c}\text { Maybe I } \\
\text { can }\end{array}$ & $\begin{array}{c}\text { I know I } \\
\text { can }\end{array}$ & $\begin{array}{c}\text { Does not } \\
\text { apply }\end{array}$ \\
$\square$ & $\square$ & $\square$ & $\square$ \\
\hline
\end{tabular}




\begin{tabular}{|l|c|c|c|c|}
\hline $\begin{array}{l}\text { 8. Stick to your exercise program when your family } \\
\text { is demanding more time from you. }\end{array}$ & $\begin{array}{c}\text { I know I } \\
\text { cannot }\end{array}$ & $\begin{array}{c}\text { Maybe I } \\
\text { can }\end{array}$ & $\begin{array}{c}\text { I know I } \\
\text { can }\end{array}$ & $\begin{array}{c}\text { Does not } \\
\text { apply }\end{array}$ \\
\hline $\begin{array}{l}\text { 9. Stick to your exercise program when you have } \\
\text { household chores to attend to. }\end{array}$ & $\begin{array}{c}\text { I know I } \\
\text { cannot }\end{array}$ & $\begin{array}{c}\text { Maybe I } \\
\text { can }\end{array}$ & $\begin{array}{c}\text { I know I } \\
\text { can } \\
\text { a }\end{array}$ & $\begin{array}{c}\text { Does not } \\
\text { apply }\end{array}$ \\
\hline $\begin{array}{l}\text { 10. Stick to your exercise program even when you } \\
\text { have excessive demands at work. }\end{array}$ & $\begin{array}{c}\text { I know I } \\
\text { cannot }\end{array}$ & $\begin{array}{c}\text { Maybe I } \\
\text { can }\end{array}$ & $\begin{array}{c}\text { I know I } \\
\text { can }\end{array}$ & $\begin{array}{c}\text { Does not } \\
\text { apply }\end{array}$ \\
\hline $\begin{array}{l}\text { 11. Stick to your exercise program when social } \\
\text { obligations are very time consuming. }\end{array}$ & $\begin{array}{c}\text { c know I } \\
\text { cannot }\end{array}$ & $\begin{array}{c}\text { Maybe I } \\
\text { can }\end{array}$ & $\begin{array}{c}\text { I know I } \\
\text { can }\end{array}$ & $\begin{array}{c}\text { Does not } \\
\text { apply }\end{array}$ \\
\hline & $\square$ & $\square$ & $\square$ & $\square$ \\
\hline 12. Read or study less in order to exercise more. & $\begin{array}{c}\text { cannot } \\
\text { canow I }\end{array}$ & $\begin{array}{c}\text { Maybe I } \\
\text { can }\end{array}$ & $\begin{array}{c}\text { I know I } \\
\text { can }\end{array}$ & $\begin{array}{c}\text { Does not } \\
\text { apply } \\
\square\end{array}$ \\
\hline
\end{tabular}




\section{APPENDIX K}

CHILD SELF-PERCEPTION OF ADEQUACY AND PREDILECTION FOR PA

SCALE (CSAPPA)

\section{WHAT'S MOST LIKE ME!!}

\section{INSTRUCTIONS:}

In this survey you have to read a pair of sentences and then circle $(O)$ the sentence you think is MORE LIKE YOU.

Try the following example.

\section{SAMPLE QUESTION}

Some kids have one

BUT
Other kids have three noses on their face!

That shouldn't be too hard for you to decide! Once you have circled the sentence that is more like you, then you have to decide if it is $R \boldsymbol{E A L L Y ~ T R U E}$ for you or SORT OF TRUE for you.

Here is another sample question for you to try. Remember; first circle the sentence that is more like you and then put a check $(\checkmark)$ in the correct box if it is really true or only sort of true for you. THERE ARE NO RIGHT OR WRONG ANSWERS, JUST WHAT IS MOST LIKE YOU.

SAMPLE QUESTION

REALLY SORT OF

TRUE TRUE

SORT OF

TRUE

REALLY

for me for me

for me

TRUE

Some kids like to other kids don't like play with computers .BUT playing with computers. 
Now you are ready to start filling in this form. Take your time and do the whole form carefully. If you have any questions just ask! If you think you are ready you can start now. BE SURE TO FILL IN BOTH SIDES OF EACH PAGE!

\begin{tabular}{|c|c|c|c|c|c|c|}
\hline $\begin{array}{l}\text { REALLY } \\
\text { REALLY } \\
\text { TRUE }\end{array}$ & $\begin{array}{c}\text { SORT OF } \\
\text { TRUE }\end{array}$ & & $\begin{array}{l}\text { SORT } \\
\text { TRUE }\end{array}$ & & OF & \\
\hline $\begin{array}{l}\text { TRUE } \\
\text { for me } \\
\text { for me }\end{array}$ & for me & & for & & me & \\
\hline 口 & 口 & $\begin{array}{l}\text { Some kids can't wait } \\
\text { to play active games BUT } \\
\text { after school. }\end{array}$ & $\begin{array}{l}\text { Other kids would } \\
\text { rather do something } \\
\text { else. }\end{array}$ & व & & ם \\
\hline
\end{tabular}

\begin{tabular}{|l|lllll|}
\hline$\square$ & $\begin{array}{l}\text { Some kids really } \\
\text { enjoy physical } \\
\text { education class. }\end{array}$ & BUT & $\begin{array}{l}\text { Other kids don't like } \\
\text { physical education } \\
\text { class. }\end{array}$ & $\square$
\end{tabular}

\begin{tabular}{|lllll|}
\hline Some kids don't like & Other kids really like \\
playing active games.BUT & playing active games.
\end{tabular}$\quad$ a

\begin{tabular}{|c|c|c|c|c|c|c|}
\hline ם & a & $\begin{array}{l}\text { Some kids don't } \\
\text { have much fun } \\
\text { plaving sports. }\end{array}$ & BUT & $\begin{array}{l}\text { Other kids have a } \\
\text { good time playing } \\
\text { sports. }\end{array}$ & 口 & 口 \\
\hline
\end{tabular}

\begin{tabular}{|llllll|}
\hline$\square$ & $\square \quad \begin{array}{l}\text { Some kids think } \\
\text { physical education } \\
\text { is the best class. }\end{array}$ & BUT & $\begin{array}{l}\text { Other kids think } \\
\text { physical education } \\
\text { isn't much fun. }\end{array}$ & $\square$
\end{tabular}$\quad \square$

Some kids are good at active games.
Other kids find active

BUT games hard to play. 


\begin{tabular}{|c|c|c|c|c|c|}
\hline a & a & $\begin{array}{l}\text { Some kids don't } \\
\text { like playing sports. } \quad \text { BUT }\end{array}$ & $\begin{array}{l}\text { Other kids really } \\
\text { enjoy playing sports. }\end{array}$ & 口 & ] \\
\hline a & a & $\begin{array}{l}\text { Some kids always } \\
\text { hurt themselves whenBUT } \\
\text { they play sports. }\end{array}$ & $\begin{array}{l}\text { Other kids never } \\
\text { hurt themselves } \\
\text { playing sports. }\end{array}$ & $\square$ & ] \\
\hline
\end{tabular}

\begin{tabular}{|c|c|c|c|c|c|c|}
\hline व & 口 & $\begin{array}{l}\text { Some kids like } \\
\text { to play active } \\
\text { games outside. }\end{array}$ & BUT & $\begin{array}{l}\text { Other kids would } \\
\text { rather read or play } \\
\text { video games. }\end{array}$ & 口 & 口 \\
\hline
\end{tabular}

\begin{tabular}{|llllll}
\hline & $\begin{array}{l}\text { Some kids do well } \\
\text { in most sports. }\end{array}$ & BUT & $\begin{array}{l}\text { Other kids feel they } \\
\text { aren't good at sports. }\end{array}$ & $\square$
\end{tabular}

\begin{tabular}{|l|llll|}
\hline$\square$ & $\begin{array}{l}\text { Some kids learn to } \\
\text { play active games } \\
\text { easily. }\end{array}$ & BUT & $\begin{array}{l}\text { Other kids find it hard } \\
\text { learning to play active } \\
\text { Games. }\end{array}$ \\
\hline
\end{tabular}

\begin{tabular}{|c|c|c|c|c|c|}
\hline$\square$ & $\square$ & $\begin{array}{l}\text { Some kids think they } \\
\text { are the best at sports. BUT }\end{array}$ & $\begin{array}{l}\text { Other kids think they } \\
\text { aren't good at sports. }\end{array}$ & $\square$ & $\square$ \\
\hline$\square$ & a & $\begin{array}{l}\text { Some kids find games } \\
\text { in physical education BUT } \\
\text { hard to play. }\end{array}$ & $\begin{array}{l}\text { Other kids are good } \\
\text { at games in physical } \\
\text { education. }\end{array}$ & व & $\square$ \\
\hline 口 & $\square$ & $\begin{array}{l}\text { Some kids like to } \\
\text { watch games being } \quad \text { BUT } \\
\text { played outside. }\end{array}$ & $\begin{array}{l}\text { Other kids would } \\
\text { rather play active } \\
\text { games outside. }\end{array}$ & 口 & $\square$ \\
\hline
\end{tabular}

\begin{tabular}{ll}
$\begin{array}{l}\text { Some kids are among } \\
\text { the last to be chosen BUT }\end{array}$ & $\begin{array}{l}\text { Other kids are } \\
\text { usually picked to play } \\
\text { for active games. }\end{array}$ \\
\hline
\end{tabular}




\begin{tabular}{|l|llll|}
\hline$\square$ & $\begin{array}{l}\text { Some kids like to } \\
\text { take it easy during } \\
\text { recess. }\end{array}$ & BUT & $\begin{array}{l}\text { Other kids would } \\
\text { rather play active } \\
\text { games. }\end{array}$ \\
\hline$\square$ & $\begin{array}{l}\text { Some kids have fun } \\
\text { in physical education BUT } \\
\text { class. }\end{array}$ & $\begin{array}{l}\text { Other kids would } \\
\text { rather miss physical } \\
\text { education class. }\end{array}$ & $\square$ \\
\hline
\end{tabular}
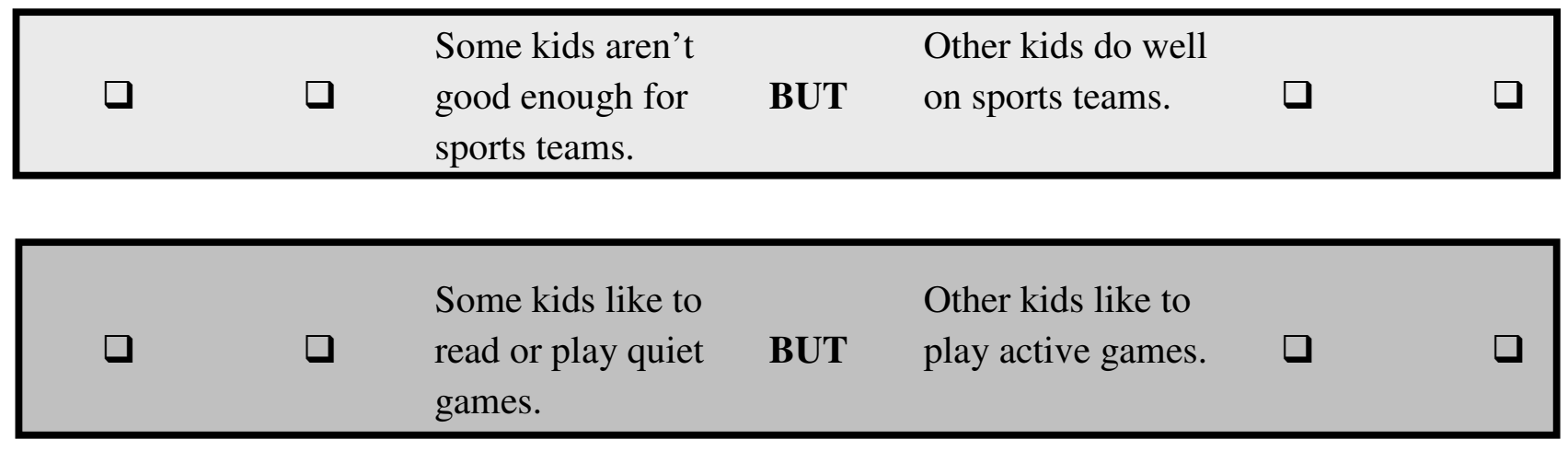

\begin{tabular}{llllll}
\hline$\square$ & $\begin{array}{l}\text { Some kids like to } \\
\text { play active games } \\
\text { outside on weekends. }\end{array}$ & BUT & $\begin{array}{l}\text { Other kids like to } \\
\text { relax and watch TV } \\
\text { on weekends. }\end{array}$
\end{tabular}$\quad$\begin{tabular}{l} 
on w \\
\hline
\end{tabular}




\section{APPENDIX L}

\section{ROSENBERG SELF-ESTEEM SCALE}

Please listen to each question carefully and decide whether you strongly agree, agree, disagree or strongly disagree. Only 1 answer for each question.

1. On the whole, I am satisfied with myself.

\begin{tabular}{|llllllll|}
\hline & Strongly & $\square$ & Agree & $\square$ & Disagree & $\square$ & Strongly \\
1 & Agree & 2 & 3 & & 4 & Disagree \\
\hline
\end{tabular}

2. At times I think I am no good at all.

\begin{tabular}{|llllllll|}
\hline & Strongly & $\square$ & Agree & $\square$ & Disagree & $\square$ & Strongly \\
1 & Agree & 2 & 3 & & 4 & Disagree \\
\hline
\end{tabular}

3. I feel that I have a number of good qualities.

\begin{tabular}{|llllllll|}
\hline & Strongly & $\square$ & Agree & $\square$ & Disagree & $\square$ & Strongly \\
1 & Agree & 2 & 3 & & 4 & Disagree \\
\hline
\end{tabular}

4. I am able to do things as well as most other people.

\begin{tabular}{|llllllll|}
\hline & Strongly & $\square$ & Agree & $\square$ & Disagree & $\square$ & Strongly \\
1 & Agree & 2 & 3 & & 4 & Disagree \\
\hline
\end{tabular}

5. I feel I do not have much to be proud of.

\begin{tabular}{|llllllll|}
\hline & Strongly & $\square$ & Agree & $\square$ & Disagree & $\square$ & Strongly \\
1 & Agree & 2 & 3 & & 4 & Disagree \\
\hline
\end{tabular}


6. I certainly feel useless at times.

\begin{tabular}{|llllllll|}
\hline & Strongly & $\square$ & Agree & $\square$ & Disagree & $\square$ & Strongly \\
1 & Agree & 2 & 3 & & 4 & Disagree \\
\hline
\end{tabular}

7. I feel that I am a worthwhile person, at least as good as other people.

\begin{tabular}{|llllllll|}
\hline & Strongly & $\square$ & Agree & $\square$ & Disagree & $\square$ & Strongly \\
1 & Agree & 2 & 3 & & 4 & Disagree \\
\hline
\end{tabular}

8. I wish I could have more respect for myself.

\begin{tabular}{|llllllll|}
\hline & Strongly & $\square$ & Agree & Disagree & $\square$ & Strongly \\
1 & Agree & 2 & 3 & & 4 & Disagree \\
\hline
\end{tabular}

9. All in all, I tend to feel that I'm a failure.

\begin{tabular}{|llllllll|}
\hline & Strongly & $\square$ & Agree & $\square$ & Disagree & $\square$ & Strongly \\
1 & Agree & 2 & 3 & & 4 & Disagree \\
\hline
\end{tabular}

10. I take a positive attitude toward myself.

\begin{tabular}{|llllllll|}
\hline & Strongly & $\square$ & Agree & $\square$ & Disagree & & Strongly \\
1 & Agree & 2 & 3 & & 4 & Disagree \\
\hline
\end{tabular}




\section{APPENDIX M:}

\section{BECK DEPRESSION INVENTORY}

On this questionnaire are groups of statements. Please read each group of statements carefully. Then pick out the one statement in each group which best describes the way you have been feeling the PAST WEEK, INCLUDIING TODAY. Check the number beside the statement you picked. If several statements in the group seem to apply, check each one. Be sure to read all the statements in each group before making your choice.

1.

\begin{tabular}{|l|}
\hline$a_{1}$ I I do not feel sad. \\
$\square_{2}$ I feel sad. \\
$\square_{3}$ I am sad all the time and can't snap out of it. \\
$\square_{4}$ I am so sad or unhappy that I can't stand it.
\end{tabular}

2.

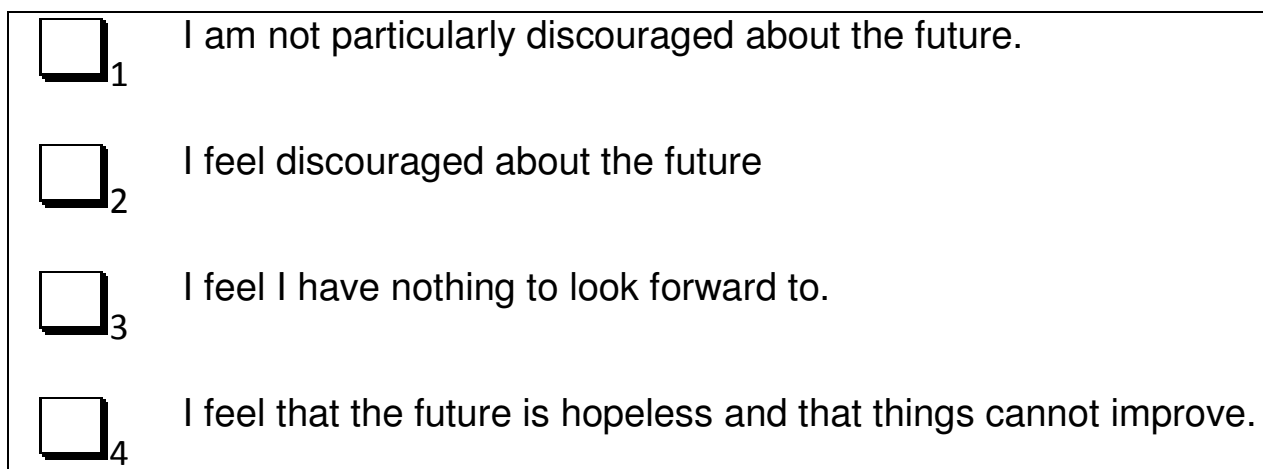


3.

\begin{tabular}{|l|}
\hline$\square_{1}$ I I do not feel like a failure. \\
$\square_{2}$ I feel I have failed more than the average person. \\
$\square_{3}$ As I look back on my life, all I can see is a lot of failures. \\
$\square \square_{4}$ I feel I am a complete failure as a person.
\end{tabular}

4.

\begin{tabular}{|l|}
\hline$\square_{1}$ I get as much satisfaction out of things as I used to. \\
$\square_{2}$ I don't enjoy things the way I used to. \\
$\square_{3}$ I Ion't get real satisfaction out of anything anymore. \\
$\square$ I I am dissatisfied or bored with everything.
\end{tabular}

5.

\begin{tabular}{|l|}
\hline$\square_{1}$ I Idon't feel particularly guilty. \\
$\square_{2}$ I feel guilty a good part of the time. \\
$\square_{3}$ I feel guilty most of the time. \\
$\square_{4}$ I feel guilty all the time.
\end{tabular}


6.

\begin{tabular}{ll}
\hline$a_{1}$ & I don't feel I am being punished. \\
$\square_{2}$ I feel I may be punished. \\
$\square_{3}$ I expect to be punished. \\
$\square_{4}$ I feel I am being punished.
\end{tabular}

7.

\begin{tabular}{|ll|}
\hline$a_{2}$ & I don't feel disappointed in myself. \\
& I am disappointed in myself. \\
$\square_{3}$ & I am disgusted with myself. \\
\hline$\square_{4}$ & I hate myself.
\end{tabular}

8.

\begin{tabular}{ll|}
\hline & I don't feel I am any worse than anybody else. \\
$\square_{3}$ I am critical of myself for my weaknesses or mistakes. \\
$\square_{4}$ I blame myself all the time for my faults.
\end{tabular}


9.

\begin{tabular}{|l|}
\hline$\square_{1}$ I Ion't have any thought of killing myself. \\
$\square_{2}$ I have thoughts of killing myself, but I would not carry them out. \\
$\square_{3}$ I would like to kill myself. \\
$\square_{4}$ I would kill myself if I had the chance.
\end{tabular}

10.

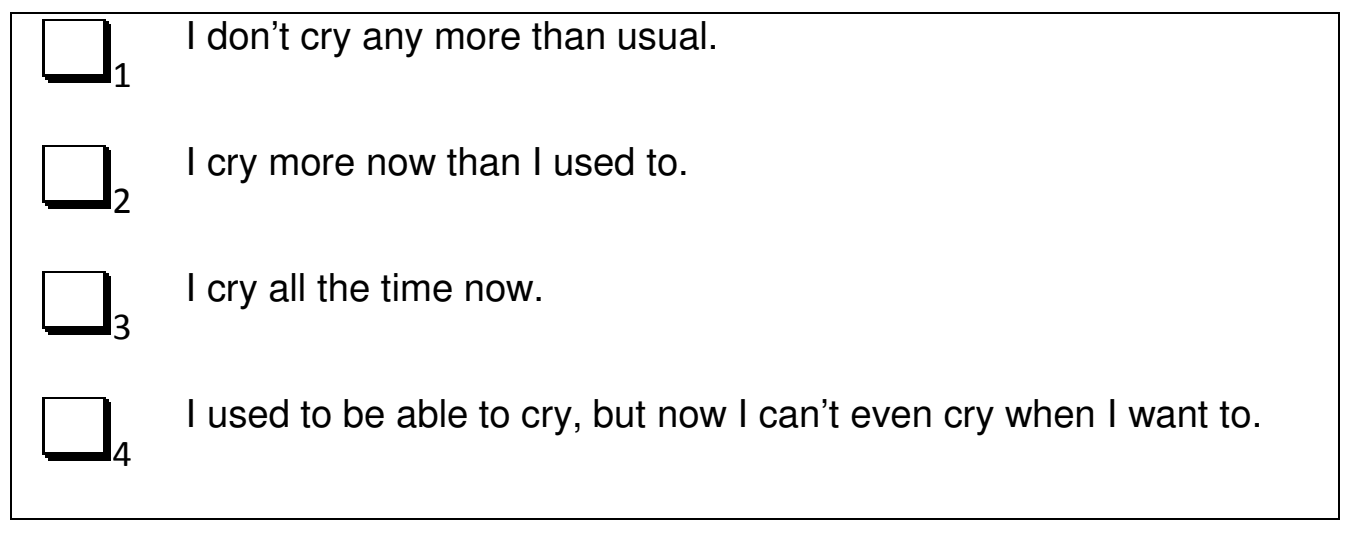

11.

\begin{tabular}{|l|}
\hline$\square_{1}$ I I am no more irritated now than I ever am. \\
$\square \square_{3}$ I I get annoyed or irritated more easily than I used to. \\
$\square, ~ I$ I don't get irritated at all by the things that used to irritate me.
\end{tabular}


12.

\begin{tabular}{ll|}
\hline I have not lost interest in other people. \\
\hline$\square_{3}$ I am less interested in people that I used to be. \\
\hline$\square_{4}$ I have lost all of my interest in other people.
\end{tabular}

13.

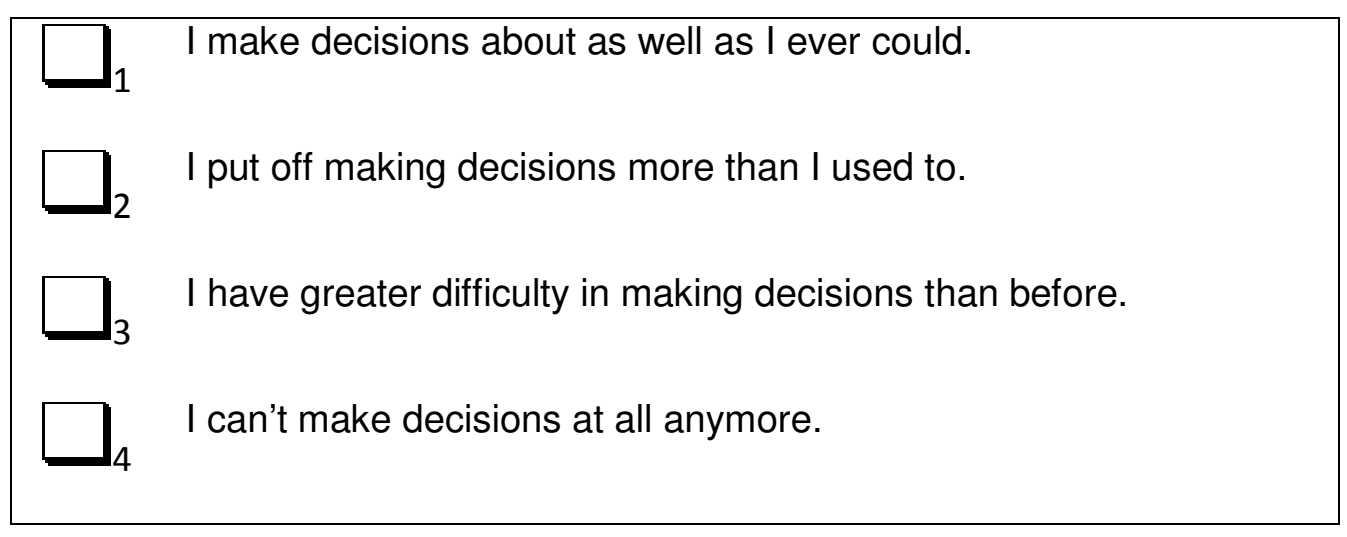

14.

\begin{tabular}{l}
\hline I don't feel I look worse than I used to. \\
$\square=\begin{array}{l}\text { I feel that there are permanent changes in my appearance that } \\
\text { make me look unattractive. }\end{array}$ \\
$\square_{4}$ I believe that I look ugly.
\end{tabular}


15.

\begin{tabular}{|l}
\hline$a_{1}$ I can work as well as before. \\
$\square_{2}$ It takes an extra effort to get started at doing something. \\
$\square$ I have to push myself very hard to do anything. \\
\hline$\square_{4}$ I can't do any work at all.
\end{tabular}

16.

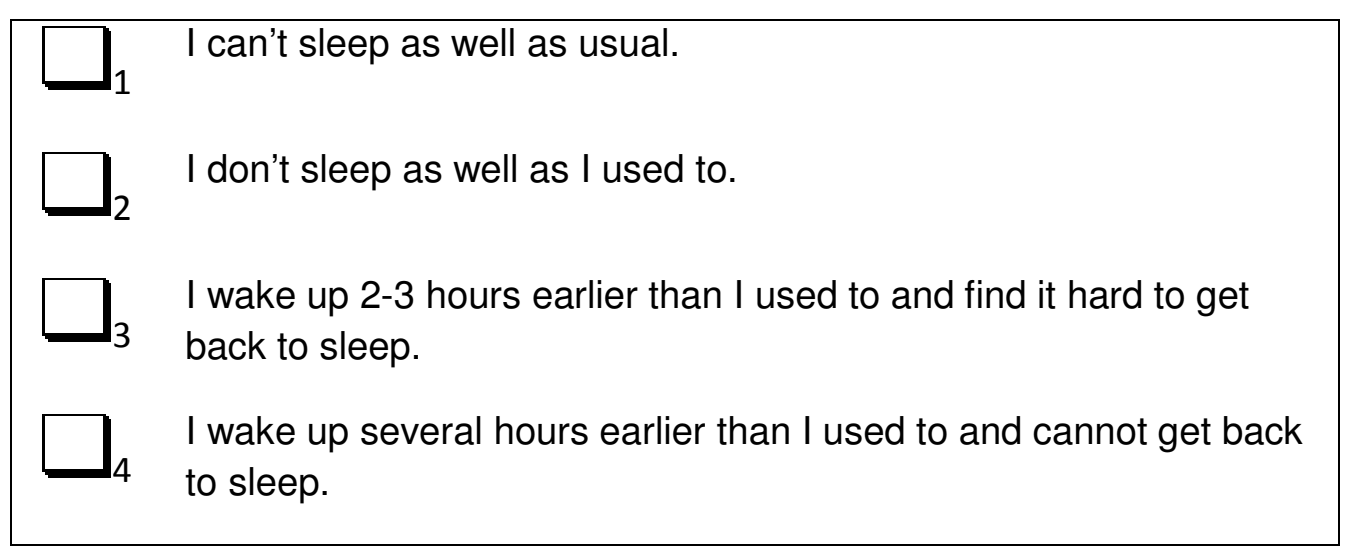

17.

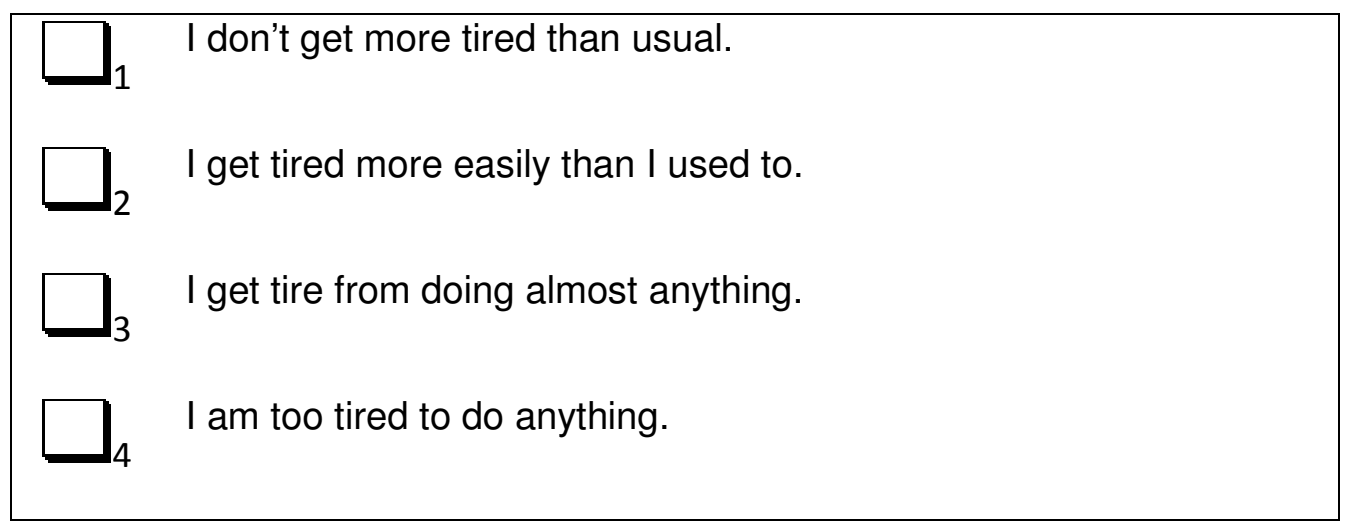


18.

\begin{tabular}{l}
\hline My appetite is no worse than usual. \\
$\square_{3}$ My appetite is much worse now. \\
$\square$ I have no appetite at all anymore.
\end{tabular}

19.

I haven't lost much weight, if any lately.
I have lost more than 5 pounds.

20.

$\square$ I am no more worried about my health than usual.
$\begin{aligned} & \text { I am worried about my physical problems such as aches and } \\ & \text { pains; or upset stomach; or constipation. }\end{aligned}$
$\begin{aligned} & \text { I am very worried about physical problems and it's hard to think } \\ & \text { about anything else. }\end{aligned}$
$\begin{aligned} & \text { I am so worried about my physical problems that I cannot think } \\ & \text { about anything else. }\end{aligned}$


21.

\begin{tabular}{|l|}
\hline$a_{1}$ I have not noticed any recent changes in my interest in sex. \\
$\square_{3}$ I am much less interested in sex than I used to be. \\
$\square$ I have lost interest in sex completely.
\end{tabular}




\section{APPENDIX N}

\section{CHILD DEPRESSION INVENTORY (CDI)}

People sometimes have different feelings and ideas. This next section lists the feelings and ideas in groups. From each group, pick one sentence that describes you best for the past two weeks. There are no right or wrong answers, just pick the sentence that best describes the way you have been feeling recently.

1.

\begin{tabular}{|ll|}
\hline$a_{2}$ & I am sad once in a while \\
& I am sad many times \\
$\square$ & I am sad all the time
\end{tabular}

2.

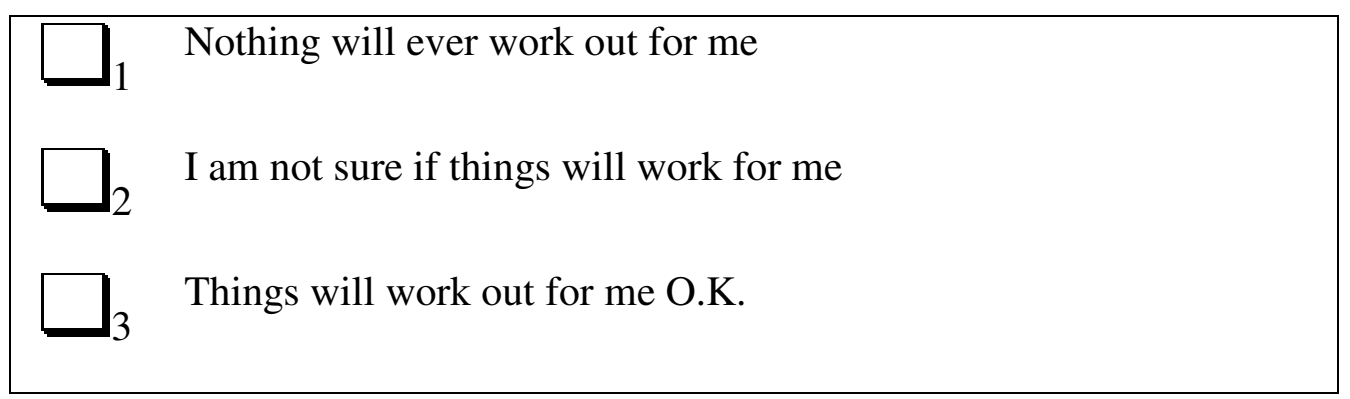

3.

$$
\begin{aligned}
& \square_{1} \text { I do most things O.K. } \\
& \square \text { I do many things wrong } \\
& \square_{3} \text { I do everything wrong }
\end{aligned}
$$


4.

\begin{tabular}{|ll|}
\hline$a_{1}$ & I hate myself \\
$\square \square_{3}$ & I do not like myself \\
$\square \square_{3}$ & I like myself
\end{tabular}

5.

$\begin{array}{ll}\square & \text { I feel like crying every day } \\ \square & \text { I feel like crying many days } \\ \square_{3} & \text { I feel like crying once in a while }\end{array}$

6.

$\square$ Things bother me all the time
$\square$ Things bother me many times
$\square \square_{3}$ Things bother me once in a while

7.

$$
\begin{array}{ll}
\hline & \text { I look O.K. } \\
\square & \text { There are some bad things about my looks } \\
\square_{3} & \text { I look ugly }
\end{array}
$$


8.

$\begin{array}{ll}\square & \text { I do not feel alone } \\ \square a_{2} & \text { I feel alone many times } \\ \square & \text { I feel alone all the time }\end{array}$

9.

\begin{tabular}{ll}
\hline$a_{1}$ & I have plenty of friends \\
$\square$ & I have some friends but I wish I had more \\
$\square$ & I do not have any friends
\end{tabular}

10.

$$
\begin{aligned}
& \square \text { Nobody really loves me } \\
& \square \text { I am not sure if anybody loves me } \\
& \square \text { I am sure that somebody loves me }
\end{aligned}
$$




\section{APPENDIX O}

\section{BODY DISSATISFACTION SCALE}

Look at the following pictures of girls. You can see that each girl has a letter on her shirt.

Please use the letters to help you answer the next 2 questions. (Circle the letter for girl's answer).

1. Which picture looks the most like you?

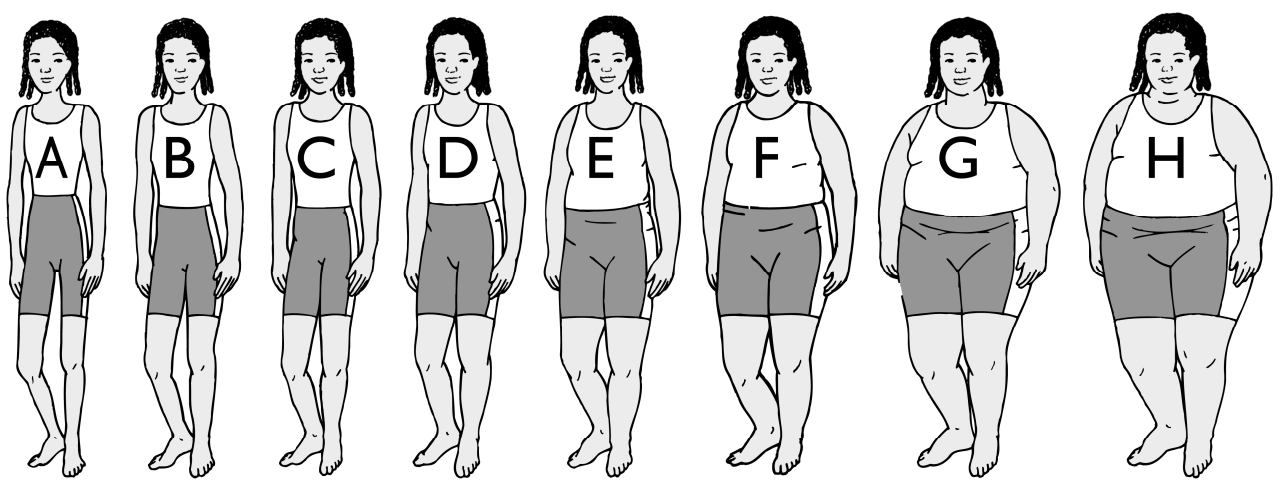

2. What picture shows the way you would like to look?

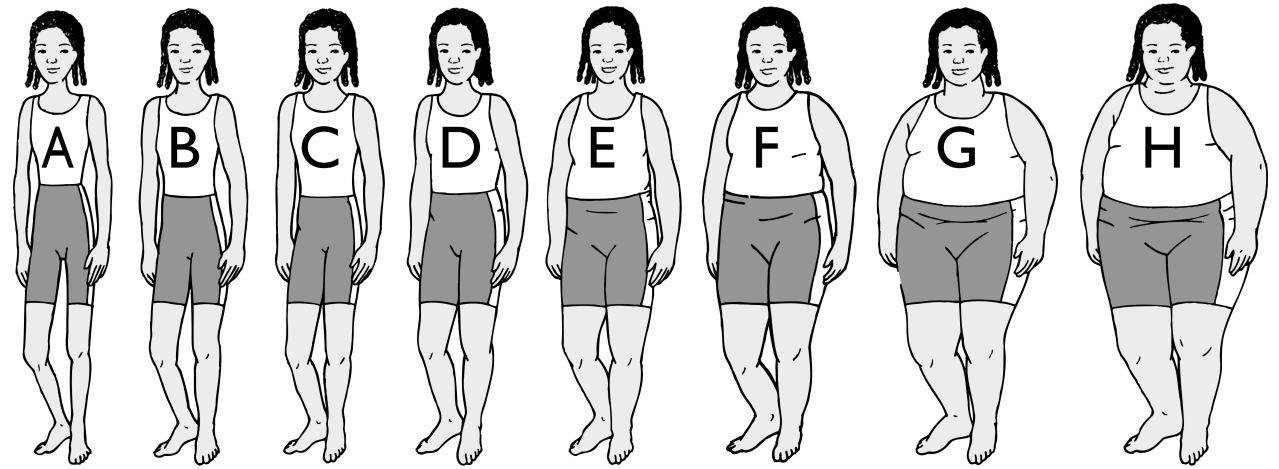

